Portland State University

PDXScholar

\title{
A study of the relationship between attitudes toward woman's roles and career choices of women graduate students
}

Barbara Backstrand

Portland State University

Follow this and additional works at: https://pdxscholar.library.pdx.edu/open_access_etds

Part of the Gender and Sexuality Commons, and the Social Psychology Commons Let us know how access to this document benefits you.

\section{Recommended Citation}

Backstrand, Barbara, "A study of the relationship between attitudes toward woman's roles and career choices of women graduate students" (1974). Dissertations and Theses. Paper 2057.

https://doi.org/10.15760/etd.2056

This Thesis is brought to you for free and open access. It has been accepted for inclusion in Dissertations and Theses by an authorized administrator of PDXScholar. Please contact us if we can make this document more accessible: pdxscholar@pdx.edu. 
AN ABSTRACT OF THE THESIS OF Barbara Backstrand for the Master of Science in Psychology presented February 21, 1974.

Title: A Study of the Relationship Between Attitudes Toward Woman's Roles and Career Choices of Women Graduate Students.

APPROVED BY MEMBERS OF THE THESIS COMMITTEE:

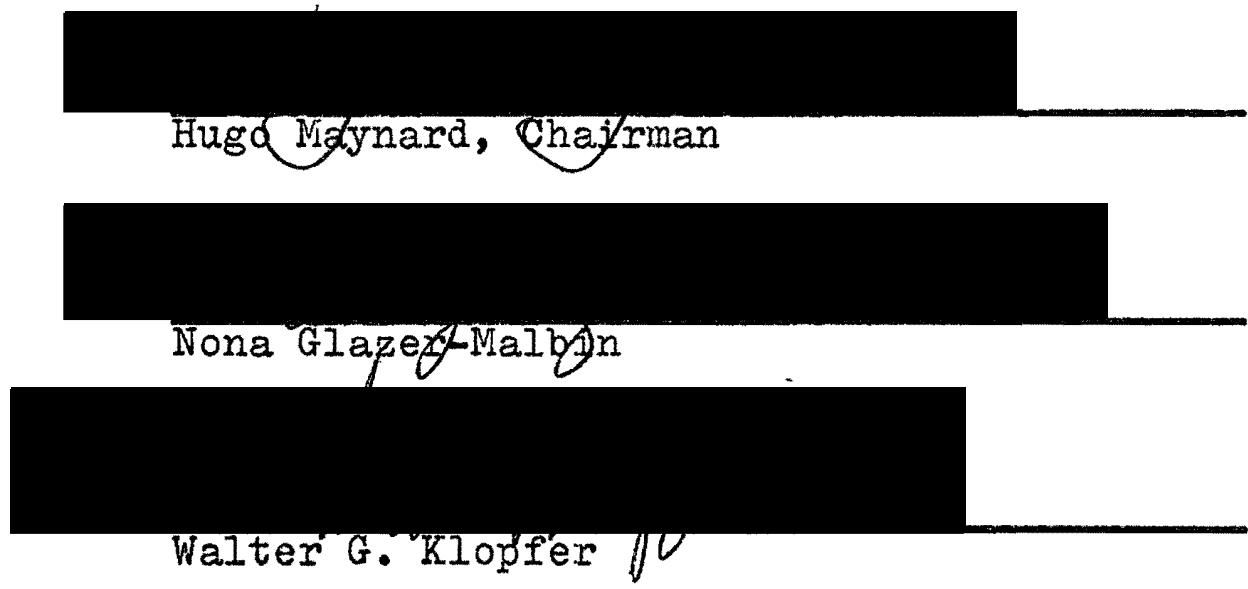

The purposes of the present study were to explore how American college women view their roles and whether or not women who choose not-traditional-for-women (NTW) careers have more or less social support from significant others for that cholce than women who choose traditional-for-women (IT) careers. A related question asked whether aspects of a woman's personal history predict her role attitudes and behavior as an adult.

Three research hypotheses were formulated in terms of 
some direct relationships among the major variables: 1) women's attitudes toward woman's roles, 2) their perceptions of the attitudes of significant others, and 3) their career choices. The significant others chosen for this study were mother, father, husband/consort, and close friend. Other questions of interest for exploratory purposes, termed supplementary questions, involved intervening variables (matemal role model, expressed identification with parents, current importance of the relations with each significant other) which might illuminate the relations among the major variables.

One hundred and eighteen women enrolled in profeso sional and Ph.D. programs at Portland State University and the University of Oregon Medical and Nursing Schools completed a questionnaire administered in groups (60\%) or by mail $(40 \%)$. The questionnaire was developed for this study and had two parts. Part One asked about the Ss' family background, current situation future plans. Part Two was a 24-item inventory of attitudes toward woman's roles and satisfactions (AWR). It was completed five times, for Self and as Ss believed each significant other would do. Reliability of the AWR inventory was tested concurrently with the administration of the main study, using a testretest method with an interval of four weeks. Validity of the AWR inventory was not established independently for use in the present study. 
For analysis, the sample $(N=96)$ was limited to American, white, women graduate students from intact homes who were between the ages of 21-45 years. Forty-nine Ss were pursuing TW careers: 47 Ss were pursuing NTW careers. Significant differences between the two career choice (CC) groups were not found in: 1) measured Self attitudes, 2) perceived attitudes of significant others, 3) maternal role model, 4) expressed identification with parents, and 5) current importance of the relations with each significant other. There also did not appear to be any differences between the two groups for other selected characteristics of personal history (educational and occupational status of father, perceptions of parents' relationship, perceptions of the overall satisfaction of mother and father with their lives) or Ss' current situation (age, marital status, career orientation). A weak effect was found for age and marital status of an $\underline{S}$ on her AWR responses, with the difference between the two groups (for Ss less than 27 years old) being in the opposite direction than expected. For the sample as a whole, $\underline{S} s^{\prime}$ attitudes were more congruent with the perceived attitudes of husband/consort and those of close friend than with the perceived attitudes of mother and those of father $(p \leq .01)$.

Two factors seemed to account for some findings which differed from previous related research. One factor was the educational level of the sample. Unlike earlier studies, 
all Ss were currently enrolled in professional or Ph.D. programs. The second factor was the passage of time; most previous studies were done before 1969. The findings might be interpreted as reflecting the recent social, economic and political changes in the culture, which are likely to affect how college women view their roles. The findings might also reflect the impact of the women's movement, as a motivating force and source of external support for the re-examination of sex roles. 


\title{
A STUDY OF THE RELATIONSHIP BETWEEN ATTITUDES TOWARD WOMAN'S ROIES AND CAREER CHOICES \\ OF WOMEN GRADUATE STUDENTS
}

\author{
by
}

BARBARA BACKSTRAND

A thesis submitted in partial fulfillment of the requirements for the degree of

\author{
MASTER OF SCIENCE \\ in \\ PSYCHOLOGY
}

Portland State University

1974 
TO THE OFFICE OF GRADUATE STUDIES AND RESEARCH:

The members of the Committee approve the thesis of Barbara Backstrand presented February 21, 1974.
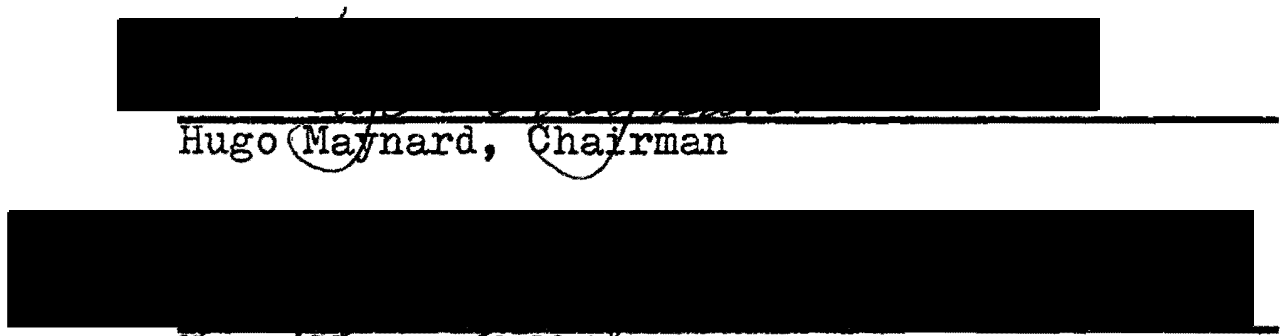

Nona Glazerglalbif

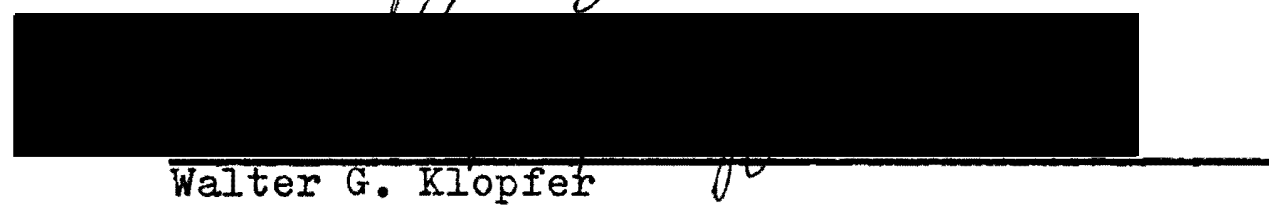

\section{APPROVED:}

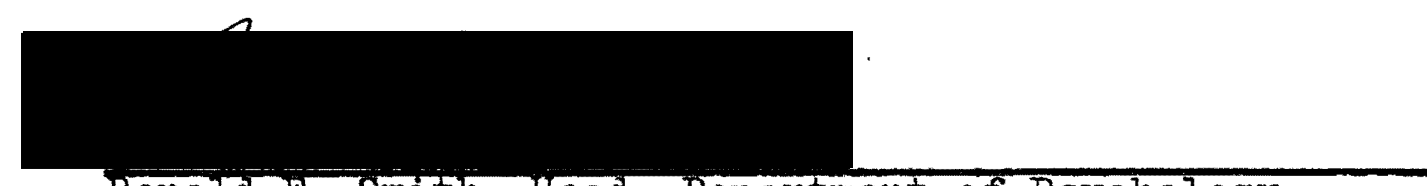

Ronald E. Smith, Head, Department of Psychology

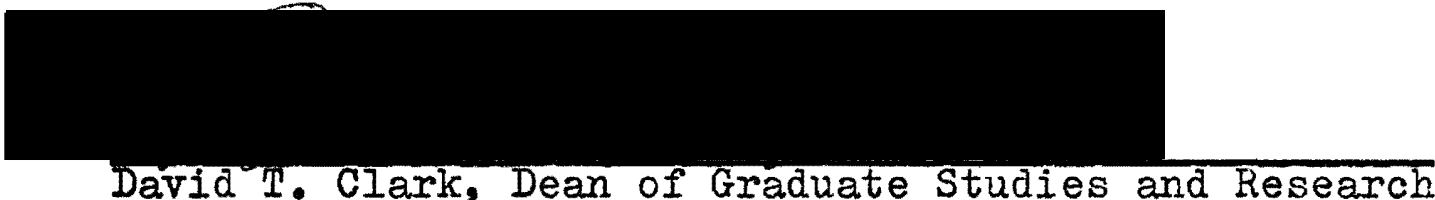

February 21, 1974 


\section{ACKNOWLEDGMENTS}

When I began this study more than one year ago, I was naive enough to believe that research on woman's roles would be manageable since the related literature was of recent origin. Although I soon discovered the error of my reasoning, many people gave invaluable encouragement by their continued interest, assistance and support. My warmest thanks and deepest appreciation are due Hugo Maynard. He not only freely gave his time and energy to the research, but also guided the project with an enviable degree of patience and sensitivity.

Gratitude is also due the other members of my committee: Nona Glazer-Malbin, for invaluable technical assistance, and Walter Klopfer, for sustained interest and support. I would also like to thank Jim Paulson, for statistical guidance, and the women who participated in the study.

Special thanks are also due my husband, Jay, and my daughter, Koren, who shared in the peak and nadir experiences of completing a thesis. 
TABLE OF CONTENTS

PAGE

ACKNOWLEDGMENTS . . . . . . . . . . . . . iii

IIST OF TABIES .................. vi

CHAPTER

I INTRODUCTION. . . . . . . . . . 1

Description of the Research Problem. . 2

Review of the Iiterature . . . . 7

Feminine Role Concepts

The Role of External Support

Parental Role Modeling and Current Importance of

Relations with Significant others

Research Hypotheses and Supplementary

Questions......... 33

II RESEARCH DESIGN . . . . . . . . 38

Selection of Subjects. . . . . 38

Sample Characteristics . . . . . 42

Collection of the Data ...... . 47

Administration of the Questionnaire

Content of the Questionnaire

Scoring of the Questionnaire

Reliability of the AWR Inventory

Validity of the AWR Inventory

III RESULTS . . . . . . . . 56

Research Hypotheses. . . . . . 56 
CHAPTER

PAGE

Supplementary Questions. . . . .

72

Maternal Role Model

Current Importance of the Relations with Significant

Others

Expressed Identification with Parents

Career Orientation . . . . . . . 94

IV DISCUSSION. • • • • • • • • • • • 96

Methodological Considerations. • . . 99

Reconsideration of the Iiterature. . 110

Sex-role Stereotyping and changes in Attitudes Toward Woman's Roles

Cultural Bias and Sex Role Research

Passage of Time. . . . . . . 130

Summary and Conclusions. . . . . 133

Results

Future Research

IIST OF REFERENCES

APPENDICES

A IETTER FOR RECRUITING SUBJECTS AND ADDI-

TIONAI INSTRUCTIONS FOR COMPIETING

THE QUESTIONNAIRE. . . . . . . . 150

B QUESTIONNAIRE, SCORING KEY AND ADDITIONAL

NOTES FOR SCORING/CODING • . . • • 156

C ATTITUDES TOWARD WOMAN'S ROLES (AWR)

INVENTORY AND ADDITIONA工 NOTES FOR

FUTURE RESEARCH. . . . . . . . 208 


\section{IIST OF TABLES}

TABIE

PAGE

I Response Rates of Subjects Initially Contacted for Study. . . . . . . . . . 40

II Composition of Sample by Degree Program and Mean Ages $(\mathrm{N}=96)$. . . . . . . 41

II Current Marital Status and Number of Children 44

IV Educational and Occupational Characteristics

of $\mathrm{S}^{\prime}$ Mothers . . . . . . . . .

$\checkmark$ Educational and Occupational Characteristics

of Ss' Fathers . . . . . . . . . .

VI Total AWR Scores of College Student Women

from Test-Retest Procedure . . . . .

VII Range of Total AWR Scores, Median or Per-

centile Scores and Group (TW, NTW)

Distributions . . . . . . . . . .

59

VII Phi Coefficients on Comparisons Between Self

Attitudes and Perceived Attitudes of

Significant Others for Total AWR Scores.

61

IX Sign Tests for Comparisons Between Self

Attitudes and Perceived Attitudes of

Mother and Father for AWR Subscale

Scores . . . . . . . . . . . . . 
X Sign Tests for Comparisons Between Self

Attitudes and Perceived Attitudes of

Significant Others for Total AWR

Scores . . . . . . . . . . . .

XI Median Tests for Group Differences in Self

Attitudes and Perceived Attitudes of

Significant Others for Total AWR

Scores . . . . . . . . . . . .

XII Median Tests for Group Differences in Self

Attitudes for AWR Subscale Scores. . .

XII Median Tests for Group Differences in Per-

ceived Attitudes of Significant Others

for AWR Subscale Scores. . . . . .

XIV Median Tests for Group Differences Due to

Age for Total AWR Scores for Self. • .

XV Median Tests for Group Differences Due to

Marital Status for Total AWR Scores

for Self . . . . . . . . . . . .

XVI Mother's Perceived Overall Satisfaction with

Her Iife $(\mathrm{N}=96)$. . . . . . . . .

XVII Mother's Perceived Overall Satisfaction when

Her Feelings about Work and Her Work

Behavior were Perceived Congruent

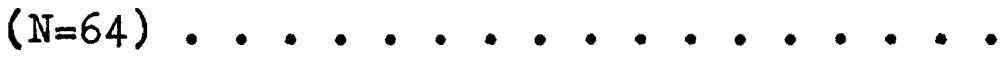


XVIII Mother's Perceived Overall Satisfaction When

Her Feelings about Work and Her Work

Behavior were Perceived Incongruent

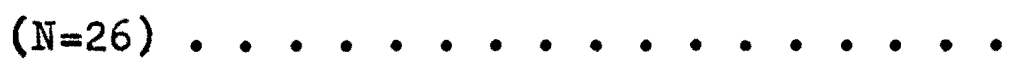

XIX Mother's Educational Level and Occupational

Status While Ss were Growing Up (N=92) •

XX Frequency of Ranks Assigned by Ss to Sig-

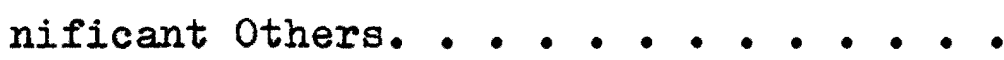

XXI Scores for Descriptive Quality of $\mathrm{Ss}^{\prime}$ Current

Relations with Significant Others. . .

XXII Ss' Ratings of Current Relations with Significant Others. . . . . . . . . .

XXIII Ss' Ratings of Satisfaction with Current

Relations with Significant Others. • •

XXIV Ss' Expressed Identification with Parents . .

XXV SS Perceptions of Overall Satisfaction of

Mother and Father $(\mathrm{N}=96)$. . . . . 90

XXVI Ss' Perceptions of Relationship Between

Parents $(N=94)$. . . . . . . 91

XXVII Ss' Intentions to Work by Expectations of

Having Children ( $\mathrm{N}=93)$. . . . . . 
CHAPTER I

\section{INTRODUCTION}

The general purpose of my study was exploratory. It was partly done in an effort to increase our knowledge of how American, white, college women view their roles. Have some of the issues raised by those in the vanguard in the Women's Iiberation movement been resolved so that some of their attitudes about sex-role definition are commonly held by college women? The public mediam-newspapers, magazines, TV, radio, as well as professional journals--reflect the growing awareness in the culture that the "feminine mystique" (Frieden, 1963) and "masculine mystique" are no longer functional and that they unduly restrict personal growth and options for both sexes (Bem, 1972; Maccoby, 1966b). Impetus for the equalization of sex roles is provided not only by the benefits for both sexes, but also, in a larger context, by the support from other current social movements to remove arbitrary barriers between groups of people.

The present study was also done to see if women who pursue non-traditional roles have more or less support from significant others than women who pursue traditional roles. A related question is: Do some aspects of a woman's personal history remain the principal determinants of her role 
attitudes and behavior, particularly career choice, as an adult? Previous research findings indicate that antecedent personal factors have precedence over current situational factors as determinants of women's role attitudes and behaviors. Those findings are based mainly on data collected before 1969, a time which has been considered to be prior to the initial impact of the women's movement (IipmanBlumen, 1972a, 1972b).

Studies which are limited to samples of white, college undergraduate, graduate or postgraduate women, necessarily limit the degree to which one can generalize to the general population of American women. However, these restricted samples can provide valuable information since the educated minority are often viewed as heralds of change. The use of such samples is one way to explore the important parameters which permit or inhibit change.

\section{DESCRIPTION OF THE RESEARCH PROBIEM}

The purpose of my study was to explore the relations among some attitudes and beliefs of American, white, women graduate students, their views of the attitudes of significant others, and their career choices. The women were asked about some of their own attitudes toward woman's roles and satisfactions as well as their perceptions of the views of specified significant others. Mother, father, husband/consort and close friend were the significant others 
chosen for this study. My interests were in seeing whether the women's views corresponded to the perceived attitudes of any of the specified significant others, and how their career choices related to some of their perceptions.

\section{Attitudes and Beliefs}

The women's own attitudes toward woman's roles and their perceptions of the views of specified significant others are the dependent variables in the present study. The attitudinal measures were selected in an effort to understand the complex interaction between formative (parents) and proximate (husband/consort, peer) influences on sex-role definition. The interaction is complex because what one brings to or seeks from peer relations often seems to depend partly upon the values and expectations which have been internalized from parent models. The value of obtaining a measure of the perceptions of the attitudes toward woman's roles of both parents gains support from recent studies interested in parent identification (Baruch, 1971; Block, von der Lippe, and Block, in press; Block, 1973; Iipman-BIumen, 1972b; Tangri, 1972). These studies have shown the value of dealing with the complexity of how one chooses from each parent model, according to specific personal and social factors, rather than looking for identification with one parent.

Sex-role Definition. It is important to clarify what I mean by sex-role definition. Others have observed that 
sex-role definition is one aspect of growing up which has often been placed together with socialization and identification in "one large conceptual grab bag" (Block et al., in press). This results in much confusion in the literature. For the purposes of my study, the following distinctions are made between the three concepts (BIock et al., in press). Sex-role definition is one part of what parents, as role models, prescribe. Socialization denotes the general process by which cultural norms, values and expectations are transmitted and internalized in a group. The process is largely carried out by interpersonal interactions. Parents are usually considered to be the principal agents socializing their children. The concept of identification seems to be most useful if it is extended and differentiated to include relationships among sex-role typing, socialization and other qualitative factors in the parent-child interaction.

\section{Significant Others}

Mother, father, husband/consort and close friend were the specified significant others in my study because they have been shown to be important in decision-making. Some studies have found that peers, particularly significant males, appear to be major influences, whether or not a woman works outside the home or what career she chooses (Bailyn, 1970; Fogarty, Rapoport and Rapoport, 1971; Hawley, 1971, 1972; Horner, 1972a, 1972b; Leland, 1966; Schwenn, 1970; Tangri, 1969). Other studies have found that although 
peer influences may be more apparent, the interaction between or mediation of formative (parents) and proximate (peers) influences should not be overlooked (Edwards, 1969; Fogarty et al., 1971).

\section{Career Choice}

Career choice is the independent variable in the present study and is defined by enrollment in a Ph.D. or professional degree program. The behavioral measure was chosen to represent one aspect of adult role choice. Adult role choice is conceptualized here as a synthesis of major cognitive and affective growth processes together with individual constitutional factors. The major processes suggested are sex-role definition, socialization and identification. Adult role choice is subject to some degree of modification as a person develops due to continuous processing, conscious and unconscious, of new information. Consequently, the shaping of attitudes and behaviors is continuous throughout a person's life, although the operations of the shaping process may be more overt for a child than an adult. One might expect, therefore, that there might be a relation between women's career choices and their perceptions of the attitudes of certain others toward woman's roles. The hypothesized relation involves congruence between woman's perceptions of the role expectations of important others and their career choices. The expected congruent relation between perceived attitudes and career 
choice also follows from the assumption that perceived attitudes of significant others have a central role in sex-role definition, the socialization process and for indicating the nature or degree of support for adult role choices.

Career choice for this study was classed "nottraditional-for-women" (NTW) or "traditional-for-women" (TW) according to the proportion of women to men in the given profession. These classifications, TW and NTW, are similar to the "traditional" and "pioneer" classifications suggested by Rossi (1965). She suggested that the distinction between typically feminine and typically masculine career orientations would be more useful for understanding women's occupational choices than a dichotomous approach of family-vs. career-oriented. Recent studies have shown the utility of this distinction (Karman, 1972; McKenzie, 1971; Wolkon, 1972). McKenzie (1971) classed women (mostly college students, $N=120$ ) as "conformists" or "nonconformists" according to whether or not the women preferred occupations which conformed to traditional feminine role expectations. The "conformists" group consisted of housewives and elementary education majors. The "nonconformists" group consisted of doctoral students in education and medical students. Karman (1972) classed upperclass women $(N=1,646)$ as "traditionals" or "nontraditionals" according to the proportion of women in the given profession. Wolkon (1972) classed women 
college alumnae $(\mathrm{N}=147)$ as "homemaker," "traditional" or "pioneer" (Rossi, 1965) according to their scores on two measures of work attitudes and values. Significant differences were found for attitudes toward woman's roles and other variables between the "conformists" and "nonconformists" (McKenzie, 1971) and between the "traditionals" and "nontraditionals" (Karman, 1972). The "homemaker," "traditional" and "pioneer" groups differed significantly in work attitudes and values (Wolkon, 1972).

\section{REVIEW OF THE IITERATURE}

My interest in the relations among women's role concepts, their perceptions of the attitudes of significant others toward woman's roles, and their career choices was stimulated by a rapidly growing literature on sex roles. The review of the literature which follows is concerned with three questions. First, what characterizes women's role concepts today? Second, is there any relation between external support and how college women view woman's roles and choose their careers? Third, do factors such as parental role modeling and the current importance of women's relations with certain significant others illuminate the relations among the major variables in the present study? In the literature, the samples most often consisted of American, white, college undergraduates, graduates or postgraduates. Some samples included both men and women, others included 
onily women.

Feminine Role Concepts

The review to follow will deal with two topics:

1) sex-role stereotypes and 2) changes in attitudes about woman's roles.

Sex-role Stereotypes. Some studies have shown that women's role concepts and self-concepts often reflect their sensitivity to the prevailing cultural sex-role stereotypes (Block et al., in press; Broverman, Vogel, Broverman, Clarkson, and Rosenkrantz, 1972; Clarkson, Vogel, Broverman, Broverman, and Rosenkrantz, 1970; Fand, 1955; Lipman-Blumen, 1972a, 1972b; Rosenkrantz, Vogel, Bee, Broverman, and Broverman, 1968). The general finding is that women show that they have learned which personality traits and roles are appropriate and valued for each sex. In other words, stereotypes are alive and well and clearly defined (Broverman et al., 1972). Other studies have indicated that women's role behaviors (e.g., career choice, family orientation) also reflect their sensitivity to current sex-role stereotypes. Moreover, women's behavioral choices are often viewed as reflecting women's sensitivity to the perceived attitudes of significant others, usually males, which appear to reinforce the current sex-role stereotypes (Bailyn, 1970; Fogarty et al., 1971; Hawley, 1971, 1972; Horner, 1972a, 1972b; Leland, 1966; Schwenn, 1970; Tangri, 1969). The general finding is that women appear to choose a role- 
orientation or career which is congruent with their perceptions of the feminine role expectations of significant male peers. For example, women who wanted to work outside the home and perceived support from their husbands were found more often working than women who expressed a desire to work but did not perceive husband's support. Or, women who pursue NTW careers usually perceive the feminine role expectations of significant males to be more nontraditional than women who pursue TW careers.

Is there a mediating factor in the relation between sex-role stereotyping and the self-concepts and role concepts of women? The answer to this question seems important for understanding who women look to for support and what kind of support they seek. The literature suggests that parental modeling is an important mediating factor in the above relation. If parental models were more androgynous than sex segregated, it appears that both men and women are able to incorporate "masculine" and "feminine" attributes which are then reflected in their self-concepts (Block et al., in press; Block, 1973); both men and women do not perceive the opposite sex only in terms of sex-appropriate traits (Vogel, Broverman, Broverman, Clarkson, and Rosenkrantz, 1970). If the parental models were more sex segregated than androgynous, then the self-concepts and sex-role concepts for both men and women tend to reflect the more stereotyped role concepts in the culture. In 
other words, the type of parental modeling (androgynous/sex segregated) provided has implications for the degree of flexibility/rigidity one might expect in a person's behavior which might also be reflected in his/her self-concepts and role concepts.

Since sex-role stereotypes appear to be an important factor in women's role concepts, it seems important to have an idea of why these conceptions are so stable and difficult to eliminate. Perhaps an understanding of the dynamics of stereotyping, of which sex-role stereotyping is one example, provides part of the explanation. Ziebarth (1970) interprets the dynamics of stereotyping within a conceptual framework of social psychology. ${ }^{1}$ She comments on the general finding that the prejudice against women in the culture is often reflected in the self-concepts of women and in their devaluation of feminine competence scores. She reasons that this occurs because prejudices or predispositions to certain beliefs based on feelings tend to become formalized in stereotypic conceptions. Once formalized, their points of origin (original context) are usually forgotten. Consequently, the prejudices or feelings are transmitted and maintained by stereotypic conceptions without reference to context. In other words, stereotypic conceptions usually develop functional autonomy. Ziebarth (1970) observes

${ }^{1}$ See Ziebarth (1970) for an extensive review of the literature on the relation between prejudice and stereotyping. 
that in most conceptions of stereotyping the most basic problem is seen to be the emphasis on cultural absolutism and the implications of inborn and unalterable psychological characteristics for ethnic and sex groups. The body of beliefs which make up the sex-role ideology in the culture and are formalized in stereotypic conceptions have been referred to as the "nonconscious ideology" (Bem and Bem, 1970). "Structured inequality" has been used to characterize one aspect of sex-role ideology (female role ideology) which is reflected in women's self-concepts (Iipman-Blumen, 1972a, 1972b).2

Changes in Attitudes about Woman's Roles. Although some aspects of cultural conditioning may be resistant or difficult to change, there have been some changes in attitudes which affect the role concepts of college women. One indication of a change in attitudes about woman's roles is the revised image of the career woman. Recent studies, many using samples of women in NTW careers, point out that achieving women are not deviant or poorly adjusted (Astin, 1969; Bachtold and Werner, 1970; Cartwright, 1970; Ginzburg,

${ }^{2}$ Others have commented on the adverse effect of stereotyping on the self-concepts of women (Broverman et al., 1972):

Most importantly, both men and women incorporate both the positive and negative traits of the appropriate stereotype into their self-concepts. Since more feminine traits are negatively valued than are masculine traits, women tend to have more negative self-concepts than men ( $p .75$ ). 
1966; Gump, 1972; Helson, 1971, 1972; Porter, 1967; Tangri, 1969, 1972). The new image contrasts with the previous one which portrayed the achieving woman as not really very feminine or very happy. The new image is most often presented with reference to the fact that the achieving woman not only favors but actively pursues what she views as two compatible and desirable goals, career and family. Another indication of changes in attitudes about woman's roles is found in the research findings of the MAFERR Foundation and Fand (1955). Since 1950, the MAFERR group of researchers has been collecting data on male and female perceptions of sex-roles for women (Steinmann, 1963; Steinmann and Fox, 1966; Steinmann, Levi, and Fox, 1964). Their findings suggest that both men and women share the view that woman's roles should be balanced between responsiveness to self and others. The two major characteristics of the data on woman's roles are described (Steinmann, Fox, and Farkas, 1968):

The first characteristic was that both sexes held reasonably close perceptions of the ideal roles women should play and their appropriate level of activity, with this level being a balance of self and family needs and with comparable components of social activity and family service. The second characteristic of the data was that women had no accurate idea of the kind of woman men would delineate, and when asked to predict male responses, described an extremely family-oriented, personaliy submissive woman, unlike the balanced woman men actually described ( $p .421)$.

Fand's results (1955) showed a similar pattern among 85 college women. The feminine role concepts of the Ss for 
"self" and "own ideal woman" were nearly identical and reflected an orientation to "self" rather than "others." These role concepts differed from the Ss' perceptions of the feminine role concepts of the "average woman" and "man's ideal woman," which emphasized orientation to "others."

In summary, changes in attitudes about woman's roles may be more often reflected in ideal role concepts (e.g., woman's ideal woman, man's ideal woman) than in women's own role concepts and behaviors. Up until this time, an individual's personal history appears to be the predominant influence on her/his role concepts and behavior. Within the culture, personal history is affected by the prevailing sex-role stereotypes with the degree of the effect related, in part, to how parents reinforce or modify the cultural role prescriptions. It has been suggested that the personal history of most women might be characterized as "structured inequality" (Iipman-Blumen, 1972b). Others have suggested that women reflect the "nonconscious ideology" in the culture in their self-concepts and role concepts (Bem and Bem, 1970). Sex-role stereotypes may be difficult to eliminate because of the tendency for stereotypic conceptions to develop functional autonomy (Ziebarth, 1970). Helson (1972) noted that the attitudinal problem women face today is personal and institutional. It seems pertinent to add that, in the current social context, both women and men are 
adversely affected.

The Role of External Support

Assuming that sex roles are currently being evaluated and redefined in our culture, what is the role of external support during the period of transition from restricted (dichotomous) to more expanded (androgynous) role options? The answers to the following three questions are of interest for the purposes of my study. Why do white college women need external support or approval for their career aspirations and choices? What is the relation between external support and the career aspirations and choices of college women? To whom do college women look for support or approval of their career choices?

The Need for External Support. Women with career aspirations in our culture may require more external support than men due to a qualitative difference in the socialization of boys and girls. Up until the present time, the values and expectations of our culture supported the belief that women belonged at home, to nurture, while men were more naturally suited to competitive striving and achievement outside the home. ${ }^{3}$ As a result, qualities such as independence, autonomy and assertiveness in activities outside

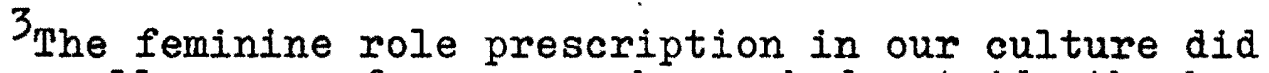
make two allowances for women who worked outside the home. A woman's femininity was not questioned if she had to work due to financial need, or was needed for work in times of national crisis, such as World War II. 
the home were discouraged for girls and encouraged for boys. External support for achievement has therefore been available to males from early childhood in the form of cultural sanctions which were transmitted and reinforced by initial significant others (e.g., parents and teachers). The evidence for the situation being different for females has been adequately documented in the literature on sex differences (Maccoby, 1966a) and child development (Hoffman, 1972). I am suggesting that one result of the differential treatment of the two sexes in the process of socialization is that women may require more external support than men for career aspirations since career achievement for women conflicts with previous cultural conditioning. ${ }^{4}$ In a recent study (Hawley, 1972) college women who were planning to enter male-dominated careers (e.g., math-science majors) were found to be more concerned with male support than were the women with traditional career goals (e.g., teachers, counselors). Only 10 percent of the Ss who were considering NTW careers said that they would pursue their present goals over the objections of significant men in their lives. I suggest, however, that male support might have appeared to be less of a concern for the other women due to less anticipation or expectation that significant men would

$4_{\text {The problems which achievement-oriented women face }}$ may be further complicated by the reluctance of many men to relinquish some of their control, another consequence of cultural conditioning. 
object to women pursuing TW careers. It seems likely that a woman pursuing a TW career is perceived as less threatening to the identity or image of many men than a woman pursuing a NTW career.

Some studies have shown that where women may require additional support varies. For example, Rossi (1965) found differential effects of marriage among the "homemaker," "traditional" and "pioneer" occupational patterns of college graduate women. For the "pioneer" (NTW), childbearing rather than marriage was the more crucial event as a source of potential role conflict. In a more recent study (ziebarth, 1970), the results suggested that the type of role conflict experienced by college undergraduate women differed according to whether their role concepts were more "traditional" or "nontraditional." The women with more traditional role concepts had more conflict about "male superiority" than the women with less traditional role concepts. Presumably the less traditional women had already discarded the myth while the more traditional women were beginning to question it. The women with less traditional role concepts had more conflict about "husband priority" than the women with more traditional role concepts. Ziebarth suggested that the more traditional women had not yer questioned this aspect while the less traditional women may be questioning this aspect and are experiencing the difficulty of confronting a possible threat to a primary 
interpersonal relationship and source of happiness. As many "high" traditional as "low" traditional women showed conflict about "child priority." Ziebarth suggested that the adage, "anatomy is destiny," is beginning to be questioned but that the question of women's responsibility for childrearing is not yet resolved.

In summary, women may have to win approval for achievement strivings. For both men and women, cultural support or approval for "cross-sex" prerogatives is not simply granted. Bakan (1966) conceptualizes the problem which men and women face as finding a way to express the dual aspects of human existence, "agency" and "communion." Up until the present time, sex-role prescriptions in our culture have maintained the separation of these aspects by sex.

The Relation Between External Support and Career Aspirations and Choices. The following two assertions appear valid. One is that both men and women require some external support (positive feedback, reinforcement) for their efforts. The second assertion is that, in our culture, women may require additional bolstering for their achievement-oriented efforts, particularly if they are considering NTW careers. If these assertions are correct, then it is legitimate to ask: What is the relation between external support and certain career aspirations and choices of women? 
In a review of research findings in child development to shed light on female achievement motives, Hoffman (1972) comments that the explanations for the failure of women to fulfill their potential are so plentiful that one wonders why women achieve at all. Perhaps part of the explanation for why women do achieve lies in one way that parents (as principal socializing agents) interpret and transmit the role values and expectations in our culture. For example, not all women have been socialized to accept the traditional female role which emphasizes a "vicarious" or passive mode of achievement. Women whose female role ideology reflects the more "contemporary" sex-role perspective usually also accept a "direct" or active mode of achievement (IipmanBlumen, 1972a, 1972b). As a result of some differences in the way parents transmit role expectations for their daughters, there are likely to be differences among women in kind (from whom) and amount of external support needed to sustain their achievement efforts. There is some evidence in the literature which suggests how external support may act as a mediating factor among the career aspirations, role and career choices and ability to sustain achievement efforts of college women (American Psychological Association, 1973; Ashcraft, 1972; Astin and Bayer, 1972; Fecher, 1972; Feldman, 1972; Ferber and Loeb, 1973; Helson, 1971; Horner, 1968, 1972a, 1972b; Jensen, 1972; Julius Guttman, 1973; Sells, 1973; Solomon, 1972; Strong, 1972; 
Tipple, 1972). In some cases the effects of the role of external support seem quite explicit. In other cases the effects are more subtle.

An example of the more explicit effects of the role of external support is suggested in the literature on achievement motivation in females. In her studies on achievement-related conflicts in women, Hormer (1968, 1972a) conceptualizes the problem which white, middle and upper-midale class college women face as the "motive to avoid success." The motive appears to be activated in a woman, particularly if she has high aspirations or shows high $\mathrm{n}$ Ach, if she anticipates that success in a competitive situation will result in negative consequences. The negative consequences include social rejection and loss of femininity and self-esteem. In other words, the fear of becoming a social outcast is aroused. 5 some studies have found that the perception of non-support from others appears to influence intellectually able, college undergraduate women to lower their career aspirations (Hormer, 1972b).

5n a recent review of Horner's original study (1968) and 46 studies generated by it, Tresemer (1973) points out some major theoretical and methodological problems which must be resolved before one can conclude that the "motive to avoid success" is indeed a motive and does in fact have to do with avoiding success. Also, it is more evident that whatever was actually measured is not unique to women. Tresemer suggests that what might have been obtained is a reflection of some kind of fear or anxiety which is more related to a woman's concern about being deviant than about being successful. The two concerns may be, but need not be, highly correlated. 
This effect has been observed for women as they progress from their freshman to senior year in college. These findings have been generally interpreted as reflecting the internal psychological barriers to achievement which remain for white, college undergraduate women. It seems clear that the psychological barriers to achievement are closely related to the external demands in our culture. In some cases the role of external support as a mediator between the career aspirations and actual achievement of women is less explicit. However, its influence may be inferred from effects such as sex differences in doctoral attrition (Sells, 1973) and barriers which are present for women and absent for men in graduate and professional schools (Feldman, 1972). Sells' research (in progress) on doctoral attrition is designed to study the differential factors which facilitate and hinder doctoral completion among men and women. Preliminary results of one aspect of the research on Woodrow Wilson Fellows who entered graduate school in the period 1958-1963 suggest how insufficient external support may be inferred from the pattern of sex differences in drop-out rates (I. Sells, personal communication, April 5, 1973). It was expected that attrition rates would be lower for this biased sample, as compared to other graduate students entering at the same time. In 1966, 49 percent of the Fellows had not yet earned the Ph.D. and were no longer in school. These were classed as "drop-outs." 
There were significant sex differences in overall drop-out rates and also in differences among disciplines. Although the drop-out rate decreased as one moved from TW to NTW fields (Humanities - Social Sciences - Physical Sciences) the magnitude of the sex differences increased in the same order. The same pattern of results was found in additional analyses controlling for second year financial support, the effect of parenthood, and faculty ratings. That is, significant sex differences were found on these factors and the magnitude of the sex differences increased from TWNTW fields.

The situations in which the role or effect of external support appear to be most subtle are for women who are active in the professions. I suggest that the effects are very subtle because these women are actively pursuing their career goals in spite of continual harassment from sex-based discriminatory practices. Some women may revise their career goals to conform to the culturally sanctioned role prescriptions in order to avoid anticipated social rejection. Others--the "achievers"--must confront daily the external barriers to achievement. The evidence of unequal status for women in the professions has rapidly accumulated. In general, career opportunities are more limited for women doctoral students than men doctoral students (Jensen, 1972). There is less likelihood that women will be hired to teach in a business college (Strong, 1972) or a professional 
administrative position in public education (Tipple, 1972). The sex-based inequities in the professions are most recently documented for mathematics (Helson, 1971), physical education (Ashcraft, 1972), college and university administration (Fecher, 1972), chemistry (Solomon, 1972), counseling (Julius Guttman, 1973), psychology (American Psychological Association, 1973), faculty members at the University of Illinois (Ferber and Loeb, 1973) and college and university teaching faculty across the country (Astin and Bayer, 1972).

In summary, I have suggested that external support often acts as a mediator between the career aspirations and choices of college women. The role of external support as a mediating factor may be quite explicit or very subtle and inferred from other effects.

The Sources of External Support. It seems clear that, until recently, a dichotomous sex-role orientation was prescribed in our culture, transmitted in the process of socialization and reinforced overtly and covertly in adult interactions. It is not surprising, therefore, that many women who are enrolled in college, graduate or professional schools appear to be very sensitive to the opinions of certain others about their career/role plans and behaviors. Whom do these women look to for support or approval? Is there any relation between proximate or "chosen" influences (peers) and antecedent or "given" influences (parents)? The review of the research which follows is directed towards 
finding the answers to these questions.

The literature strongly suggests that women's performance, aspirations, role-orientations and career choices are directly related to their perceptions of support or non-support from significant peers, particularly male, such as boyfriend and husband (Bailyn, 1970; Fogarty et al., 1971; Hawley, 1971, 1972; Horner, 1972a, 1972b; Leland, 1966; Schwenn, 1970; Tangri, 1969). This seems reasonable in view of the sensitivity of women to peers during college years and after, together with most women's concern with finding a husband. However, other studies interested in parent identification suggest that what parents transmit in terms of sex-appropriate behavior, etc., may essentially set the stage for what is played out during post-adolescence and as an adult in relations with peers (Block et al., in press; Block, 1973; Lipman-Blumen, 1972a, 1972b; Tangri, 1972). Other studies interested in women's role orientation, role conflict and career choices also suggest that women do mediate antecedent (parents) and proximate (peer) influences, although not necessarily consciously or in a way which is directly measurable (Cartwright, 1972; Edwards, 1969; Fogarty et al., 1971; Ziebarth, 1970). Fogarty et al. (1971) commented that the interactions between parent and peex influences may account for more of the observed patterns than eithex set alone. Bailyn (1964) observed that for a married woman, as long as there is strain between her role 
in the family and community, the most important potential source of support or hostility is her husband. Others agree, observing that in a conflict situation current influences are unusually likely to override predispositions, and that married women with children are usually ambivalent about continuing careers (Fogarty et al., 1971). Similarly, one could expect that single women who express traditional attitudes toward woman's roles and seek satisfactions primarily through family-orientation would be particularly sensitive to perceptions of boyfriends or male peers who are potential husbands. 6 I am suggesting that the more apparent source of support or hostility for a woman's career aspirations may be among peers but, perhaps, a woman chooses certain peers to reinforce her own feelings of selfconfidence or self-doubt. In Edwards' (1969) view, parents ("givens") and peers ("chosens") have different kinds of importance. Parents, school and society "represent sources of tradition and guidance which are often with maturity, replaced with more internal, self-directiveness" (p. 39). Girlfriend and boyfriend, unlike the traditional socializing agents, are associated with achievement of independence. "Perhaps, most important, they are not the original 'givens' of Ss interpersonal environment" (p. 39). Edwards cites an

6 A recent observation for women who are now confronting the problem of "recycling their lives" is that peer support, preferably not from a spouse, seems to be most needed (Bergquist, $1 9 7 3 \longdiv { \text { . } }$ 
observation of Newcomb (1961), from his study of friendship formation, that "values of friends are not simply a source of influence but are also an important factor in the original formation of the friendship" (Edwards, 1969, p. 39).

To sum up the preceding discussion, in order to interpret the findings of an absence or presence of a direct relation between women's role/career choices and their perceptions of support/non-support from significant peers, at least two factors should be considered: 1) the woman's stage in the life-cycle and 2) her own aspirations and attitudes toward woman's roles. There are also at least three factors in study design to consider: 1) the sample used, 2) specific design problems, and 3) the questions of interest and the procedures used. In general, although college samples may be more related to each other than to a general population sample, it does not follow that they are alike. Some problems in the design of earlier studies of college women further limits the interpretation of some results. For example, Hawley (1972) asked college women for their perceptions of what "significant males" in their lives believed was the feminine ideal. She found a difference between the perceptions of women in TW fields (teaching) and those in NTW fields (math-science). The direction of the difference was consistent with the career choices (TW, NTW) of the college student women. However, the women were not asked about their own attitudes and it was also not clear 
who the Ss were thinking of when responding to "significant males in my life believe ..." Another example is Ziebarth's (1970) study in which a direct relation was not found between the expectations of certain others and role conflict of college student women. Role conflict was measured by scaled response to eight hypothetical roleconflict situations which were classed as "male superiority," "child priority" or "husband priority." The ends of the scale represented traditional and self-achieving orientations. For the single $\underline{S} s$, expectations of others was measured by Ss' perceptions of the behavior "potentially relevant" others would prefer in the eight situations. Potentially relevant others were specified: mother, father, husband, best girlfriend, most men, most women. For the married Ss, a measure of expectations of others was obtained by having the husbands complete a 52-item Feminine Role Concept (FRC) inventory, which all $\underline{S}$ s completed for a measure of their own role concepts. Ziebarth commented that the hypothetical situations might have had little reality for the Ss. For example, how would they act in situations (e.g., having children) in which they had no prior experience? $I$ also suggest that the kinds of persons that $\underline{S} s$ were asked to role-play (e.g., an artist) might have produced responses which were ambiguous to interpret. For the measure of expectations of others, Ziebarth observed that the husband's expectations might have been more accurately reflected if 
he had been asked to choose the alternative in the hypothetical situations that he would expect from his wife. From other research findings (Steinmann and Fox, 1966), it is possible that the husband's generalized liberal attitudes, as reflected in total FRC scores, may not relate to his expectations in specific interpersonal situations. To date, only a few studies have collected data on women's own attitudes toward woman's roles and their perceptions of the attitudes or expectations of others in order to explore the relation between these variables and women's career or role choices (Bailyn, 1970; Edwards, 1969; Fogarty et al., 1971; Hawley, 1971, 1972; Ziebarth, 1970). 7 The results are not uniform and are difficult to compare due to different questions asked and different procedures used. Edwards (1969) asked about the relation between role values and the family/career role-orientation

7 It is possible that the perceptions by an individual of the attitudes of others may not be accurate. However, it is these perceptions which appear to provide a person with certain expectations which may be reflected in his/her behavior. Iong-term research (since 1950) on the perceptions of sex roles for women and men by American, white, women and men by the MAFERR Foundation show that both men and women "misperceive" the role expectations of and for each other (Steinmann, 1963; Steinmann and Fox, 1966; Steinmann, Fox, and Farkas, 1968). One study was done to see if being married improved the accuracy with which men and women perceived each other's role expectations (Rappaport, Payne, and Steinmann, 1970). There was no more male-female concensus found among 45 married couples than among 45 dating couples drawn from a university community. The most reasonable explanation for the overall pattern of results is that both men and women send double messages and misinterpret each other's cues (Steinmann and Fox, 1966). 
of college student women. ${ }^{8}$ Ziebarth (1970) asked about the relations between role conflict and role concepts, expectations of others and matemal role modeling for college student women. ${ }^{9}$ Bailyn (1970) and Fogarty et al. (1971) asked about the determinants of family/career patterns of married college graduate women. ${ }^{10}$ Hawley (1971, 1972) asked about the relation between the perceptions of the attitudes of significant males toward women and the career choices of women. ${ }^{11}$ A brief review of the findings follows.

The studies by Edwards (1969) and Ziebarth (1970) did not show a direct relation between woman's role orientation

8 The sample $(N=572)$ consisted of women in their senior year of nursing diploma and teaching degree programs. All Ss who were older than 23 years were omitted from the sample. Iess than 5 percent of the sample were married. All Ss came from intact homes.

$9_{\text {The sample }}(\mathrm{N}=101)$ consisted of women who were college students $(78 \%)$ or who were married to graduate students (22\%). The average age of the sample was 22 years. One-half of the sample were married.

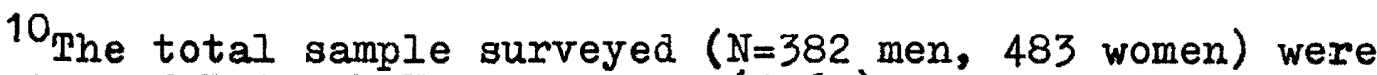
graduates of British Universities (1960) who completed a questionnaire in 1968. One-half of the sample were married. Sixty percent of the sample had at least one child. The findings reported were for the married women in the sample (Fogarty et al., 1971) and for the married couples ( $N=224)$ in the sample (Bailyn, 1970).

${ }^{11}$ In the replication study (1972) the sample $(N=136)$ consisted of teachers-in-preparation, math-science majors and counselors-in-preparation. The mean age for the teacher and math-science groups was 26 years and for the counselor group was 33 years. One-half in each group were married. The sample in the earlier study (1971) consisted of women who averaged one year of college attendance. 
or role conflict and their perceptions of the role values or expectations of certain others. Edwards (1969) found that peer values, not necessarily of males, appear to be more significant than the views of "given" authority figures (e.g., parents, school, society). The perceptions of boyfriend's role values were only significantly related to "family-oriented" Ss. For the other two role-orientations ("compromise" and "career") the perceived values of significant others which seemed important included best girlfriend, early and current values of mother, and school. Ziebarth (1970) found that the main factors for determining women's role conflicts were their own role concepts and career orientations. There was some effect found due to the type of maternal role model and almost no effect due to the expectations of others. (Design problems which limit the interpretation of her results were previously cited.) Bailyn (1970) and Fogarty et al. (1971) found three significant factors to account for the married women's family-career patterns: 1) S's perceptions of husband's orientations, 2) S's perceptions of husband's commitment to the idea of married women having a career, and 3) mother's work experience and S's perceptions of her attitudes about working or not working. In concluding, Fogarty et al. (1971) observed that a woman's career commitment depends upon external support plus her own emotional resources. The latter is particularly important where 
external support is lacking. In their findings, overall, external support appeared to make the most difference. Hawley's study (1972) replicated a previous finding (Hawley, 1971) that a significant relationship exists between the careers women choose and their beliefs about significant men's views of the feminine ideal. (Design problems which limit the interpretation of her results were previously cited.)

Parental Role Modeling and Current Importance of Relations with Significant others

The major variables in my study were: 1) women's career choices, 2) their attitudes toward woman's roles, and 3) their perceptions of the views of significant others (mother, father, husband/consort, close friend). Three intervening variables which were considered potentially useful for illuminating the relations among the major three variables were: 1) expressed identification with parents, 2) maternal role modeling, and 3) the current importance of the women's relations with each specified significant other. Expressed Identification with Parents. This variable was selected to represent one aspect of parental role modeling. It was chosen to see how the graduate student women perceived the points of convergence with and divergence from both of their primary sex-role models (i.e., parents in intact homes). In the recent literature on parental identification (mentioned on page three), the general finding 
is that both women and men often identify with different aspects of both parents. Until recently, research on sex roles primarily focused on the process of parental identification in terms of one-parent outcomes, i.e., same-sex or cross-sex identification with one parent. One consequence of this orientation is to disregard information which is pertinent for understanding complex phenomena such as attitudes and behaviors related to sex roles. Perhaps the orientation to one-parent outcomes for questions about parental or sex-role identification is partly due to some implicit assumptions in psychological research. One is that the result of successful socialization will be the modeling of oneself after either mother or father. ${ }^{12}$ other implicit assumptions were recently pointed out in a review of the psychological literature on sex roles (Bem, 1972). She commented on two sets of assumptions which are responsible for psychology's neglect of the "androgynous" person. One set of assumptions is relevant to the present discussion and refers to the version of sex-role ideology which underlies the work of psychologists concerned with the process of sex-typing and sex-role development. In that version there

${ }^{12}$ Moreover, whether same-sex or cross-sex parental identification is desirable depends upon the context of the question being asked. For example, if one is asking about parental identification in relation to social "adjustment," same-sex identification is the norm. However, if one is asking about parental identification in relation to intellectual development, then cross-sex identification is more desirable (Maccoby, 1966b). 
is implicit support not only for the idea that the sextyping process is desirable, but also for society's stereotypes of sex-appropriate behaviors. Furthermore, there is confusion in the literature from using the terms parental identification and sex-role identification as if they referred to the same process which they do not (Block et al., in press).

Maternal Role Model. This variable was selected to represent another aspect of parentai role modeling. It was not chosen because it may be more important than the paternal role model for understanding the role attitudes and behavior of women. Rather, prior research has shown its utility for understanding the relations between role concepts and career choices among white, college women (Baruch, 1972; Fogarty et al., 1971; Lipman-Blumen, 1972a, 1972b; Tangri, 1969, 1972; Vogel, Broverman, Broverman, Clarkson and Rosenkrantz, 1970). Most studies (cited above) have found that the important aspects of the maternal role model are whether or not mother worked, together with her daughter's perceptions about how mother felt about what she did. Ziebarth (1970) did not find that information about mothers to be useful. She reasoned that what was probably more influential on a daughter's role concepts and behaviors were the mother's own role concepts and possible role conflicts and how these were communicated. The fact that mother works does not necessarily mean that she has less traditional role concepts. 
Current Importance of Relations with Significant

Others. In the present study this variable is conceptualized as reflecting the role of women as mediators of earlier (parents) and later (peer) influences. To date, only one study has tried to assess this variable (Edwards, 1969). He asked college women to rate the relative importance of significant others. His hypothesis that the ratings might be possible predictors of $\underline{\text { S' }}$ role-decision groups was not supported. The women were also asked who was the most important influence on their future plans. Edwards hypothesized that those significant others whose perceived role values appeared important from prior analysis would be considered to be the most important influence on the future plans of the Ss. No support was found for this hypothesis. However, Edwards did allow his $\underline{S} s$ to respond "self," which is the modal response when the question is asked in this way. Edwards concluded with the comment that the values of significant others are unquestionably relevant, but that their importance is subtle, complex and tempered by the mediating capabilities of the $\underline{S}$.

\section{RESEARCH HYPOTHESES AND SUPPIEMENTARY QUESTIONS}

The general purpose of the present study was to explore how women view their roles together with whether or not women who choose NTW occupations (i.e., representing a more deviant choice) have greater social support for that 
choice. Social support was defined by: 1) antecedent, background factors (e.g., maternal role modeling and expressed identification with parents) and 2) proximate factors (e.g., perceptions of the views of certain significant others about women's roles and current importance of the relations with those significant others). The specified significant others were: 1) mother, 2) father, 3) husband/consort, and 4) close friend.

The research hypotheses were formulated in terms of some direct relationships which might be expected among the major variables in the present study. Some other questions of interest for exploratory purposes were termed supplementary questions. Two of these questions involved intervening variables which might illuminate the relations among the major variables. They were not formulated as specific hypotheses because a prediction could not be made about the direction of the difference. The specific hypotheses and supplementary questions were formulated with my particular sample in mind, i.e., white, American, graduate student women from intact homes.

Hypothesis 1

For the sample as a whole, it is predicted that the women's own scores on the Attitudes Toward Woman's Roles (AWR) inventory will be more congmuent with the AWR scores for their perceptions of the views of husband/consort and close friend than for the perceived views of mother and 
father. This expectation is based on two assumptions. One is that people see generations as differing in attitudes toward woman's roles. The second assumption is that there is a difference in the way that parent (given) and peer (chosen) figures are determined for each person. Presumably a person seeks out or chooses a husband/consort and close friend among those persons whose attitudes are perceived to be the same or quite similar to one's own.

\section{Hypothesis 2}

It is predicted that women who select NTW occupations are more likely to have high scores on the AWR inventory, reflecting a preference for androgynous roles; it is predicted that women who select TW occupations will have lower scores on the AWR inventory, reflecting a preference for dichotomous roles. This expectation is based on the assumption that a woman's view of woman's roles is more likely to be congruent with or reflected in one aspect of adult role choice, e.g., occupational choice. Some support for the adequacy of this assumption has been found in recent studies with college samples.

\section{Hypothesis 3}

It is predicted that women who select NTW occupations will perceive husband/consort and close friend preferring androgynous roles; i.e., scores on the AWR inventory for these perceived views will be high. It is predicted that 
women who select TW occupations will perceive husband/consort and close friend preferring dichotomous roles. This expectation follows from the assumption that a woman seeks out others who will support or reinforce her own views about woman's roles and certain behavioral choices, one of which is occupational choice. In other words, a woman is likely to be sensitive to the expectations of certain others who confirm her own predispositions in attitudes as well as behaviors.

\section{Supplementary Questions}

If it is reasonable to expect more social support for the more deviant choice (e.g., NTW occupations), where might that support be found? The following questions were included for exploratory purposes. Specific hypotheses were not formulated.

Question 1. Are there differences in the backgrounds of women who choose TW and NTW occupations which might indicate differences in parental modeling? The principal measures are maternal role modeling and women's expressed identification with parents.

Question 2. Will women pursuing NTW occupations perceive mother and father preferring androgynous roles? Will women pursuing TW occupations perceive mother and father preferring dichotomous roles? The perceived views of mother and father are measured by the AWR inventory. Possible interaction effects of maternal role modeling and expressed 
identification with parents were considered.

Question 3. Might differences in external support for women's TW and NTW occupational choices be reflected in the current importance of their relations with each specified significant other (mother, father, husband/consort, close friend)? The proposed measures are: 1) ratings of the current relations and feelings of satisfaction with those relations, 2) ranking others according to whose opinion is most valued concerning the woman's plans, behavior, etc., and 3) characteristics which describe the interpersonal quality of those current relations. 
CHAPTER II

\section{RESEARCH DESIGN}

\section{SELECTION OF SUBJECTS}

Women currently enrolled in Spring, 1973 in Ph.D. and professional degree programs at Portland State University and the University of Oregon Medical and Nursing Schools were asked to participate in a study of current attitudes of women graduate students toward woman's roles. Women graduate students were of interest for three reasons. First, women pursuing degrees at this level are showing serious interest in a professional or academic career. They will also soon be eligible for jobs. Second, the mean age of the sample is expected to be older than most samples of college student women. As a result, their attitudes toward woman's roles and their career choices might reflect more reality testing of earlier hopes, aspirations and expectations, particularly for those women with family-role responsibilities. The third reason is that except for a study by MaKenzie (1971), previous studies of this kind have not included women in graduate school.

of 284 women asked, 118 agreed to complete a questionnaire. For each subgroup (different degree program) often 50 percent or more of those asked showed interest. Two 
subgroups showed a much poorer response. Only one-third of the women enrolled in the School of Social Work (MSW) program and one-fifth of the women reached in the School of Education programs (MS/MA in Education, Certificate Programs--Educational Specialists, MAT, MST) responded (See Table I). The poorer responses can be partly explained. For the MSW women, the combination of year-end deadines and the fact that they fill out many questionnaires for each other's studies appeared to evoke a strong negative reaction to my appeal. For the women in the School of Education programs, the poor response is largely due to the procedure used to make the initial contacts. Names were randomly selected from the graduate school files in the School of Education. These files proved to be very inaccurate. The sample was chosen to represent two distinct career-choice (CC) groups. For final analysis $(\mathrm{N}=96)$, careers considered traditional-for-women (TW) were represented by Masters programs at Portland State University (Education, Social Work) and at the University of Oregon Medical (Medical Technology) and Nursing Schools. Careers considered not-traditional-for-women (NTW) were represented by Masters and Ph.D. programs at Portland State University (Business Administration, School Administration, Environmental Sciences and Resources, Urban Studies) and the MD and various $\mathrm{Ph} . \mathrm{D}$. programs at the University of Oregon Medical School (See Table II). 
TABIE I

RESPONSE RATES OF SUBJECTS INITIAIIY

CONTACTED FOR STUDY

\begin{tabular}{|c|c|c|c|}
\hline Professional Degree Program & $\begin{array}{l}\text { Number of } \\
\text { Ss Con- } \\
\text { tacted }\end{array}$ & $\begin{array}{l}\text { Number of } \\
\text { Ss Parti- } \\
\text { cipated }\end{array}$ & $\begin{array}{l}\text { Percent } \\
\text { Partici- } \\
\text { pated }\end{array}$ \\
\hline \multicolumn{4}{|l|}{ Portland State University } \\
\hline Art and Architecture (MFA) & 1 & 0 & $0 \%$ \\
\hline $\begin{array}{l}\text { Business Administration } \\
\text { (MBA) }\end{array}$ & 18 & 10 & $56 \%$ \\
\hline $\begin{array}{l}\text { Education (MA/MS Educa- } \\
\text { tion, Counseling, School } \\
\text { Administration, MAT, MSI } \\
\text { Certificate Programs) }\end{array}$ & 70 & 14 & $20 \%$ \\
\hline Social Work (MSW) & 90 & 29 & $32 \%$ \\
\hline $\begin{array}{l}\text { Environmental Sciences and } \\
\text { Resources (Ph.D.) }\end{array}$ & d & 4 & $80 \%$ \\
\hline Systems Science (Ph.D.) & 4 & 0 & $0 \%$ \\
\hline Urban Studies (Ph.D.) & 17 & 16 & $98 \%$ \\
\hline \multicolumn{4}{|l|}{$\frac{\text { University of Oregon Nursing }}{\text { School }}$} \\
\hline Nursing (MSN) & 33 & 16 & $48 \%$ \\
\hline \multicolumn{4}{|l|}{$\frac{\text { University of Oregon Medical }}{\underline{\text { School }}}$} \\
\hline $\begin{array}{l}\text { Medical Technology (MS } \\
\text { Medical Technology) }\end{array}$ & 1 & 1 & $100 \%$ \\
\hline MD & 37 & 24 & $65 \%$ \\
\hline \multicolumn{4}{|c|}{$\begin{array}{l}\text { Ph.D. (Biochemistry, Clini- } \\
\text { cal Pathology, Medical } \\
\text { Psychology, Physiological } \\
\text { Psychology) }\end{array}$} \\
\hline TOTALS & 284 & $N=118$ & \\
\hline
\end{tabular}

$a_{\text {The only programs which were randomly sampled were }}$ those in the School of Education because of a very large enrollment. 
TABIE II

COMPOSITION OF SAMPLE BY DEGREE PROGRAM AND MEAN AGES $(\mathrm{N}=96)$

Professional Degree Program Number of SS Mean Age (Years)

Traditional-for-Women (TW)

MA/MS Education, Counseling; Iibrary Certificate

29.3

MS Medical Technology

1

35.0

MSN

14

31.9

NSW

$$
\frac{21}{n_{1}=49}
$$$$
28.6
$$

Not-Traditional-for-Women (NTW)

Environmental Sciences and

Resources, (Biology),

$\mathrm{Ph}$.D.

38.3

MBA

9

34.0

MD

18

23.8

MS School Administration

1

35.0

Biochemistry, Physiological

Psychology, Ph.D. (Uni-

versity of Oregon Medical

School)

2

28.1

Urban Studies, Ph.D.

$\frac{14}{n_{2}=47}$

30.6 
For analysis, the sample consisted of $49 \underline{\mathrm{S}}$ in the TW groups and $47 \underline{\mathrm{S} s}$ in the NTW group. For the purposes of this study, the sample for analysis was limited to American, white, graduate student women from intact homes. That means that they lived with the same set of parents most of the time they were growing up, or until they completed high school. All Ss between the ages of 21 and 45 years were included to represent a range of continuity in career preparation. All Ss older than 45 years were omitted from the present analysis.

\section{SAMPIE CHARACTERISTICS}

The Ss ranged in age from 21 to 44 years. The overall mean age was 29.05 years. The mean age for the TW group was 29.9 years and for the NTW group it was 28.2 years (See Table II). Overall, 64 percent of the sample were married or living in a marriage-like arrangement. The CC groups were balanced on this factor and other factors. The mean number of years the Ss were living with their current mates was 7.5 years. Overall, 36 percent of the sample had at least one child and were currently living with their child(ren). This represented 57 percent of the women who are currently or have previously been married. The two CC groups were balanced on: 1) the number of $\underline{S} s$ who had children, 2) the number of children the $\underline{S} s$ had, and 3) the number of children who are currently less than six years old. For the $\underline{S} s$ with 
children, 83 percent had no more than three children and almost one-half had at least one child less than six years old (See Table III).

The two CC groups were also balanced on educational and occupational characteristics of the parents. Overall, nearly 75 percent of the mothers did not have a college degree. For approximately two-thirds of the sample, mother's principal occupation while the Ss were growing up was housewife. Iess than 10 percent of the mothers who worked outside the home were in occupations considered NTW. Mother's current occupation showed that approximately one-half were housewives and one-half were working outside the home, almost all in TW occupations (See Table IV). As would be expected, fathers attained a higher level of education than mothers. Fifty-six percent did not have a college degree in contrast to almost 75 percent of the mothers. While the Ss were growing up more than two-thirds of the fathers were engaged in occupations which fell in the top three ranks of an Index of Social Position (Hollingshead and Redlich, 1958). Thus, Ss in the present study are mainly from middle and upper-middle class backgrounds as is usual for samples of white, college students. The $\underline{S}$ in the NTW group do appear to come from backgrounds with higher social ranking (See Table V).

The most obvious difference between the TW and NTW groups is that only the latter group includes persons drawn 
TABIE III

CURRENT MARITAL STATUS AND

NUMBER OF CHIIDREN

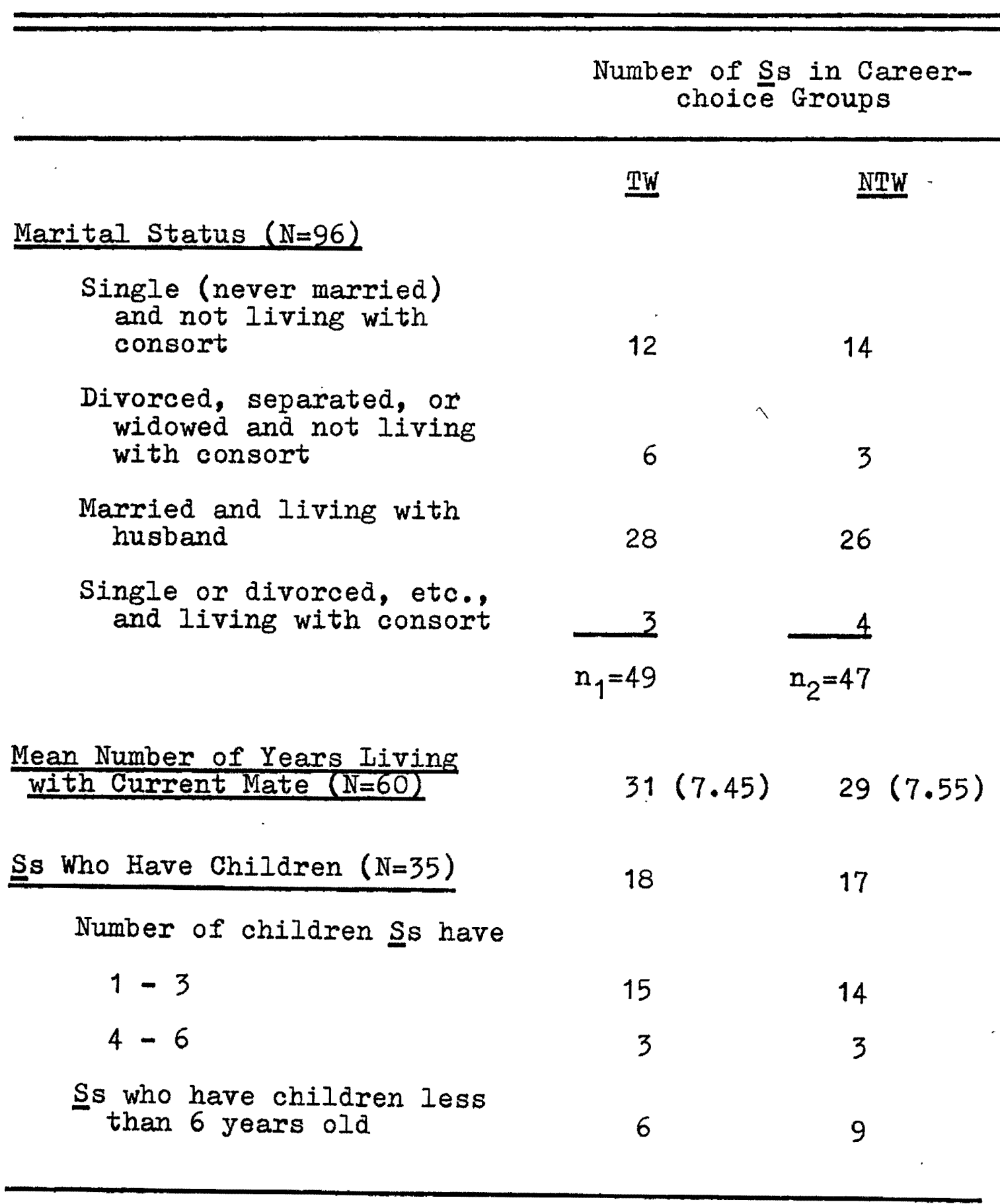


TABIE IV

EDUCATIONAL AND OCCUPATIONAL CHARACTERISTICS

OF SS' MOTHERS

\section{Number of Ss in Career- choice Groups}

Educational Level ( $N=95)$

Educational Level ( $N=95)$
Less than college degree
Coliege degree, post-
graduate degree

38

32

Educational Level ( $N=95)$
Less than college deg-
Coliege degree, post-
graduate degree

Educational Level $(\mathrm{N}=95)$
Less than college deg
Coliege degree, post-
graduate degree

TW

$\underline{\mathrm{NTW}}$

Principal Occupation While

Ss were Growing Up

Housewife

31

31

Traditional-for-women (TW) occupation

17

13

Not-traditional-for-women (NTW) occupation

1

15

10 


\section{EDUCATIONAI AND OCCUPATIONAI CHARACTERISTICS OF Ss' FATHERS}

Number of $\underline{S} s$ in Careerchoice Groups

TW

NTW

Educational Level ( $N=95)$

Less than college degree

30

24

College degree, postgraduate degree

19

22

Principal Occupation While Ss

Were Growing Up (N=90)

Ranks $1,2, a^{3}$ (Index of Social

26

36

Ranks 4, 5, 6, 7 (Index of Social Position)a

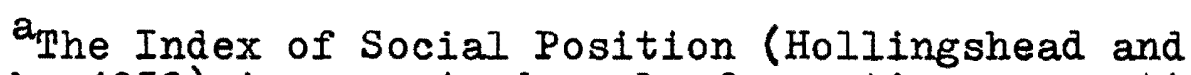
Redlich, 1958) is a revised scale for rating occupations. It is a revision of the Alba Edwards system of classifying occupations which is used by the United States Bureau of the Census. The scale used in the Index of Social Position ranks professions into different groups and businesses by their size and value. The Edwards system does not differentiate among kinds of professionals or the size and economic strengths of businesses. 
from doctoral programs. However, this difference becomes less important if one notes that the total sample is chosen from programs giving the terminal degree in each career field. It is that proximity to a professional career that was the main criterion for choosing the sample. It is also plain from the tables comparing the two CC groups that they are very similar to each other in all other respects. Finally, the sample is drawn from students in programs of study-not graduates of those programs, who might be expected to be more different from each other.

III. COLIECTION OF THE DATA

Administration of the Questionnaire

When the $\underline{S} s$ were initially contacted by letter requesting their participation in my study they were told that participation meant completing a questionnaire. They were informed that the questionnaire was not expected to take more than one hour to complete and that it had to be completed on campus. The questionnaire was to be administered in groups at times which were convenient for the $\underline{S}$ s as indicated on the form provided (See Appendix A). Administration on campus was stipulated in order to introduce some control for the situation and mood in which the Ss would complete the questionnaire. It was also done to minimize the loss of data from mail-in questionnaires.

of the $118 \underline{\text { S }}$ who agreed to participate, it turned 
out that groups could be arranged conveniently for only 71 Ss. Rather than lose a great deal of data it was decided that the remaining 47 Ss should be allowed to do a mail-in questionnaire. Additional instructions for completing the questionnaire at home were enclosed with the form (See Appendix A). The return rate among the $47 \mathrm{Ss}$ was very high. Only four Ss did not return the questionnaire.

Nine different meetings were set up at Portland State University and the University of Oregon Medical School. The size of the groups ranged from five to ten Ss. The standard procedure was as follows. I met with the groups and thanked the women for their cooperation. I reminded them to read the cover sheet before they began and to answer the questions in the order given (i.e., not to look ahead in the questionnaire). I requested that if they were interested in receiving results of the study they put their names and addresses on a separate sheet of paper (which was provided) before they left. Only three Ss were not interested. The Ss were allowed to take as much time as they wanted to fill out the questionnaire. Most of the Ss completed the questionnaire in less than 45 minutes.

\section{Content of the Questionnaire}

The questionnaire (reproduced in Appendix B) which was used was developed for this study and consisted of two parts. The overall scheme included items for affect and behavior. 
Part 0ne. This part consisted of 38 questions about the SS' family background, current situation and future plans. Part One was designed to collect data on the independent variable (career choice) and the three intervening variables (maternal role modeling, expressed identification with parents, current importance of the relations with significant others: mother, father, husband/consort and close friend). Items ranged in degrees of stmucturing from free response (e.g., age), to moderate structuring (i.e., scaled and ranked responses), to structured responses (i.e., multiple-choice format). The measures used to collect the data were based on previous research.

Indices of career orientation of the $\underline{S}$ included: 1) the major field of interest in graduate school, 2) the degree expected, 3) intentions to work after getting the degree, and 4) intentions to work in relation to having children. For the purposes of the present study, career choice (independent variable) refers only to the degree expected. That is, whether the degree program is considered to be TW or NTW.

Indices of the type of maternal role model included items for affect and behavior. The items for behavior were: 1) mother's educational status and occupation (while Ss were growing up and currently) and 2) mother's principal activities while the $\underline{S} s$ were growing up. The items for affect were the Ss' perceptions of: 1) mother's overall satisfac- 
tion with her life, 2) whether mother's overall satisfaction had to do with working outside the home, 3) mother's feelings about working outside the home and 4) activities and personal relations which seemed most important to mother. These items were scored on a nominal or ordinal scale. Comparisons between the two CC groups were made on the basis of the items singly or in combination, as patterns of response.

Indices of $\mathrm{Ss}^{\prime}$ identification with parents included items which pertained to expressive and instrumental

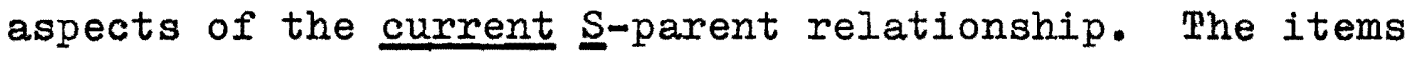
for the instrumental dimension were: 1) Which parent are you most like in terms of personality, temperament and outlook on life? 2) Which parent comes closest to your idea of an attractive person? 3) Which parent's values, in general, do you agree with? 4) Which parent's career goals for you do you agree with? The items for the affective dimension were: 1) Which parent shows more understanding of you? 2) Which parent do you feel closest to? These items were treated as nominal units rather than combined into one summary score.

The items for assessing the current importance of the S.s' relations with each specified significant other were: 1) ratings of the current relations and the degree of satisfaction with those relations, 2) ranking "others" whose opinions about the SS' behavior were most important, and 3 ) 
selecting statements which came closest to describing the expressive quality of those current relations. These items were also placed on a nominal or ordinal scale.

Part Two. This part consisted of a 24-item inventory of some attitudes toward women's roles and satisfactions (AWR) devised for this study. The items were used or adapted from those used in previous studies (Hawley, 1970; Porter, 1967; Ziebarth, 1970). (See Appendix C for the concepts and list of statements making up the five subscales of the AWR inventory.) The items were counterbalanced and the order of presenting the items was randomized. The SSs responded to each item along a 4-point Likerttype scale, ranging from strongly disagree to strongly agree. The AWR inventory was completed first for Self attitudes for all $\underline{S}$. The $\underline{S}$ s then completed the same form of the AWR inventory as they believed each of the specified significant others would do if they were given the questionnaire today. The order of responding for the significant others was randomized. The inventory scores were conceptualized in my study as falling along a dichotomousandrogynous continuum of attitudes toward woman's roles (Hawley, 1970):

Scores at the dichotomous end indicate the belief that behavior is appropriately male or female. Scores at the androgynous end indicate the belief that no sex referent is necessary in the circumstances specified $(p, 4)$.

The individual subscale scores (possible range of scores for 
each: $1.0-5.0$ ) and total AWR scores (possible range of scores: $5.0-25.0$ ) were used for measures of the dependent variables in the present study: 1) attitudes toward woman's roles and 2) perceptions of the attitudes of mother, father, husband/consort and close friend.

The particular method and format which was used in the present study for assessing the perceptions of attitudes toward woman's roles/satisfactions for Self and Others was developed by Fand (1955). It has been used extensively since then, sometimes revised or modified to suit individual research purposes (Edwards, 1969; Hawley, 1971, 1972; MAFERR Foundation, see references for Steinmann, 1963; Steinmann et al., 1964, 1966, 1968; Rappaport et al., 1970; McKenzie, 1971; Porter, 1967; Ziebarth, 1970).

Scoring of the Questionnaire

The overall scheme for scoring responses included nominal and ordinal scales. Both parts of the questionnaire were coded and scored by the researcher. All of the responses were given number scores. The key which was used for coding and scoring is included in the reproduced questionnaire (See Appendix B). The numbers in parentheses, which appear in the blank spaces which were provided for the Ss' responses, did not appear on the form completed by the Ss. These numbers provide the key for coding and scoring the various items. In some cases where the scoring procedure is more complicated (e.g., Question 17) additional 
notes are provided. The notes are included in additional pages following the reproduced questionnaire.

Reliability of the AWR Inventory

Reliability was tested concurrently with the administration of the main study. A test-retest method (with an interval of four weeks) was used. The $\underline{S}$ were women volunteers from upper division psychology classes at Portland State University. For final analysis $(\mathrm{N}=19)$ Ss included both undergraduate and graduate students. The $\underline{S} s$ were given the same questionnaire used in the main study except for a shortened form of the AWR inventory. Each $\underline{S}$ completed the AWR inventory for Self and as she perceived one other person would do. One-half of the $\underline{S}$ s were instructed to respond as mother would, the other half of the $\underline{S}$ s were instructed to respond as father would. The questionnaires for both the test and retest portions were administered as a mail-in. Analyses were done for total AWR (summed subscales) scores. The results of the test-retest procedure suggested that the AWR inventory as a measure of attitudes toward woman's roles has some consistency over time. All three scores were found to be highly reliable over the four week interval: Self attitudes $(N=19), r=.60 \quad(t=3.09, p<.01)$; perceptions of mother's attitudes $(N=9), r=.92 \quad(t=6.28$, $p<.001)$; perceptions of father's attitudes $(N=10), r=.87$ $(t=5.02, p<.01)$. (Table VI shows the scores obtained.) 
TABIE VI

TOTAI AWR SCORES OF COLLEGE STUDENT WOMEN FROM TEST-RETEST PROCEDURE

\begin{tabular}{|c|c|c|c|c|c|c|}
\hline \multirow[b]{2}{*}{ S No. } & \multicolumn{2}{|c|}{ Self } & \multicolumn{2}{|c|}{ Perceived Mother } & \multicolumn{2}{|c|}{ Perceived Father } \\
\hline & Test & Retest & Test & Retest & Test & Retest \\
\hline 1 & $24 \cdot 1$ & 23.8 & $21 \cdot 4$ & $18 \cdot 5$ & $-\infty$ & -- \\
\hline 2 & 20.2 & 20.7 & $10 \cdot 9$ & $12 \cdot 5$ & -- & - \\
\hline 3 & $14 \cdot 3$ & 16.7 & 8.2 & 9.3 & -- & -- \\
\hline 4 & 23.3 & 22.9 & 11.2 & $11 \cdot 4$ & -- & -- \\
\hline 5 & 23.2 & 23.2 & $15 \cdot 1$ & $15 \cdot 4$ & - & - \\
\hline 6 & 19.2 & 21.1 & 11.0 & 9.4 & -- & -- \\
\hline 7 & 23.7 & $24 \cdot 7$ & $18 \cdot 7$ & $16 \cdot 9$ & -- & -- \\
\hline 8 & $17 \cdot 5$ & $18 \cdot 9$ & 12.6 & 11.7 & -- & - \\
\hline 9 & $24 \cdot 2$ & $24 \cdot 1$ & $13 \cdot 3$ & $15 \cdot 7$ & - & -- \\
\hline 10 & 23.7 & 24.0 & $-\infty$ & -- & $13 \cdot 5$ & 11.9 \\
\hline 11 & 22.5 & 23.0 & -- & -- & $15 \cdot 7$ & 13.8 \\
\hline 12 & $24 \cdot 5$ & 24.8 & -- & -- & 9.5 & 6.9 \\
\hline 13 & 22.5 & $22 \cdot 3$ & -- & -- & 15.2 & 13.5 \\
\hline 14 & 21.9 & $22 \cdot 7$ & -- & -- & $16 \cdot 3$ & 17.2 \\
\hline 15 & 21.5 & 21.8 & -- & -- & 16.5 & 16.6 \\
\hline 16 & 22.8 & 23.8 & -- & -- & 10.7 & 9.7 \\
\hline 17 & 20.7 & 20.7 & -- & -- & $7 \cdot 9$ & $10 \cdot 6$ \\
\hline 18 & 21.4 & 21.6 & -- & -- & 16.1 & 17.0 \\
\hline 19 & $24 \cdot 5$ & 23.0 & -- & -- & 13.4 & $14 \cdot 5$ \\
\hline
\end{tabular}


Validity of the AWR Inventory

The validity of the AWR inventory was not established independently for use in the present study. Since all but three of the items had been used or adapted from those used successfully in previous studies, it was felt that some validity for the scale had been shown. Previous studies using similar scales found significant correlations between the attitudes of college women toward woman's roles and their behavior (e.g., role/career choice, plans, aspirations, expectations). 
CHAPTER III

\section{RESUITS}

The findings in my study will be reported in the following order: 1) research hypotheses, 2) supplementary questions, and 3) indices of career orientation.

\section{RESEARCH HYPOTHESES}

The three research hypotheses were formulated about relationships among the major variables which were: 1) attitudes toward woman's roles, 2) perceptions of the attitudes of certain significant others (mother, father, husband/ consort and close friend), and 3) career choices. The subjects were American, white, graduate student women enrolled in Ph.D. or professional degree programs at an urban state university.

\section{Hypothesis 1}

Ss' attitudes toward woman's roles would be more congruent with the perceived attitudes of husband/consort and close friend than with the perceived attitudes of mother and father.

\section{Hypothesis 2}

Ss pursuing TW careers would reflect more dichotomous 
role attitudes than $\underline{S} s$ pursuing NTW careers who would reflect more androgynous role attitudes.

\section{Hypothesis 3}

Ss pursuing TW careers would perceive husband/support and close friend preferring more dichotomous roles than $\underline{S}$ pursuing NTW careers who would perceive husband/consort and close friend preferring more androgynous roles.

\section{Indicators}

Career choice (TW, NTW) was defined by the degree programs in which Ss were enrolled. Measures of Self attitudes and the perceptions of the attitudes of the specified significant others were based on $\underline{S}^{\prime}$ scores on the Attitudes Toward Woman's Roles (AWR) inventory devised for this study. The analyses of the attitudinal measures usually used median scores of the five AWR subscale and total (AWR) (summed subscales) scores. (Due to the actual distribution of the scores obtained, the tests were sometimes based on percentile rather than median scores.) The possible range of scores for each AWR subscale was 1.0 - 5.0. The possible range of scores for the total AWR score was 5.0 - 25.0. This represents a conversion of raw scale scores so that subscale comparisons could be easily made (See Appendix B). Overall, the total AWR scores for the measured Self attitudes and the perceived attitudes of husband/consort and close friend tended to cluster towards the androgynous end 
of the scale. The total AWR scores for the perceived attitudes of mother and father tended to cluster towards the dichotomous end of the scale. Table VII shows the ranges of total AWR scores obtained, the median or percentile score for each range, and the distribution of the two CC groups in relation to the median or percentile scores. The ranges of AWR subscale scores obtained and the distribution of the two $C C$ groups in relation to the median scores are not reported. (See Table XII for the median score for each range of AWR subscale scores obtained.)

Results

Only Hypothesis 1 was supported by the results of the analyses. The findings for each hypothesis are reported together with the results of additional analyses for possible effects of age and marital status on $\underline{S} s^{\prime}$ responses.

Hypothesis 1. Phi coefficients were calculated to see if there was a relation between the measured Self attitudes and the perceived attitudes of the specified significant others. Statistically significant positive correlations were found for four of the six comparisons made $(p \leq .01):$ 1) Self and perceived husband/consort, 2) Self and perceived close friend, 3) perceived mother and perceived father, and 4) perceived husband/consort and perceived close friend. The correlations were not statistically 


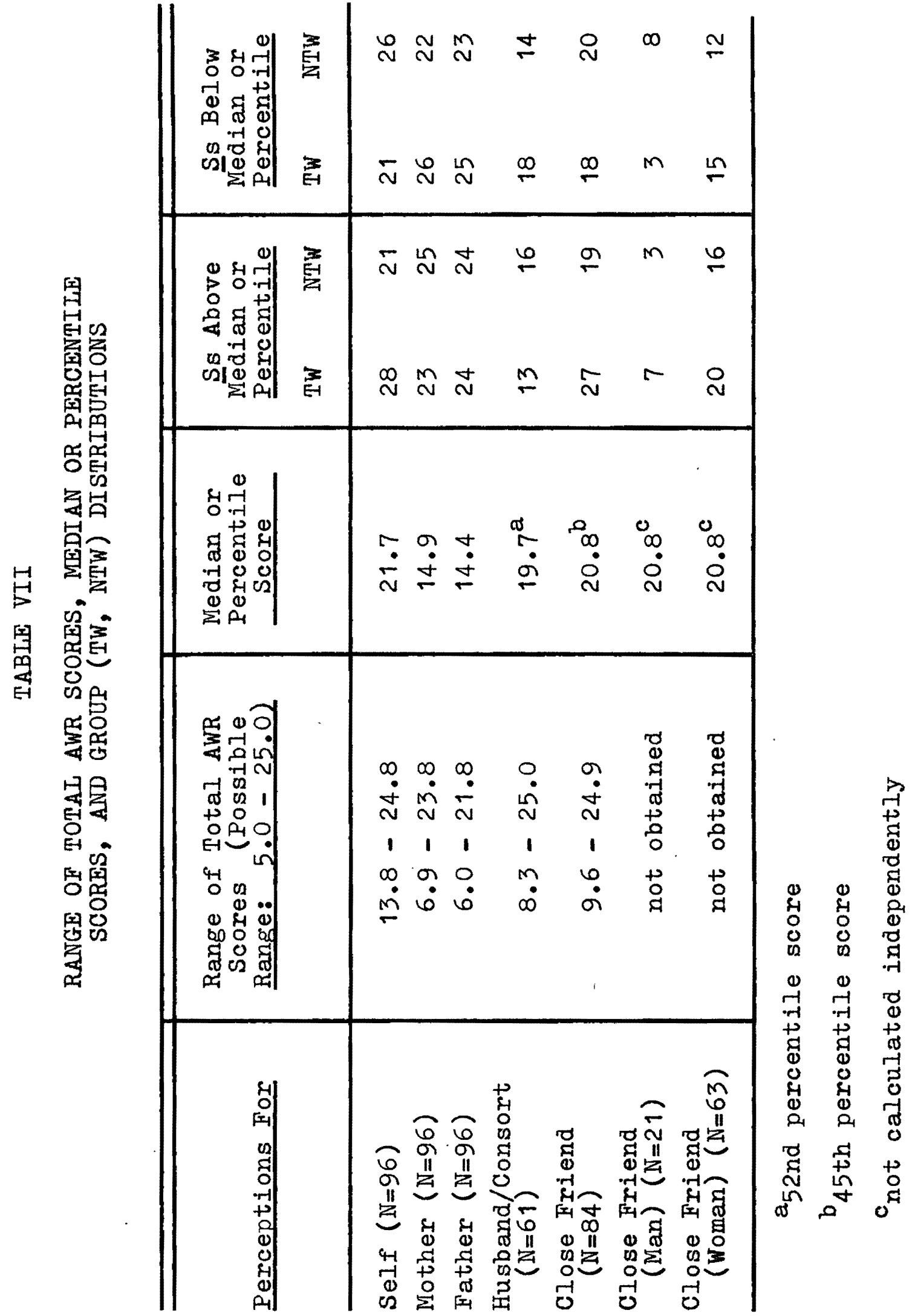


significant for the comparisons between: 1) Self and perceived mother and 2) Self and perceived father (See Table VIII). The results indicated that there was less relation between the attitudes of the $\underline{S} s$ and the perceived attitudes of mother or father than between any of the following: 1) Self attitudes and the perceived attitudes of husband/consort or those of close friend, 2) the perceived attitudes of husband/consort and those of close friend, and 3) the perceived attitudes of mother and those of father.

Sign tests were done to see if there was a difference, on the average, between the scale values for measured Self attitudes and the scale values for the perceived attitudes of the specified others. Analyses for value differences between measured Self attitudes and the perceived attitudes of mother and father were done for AWR subscale scores. The results of all ten analyses were significant beyond the .0001 level (See Table IX). Additional analyses were done comparing two sets of differences (i.e., four total AWR scores) for: 1) perceived mother - Self and Self - perceived husband/consort, 2) perceived father - Self and Self - perceived husband/consort, 3) perceived mother Self and Self - perceived close friend, and 4) perceived father - Self and Self - perceived close friend. The results of all four analyses were significant beyond the .0001 level (See Table X). Hypotheses 2 and 3. Median tests were done to see 
TABLE VIII

PHI COEFFICIENTS ON COMPARISONS BETWEEN SELF ATTITUDES AND PERCEIVED ATTITUDES OF SIG-

NIFICANT OTHERS FOR TOTAI AWR SCORES

\begin{tabular}{|c|c|c|c|c|}
\hline Comparison & $\mathrm{N}$ & $\begin{array}{l}\text { Median or } \\
\text { Percentile } \\
\text { Score }\end{array}$ & $\underset{\text { Phi }}{\text { Coefficient }}$ & $\begin{array}{l}\text { Results of } \\
\text { Tests of } \\
\text { Significance }\end{array}$ \\
\hline $\begin{array}{l}\text { Self - } \\
\text { Perceived } \\
\text { Mother } \\
\text { Self - } \\
\text { Perceived } \\
\text { Father } \\
\text { Self - } \\
\text { Perceived } \\
\text { Husband/ } \\
\text { Consort } \\
\text { Self - } \\
\text { Perceived } \\
\text { Close } \\
\text { Friend } \\
\text { Perceived } \\
\text { Mother - } \\
\text { Perceived } \\
\text { Father } \\
\text { Perceived } \\
\text { Husband/ } \\
\text { Consort } \\
\text { Perceived } \\
\text { Close } \\
\text { Friend }\end{array}$ & 84 & $\begin{array}{l}21.7 \\
14.9 \\
21.7 \\
14.4 \\
21.7 \\
19.7^{\mathrm{a}} \\
21.7 \\
20.8^{\mathrm{b}} \\
14.9 \\
14.4^{2} \\
19.7^{\mathrm{a}} \\
20.8^{\mathrm{b}}\end{array}$ & $\begin{array}{r}.0625 \\
.4769 \\
.3065 \\
.4583\end{array}$ & $\begin{array}{l}3.748 * * * \\
2.84 * *\end{array}$ \\
\hline $\begin{array}{r}a_{52 \text { nd }} \\
b_{45 \text { th }} \\
* p=.0 \\
* * p< \\
* * * p< \\
* * * * p<\end{array}$ & & $\begin{array}{l}\text { Le score } \\
\text { Le score }\end{array}$ & & . \\
\hline
\end{tabular}


TABLE IX

SIGN TESTS FOR COMPARISONS BETWEEN SELF ATTITUDES AND PERCEIVED ATTITUDES OF MOTHER

AND FATHER FOR AWR SUBSCAIE SCORES

\begin{tabular}{l|l|l|c}
\hline Comparison & $\mathrm{N}$ & Subscale & $\begin{array}{c}\text { Test Statistic } \\
(\mathrm{p}<.0001)\end{array}$ \\
\hline Self - Perceived & & & \\
Mother & 95 & Satisfactions & 8.271 \\
& 90 & Relation to Mate & 6.826 \\
94 & Being a Parent & 8.507 \\
Self - Perceived & 94 & Being a Homemaker & 8.711 \\
Father & 90 & Woman as Worker & 8.087 \\
& 93 & Satisfactions & 9.116 \\
& 90 & Relation to Mate & 8.716 \\
& 93 & Being a Parent & 8.908 \\
& 94 & Being a Homemaker & 9.121 \\
& & Woman as Worker & 9.346 \\
& & & \\
\hline
\end{tabular}


TABIE X

SIGN TESTS FOR COMPARISONS BETWEEN SELF ATTITUDES

AND PERCEIVED ATTITUDES OF SIGNIFICANT

OTHERS FOR TOTAI AWR SCORES

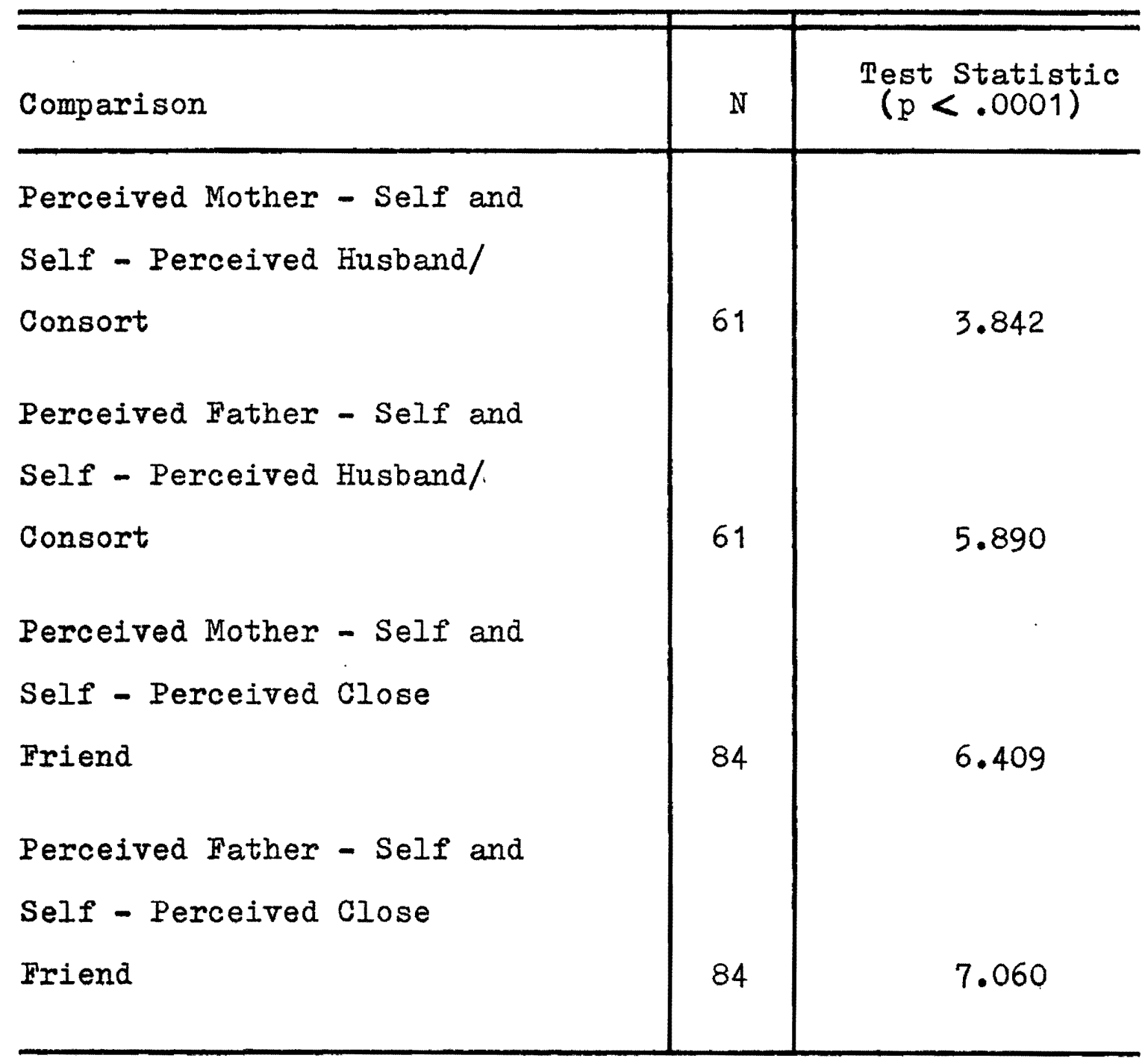


if either measured Self attitudes (Hypothesis 2) or the perceived attitudes of husband/consort and close friend (Hypothesis 3) would serve as a predictor of the career choices (TW, NTW) of the SS. Analyses done for AWR subscale and total AWR scores showed no significant differences between the two CC groups in Self attitudes or in the perceived attitudes of the specified others. Tables $X I, X I I$ and XIII summarize the statistical data for the overall finding. Of 44 tests performed on the data, only three yielded significant differences between the groups. Two of the three significant differences were in the opposite direction than expected and all three significant differences were found in the analyses of measured Self attitudes for AWR subscale scores (See Table XII).

The analyses of measured Self attitudes $(N=96)$ yielded one significant difference on the Homemaker subscale $\left(x^{2}=3.853, p=.05\right)$ which was in the opposite direction than expected. More $\underline{S} s$ who scored above the 41 st percentile were in the TW group ( $34 \underline{S}$ ) rather than in the NTW group (23 Ss) as predicted. The higher scores on the scale were conceptualized as reflecting an androgynous role preference. The other two significant differences were found in more refined analyses of measured Self attitudes. That is, measured Self attitudes were not only analyzed for the total sample $(N=96)$, but also for $S s$ who completed the AWR inventory for a close friend $(N=84)$ and husband/consort 
TABIE XI

MEDIAN TESTS FOR GROUP DIFFERENCES IN SELF ATPITUDES AND PERCEIVED ATTITUDES OF SIGNIFICANT OTHERS FOR TOTAL AWR SCORES

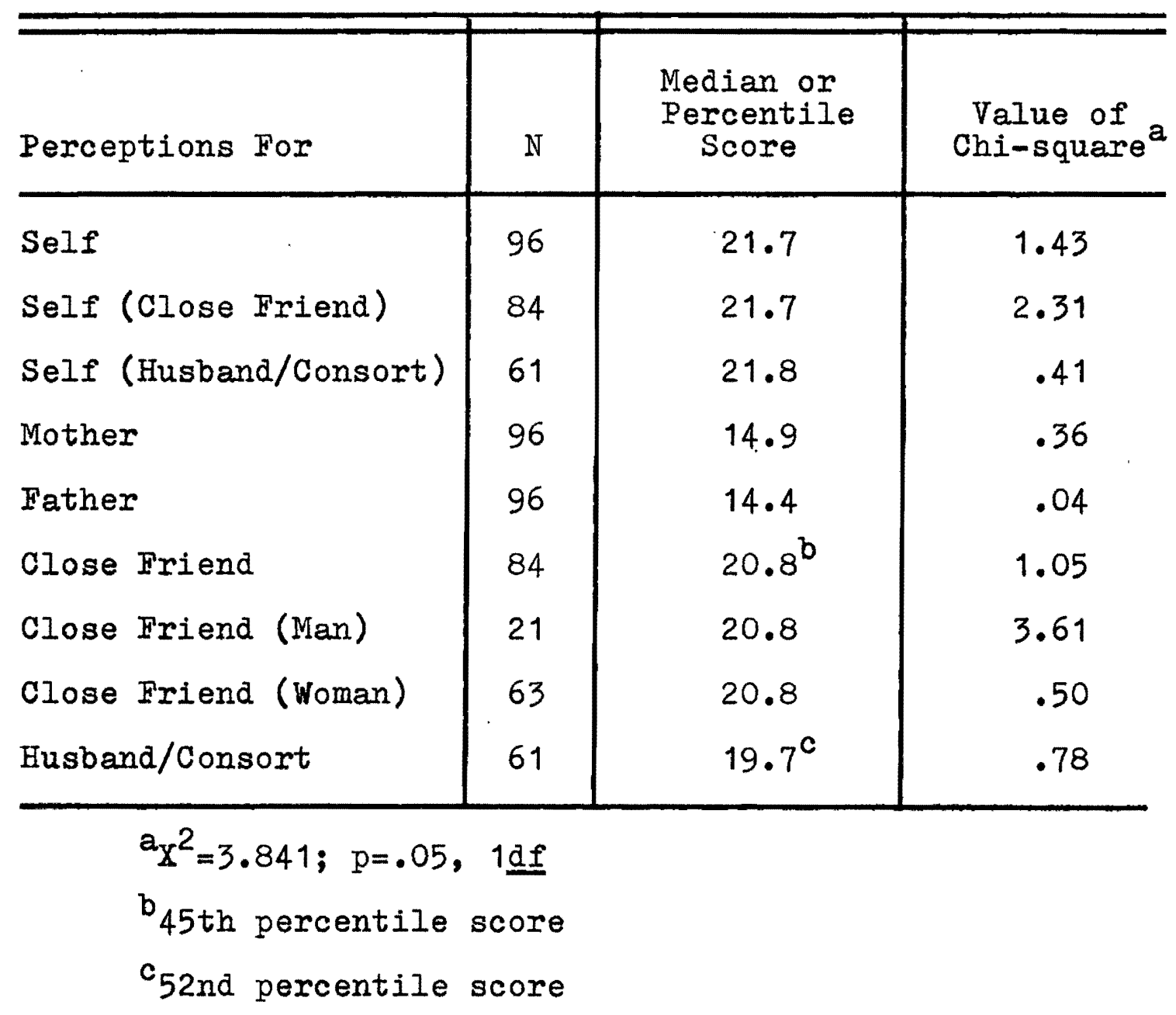


TABLE XII

MEDIAN TESTS FOR GROUP DIFFERENCES IN SELF ATTITUDES FOR AWR SUBSCAIE SCORES

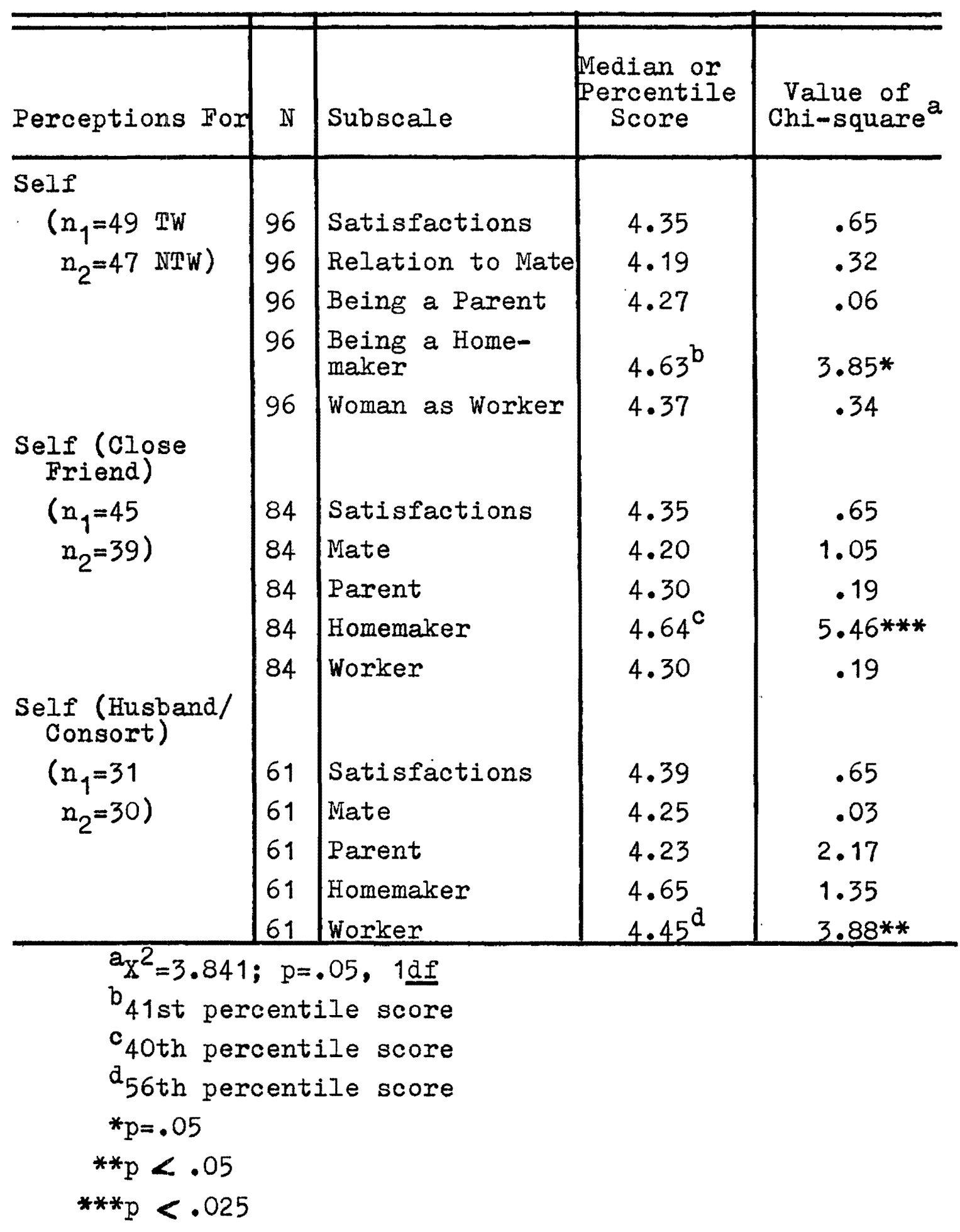


TABIE XIII

MEDIAN TESTS FOR GROUP DIFFERENCES IN PERCEIVED ATTITUDES OF SIGNIFICANT OTHERS FOR AWR SUBSCALE SCORES

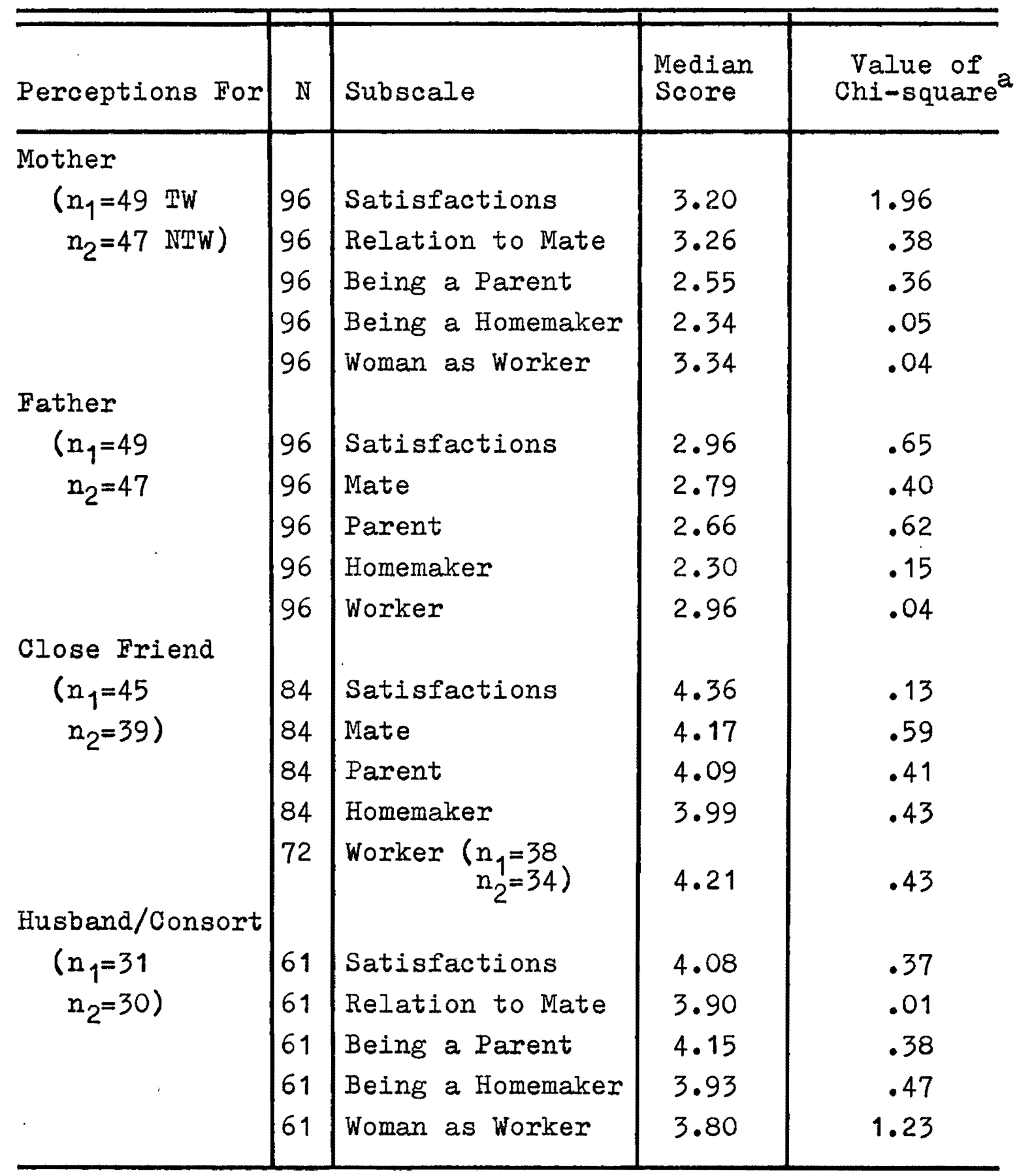

$a_{x}{ }^{2}=3.841 ; p=.05,1 \underline{d f}$ 
$(N=61)$. One significant difference was found on the Homemaker subscale in the analyses for Self-close friend $(N=84)$ and was in the opposite direction than expected $\left(X^{2}=5.465\right.$, p (.025), i.e., more Ss who scored above the 40th percentile were in the $T W$ group ( $32 \underline{S} s$ ) rather than the NTW group (18 Ss). The other significant difference was found on the Worker subscale in the analyses for Self-husband/ consort and was in the expected direction $\left(x^{2}=3.88, p<.05\right)$, i.e., more $\underline{S}$ sho scored above the 56 th percentile were in the NTW group. None of the three were considered to merit further consideration because one would expect 2.2 tests out of 44 to be significant by chance $(p=.05)$.

\section{Age and Marital Status}

Median tests were done for measured Self attitudes to see if either the age or marital status of $\underline{S}$ affected her total AWR scores.

Age. The median age of the total sample $(\mathrm{N}=96)$ was 27.0 years. The sample used for the analyses of age $(\mathbb{N}=85)$ consisted of 44 Ss who were less than 27 years old and 41 Ss who were more than 27 years old. Ss who were omitted from this analysis were those who either were 27 years old (median age) or whose total AWR scores were 21.7 (median score). No significant difference was found between the two age categories (less than 27 years old, more than 27 years old). When career choice (TW, NTW) was also controlled, no significant difference was found between $\mathrm{TW}$, 
NTW Ss in the older group (more than 27 years old). A significant difference was found in the younger group and was in the opposite direction than expected $\left(x^{2}=5.805, p<.025\right)$ with significantly more young $\underline{S}$ in $T W$ careers having total AWR scores reflecting an androgynous role preference than Ss pursuing NTW careers (See Table XIV).

Marital Status. The sample used for the analyses of marital status ( $N=94)$ consisted of 34 Ss who were currently living alone (i.e., without husband/consort) and $60 \mathrm{~S} s$ who were currently living with either a husband or consort. Two Ss whose total AWR scores were 21.7 (median score) were omitted from this analysis. No significant difference was found between the two groups (with, without mate). When career choice (TW, NTW) was also controlled, no significant difference was found between TW, NTW $\underline{S} s$ who were currently married or living in a marriage-like relationship. A significant difference was found in the group of $\underline{S}$ s without mate and was in the opposite direction than expected $\left(x^{2}=5.316, p<.025\right)$. That is, significantly more $\underline{s} s$ who were currently living without a mate and showed an androgynous role preference were pursuing TW careers rather than NTW careers (See Table XV). The similarity between these results and the results in the preceding paragraph (for age) may be partly because 65 percent of $\underline{S}$ s currently living without mates $(N=34)$ were also less than 27 years old. 
TABLE XIV

MEDIAN TESTS FOR GROUP DIFFERENCES DUE TO AGE FOR TOTAI AWR SCORES FOR SEIF

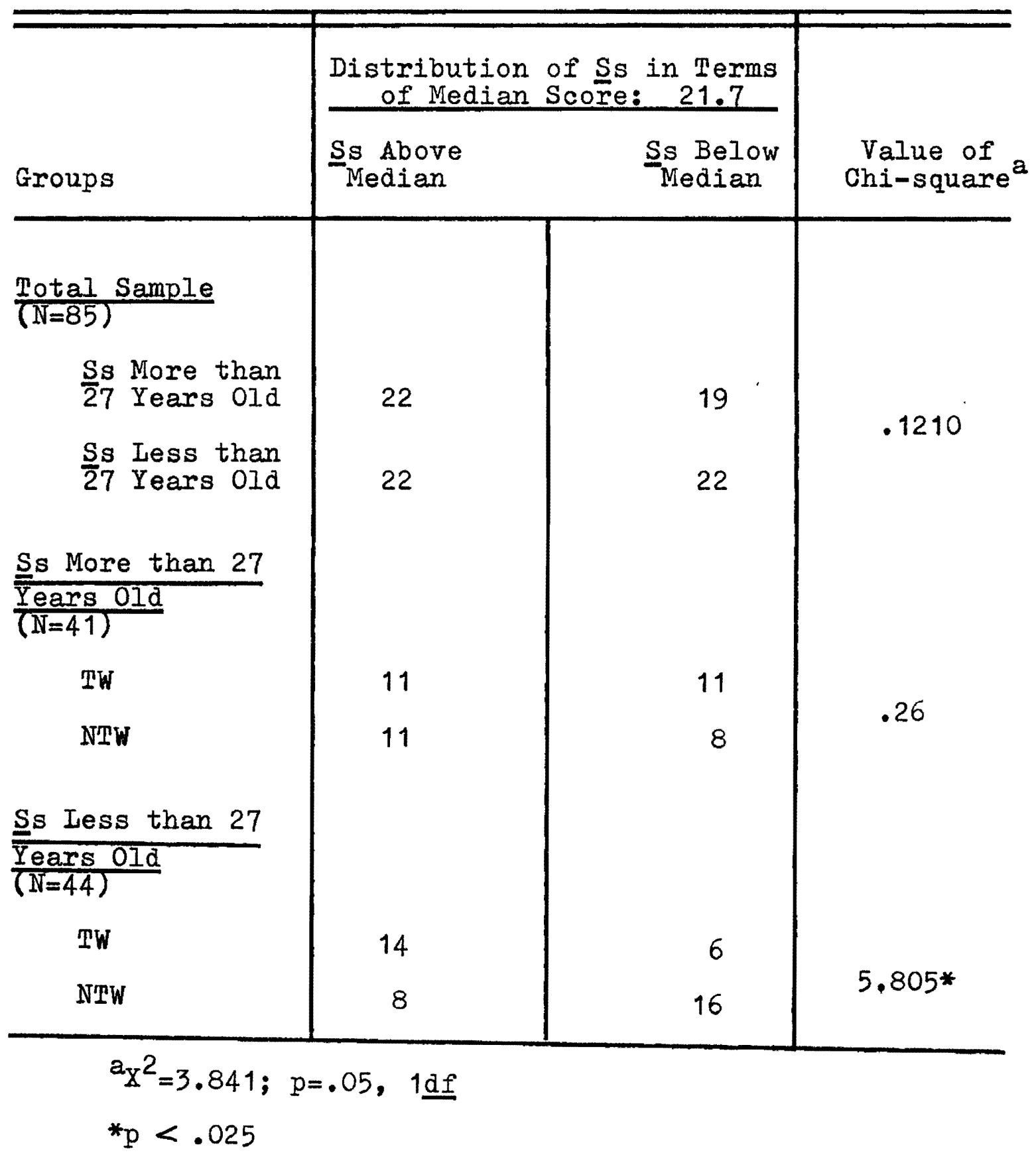


TABLE XV

MEDIAN TESTS FOR GROUP DIFFERENCES DUE TO MARITAI STATUS FOR TOTAI AWR SCORES FOR SELF

\begin{tabular}{|c|c|c|c|}
\hline \multirow[b]{2}{*}{ Groups } & \multicolumn{2}{|c|}{$\begin{array}{l}\text { Distribution of Ss in Terms } \\
\text { of Median Score: } 21.7 \\
\end{array}$} & \multirow[b]{2}{*}{$\begin{array}{l}\text { Value of } \\
\text { Chi-square }\end{array}$} \\
\hline & Ss Above & $\begin{array}{l}\text { Ss Below } \\
\text { Median }\end{array}$ & \\
\hline \multicolumn{4}{|l|}{$\frac{\text { Total Sample }}{(\bar{N}=94)}$} \\
\hline$\underline{S}$ Iiving Alone & 18 & 16 & 2024 \\
\hline $\begin{array}{l}\text { S Living with } \\
\text { Mate }\end{array}$ & 29 & 31 & \\
\hline$\frac{S}{(N=34)}$ & & & \\
\hline TW & 13 & 5 & $5316 *$ \\
\hline NTW & 5 & 11 & \\
\hline$\frac{\text { S Living with }}{\text { Mate }(N=60)}$ & & & \\
\hline $\mathrm{TW}$ & 13 & 17 & 63 \\
\hline NTW & 16 & 14 & \\
\hline
\end{tabular}




\section{SUPPIEMENTARY QUESTIONS}

One additional question asked whether the perceived attitudes of mother and father toward woman's roles would differentiate $\underline{S} s$ pursuing TW careers from those $\underline{S}$ s pursuing NTW careers. The question was not stated as a formal hypothesis because it was not possible to specify the direction of the possible difference between the groups. The data collected did not, in fact, indicate any difference between TW and NTW SS in perceptions of the views of mother or father, with an almost identical number of TW and NTW Ss having total AWR scores falling above and below the respective median scores for the perceived attitudes of those significant others.

Two additional questions were formulated to examine the possible effects of intervening variables on the relations among the major variables (attitudes toward woman's roles, perceptions of the attitudes of significant others, and career choices). Would the variables show how the $\underline{S}$ mediated some antecedent (mother, father) and proximate (husband/consort and close friend) influences? The intervening variables used were: 1) maternal role model, 2) expressed identification with parents, and 3) current importance of the relations with each specified significant other. Maternal role model and expressed identification with parents were conceptualized in my study as two com- 
ponents or aspects of parental role modeling. Maternal role model was defined by mother's behavior and $\underline{\text { S }}$ ' perceptions of the consequences of her behavior, to gain an idea of how Ss perceived the role experiences of their mothers. Previous research had suggested this approach was most useful for the interests of my study. The data collected on this variable included questions about what mother did and Ss' perceptions of how she felt about what she did, and asked about other aspects of the role model besides working/not working outside the home. Expressed identification with parents was defined by $\underline{\text { S }} s^{\prime}$ perceptions of their affinity with or disassociation from their primary sex-role models (i.e., parents in intact homes). The data collected on this variable focused on instrumental and expressive aspects of the role models. Current importance of the relations with significant others was conceptualized in my study as reflecting the Ss' role as mediators of earlier (parents) and later (peer) influences and was used as an indicator of external support for Ss' $^{\prime}$ career choices. The variable was defined by Ss' perceptions of 1) how good/ poor the current relations were, 2) how satisfied/dissatisfied they felt about the current relations, 3) whose opinions were most important to the Ss, and 4) how the interpersonal quality of the current relations was characterized.

Overall, the intervening variables did not show group 
differences or suggest new hypotheses, but the patterns appeared to be potentially useful for future research and therefore will be reported in the following sections.

Maternal Role Model

Several indices for the maternal role model were included in the questionnaire in an effort to broaden the definition of the type of model (traditional, non-traditional) to include aspects other than mother's work behavior and perceptions of her feelings about work. Items for behavior (what mother did) and affect (mother's perceived feelings) were included.

Behavioral Indices. No group differences were found on mother's behavioral indices of: 1) educational level, 2) occupational status (either while the $\underline{S}$ s were growing up or currently), or 3) the number of years mother worked while children were at home (See Table IV). Since responses of the $\underline{S} s$ to 4) a question about mother's principal activities while $\underline{S}$ sere growing up (See Appendix B, Question 17) were difficult to interpret, no data are available for analyses.

Affective Indices. No group differences were found on Ss' perceptions of: 1) mother's overall satisfaction, 2) whether mother's overall satisfaction was related to working outside the home (See Tables XVI, XVII, and XVIII). Even when the indices of mother's educational level and 
principal occupation while the $\underline{S}$ s were growing up were com-

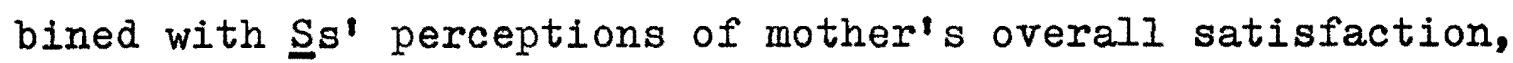
no group differences were apparent. Since responses of the Ss to 4) a question about the activities and personal relations which seemed most important to mother (See Appendix B, Question 30) were difficult to interpret, no data are available for analyses. The instructions given for answering the question were apparently misunderstood by most $\underline{S}$.

of particular interest for the purposes of my study were the mothers who had college or postgraduate degrees. Only one of twelve mothers with college or postgraduate degrees who were full-time housewives were perceived as dissatisfied because she did not work outside the home. All eleven mothers with college or postgraduate degrees who worked outside the home were perceived as having their working contribute to their overall satisfaction (See Table XIX).

TABLE XVI

MOTHER'S PERCEIVED OVERAII SATISFACTION WITH HER IIFE $(\mathrm{N}=96)$

\begin{tabular}{|c|c|c|c|c|}
\hline \multirow[b]{2}{*}{ CC Group } & \multicolumn{4}{|c|}{ Distribution of Ratings } \\
\hline & $\begin{array}{l}\text { Not At AII } \\
\text { Satisfied }\end{array}$ & $\begin{array}{l}\text { Slightly } \\
\text { Satisfied }\end{array}$ & $\begin{array}{l}\text { Moderately } \\
\text { Satisfied }\end{array}$ & $\begin{array}{c}\text { Very } \\
\text { Satisfied }\end{array}$ \\
\hline$T w\left(n_{1}=49\right)$ & 7 & 8 & 17 & 17 \\
\hline NTW $\left(n_{2}=47\right)$ & 5 & 4 & 16 & 22 \\
\hline
\end{tabular}


TABIE XVII

MOTHER'S PERCEIVED OVERAII SATISFACTION WHEN HER FEELINGS ABOUT WORK AND HER WORK BEHAVIOR

WERE PERCEIVED CONGRUENT $(\mathrm{N}=64)$

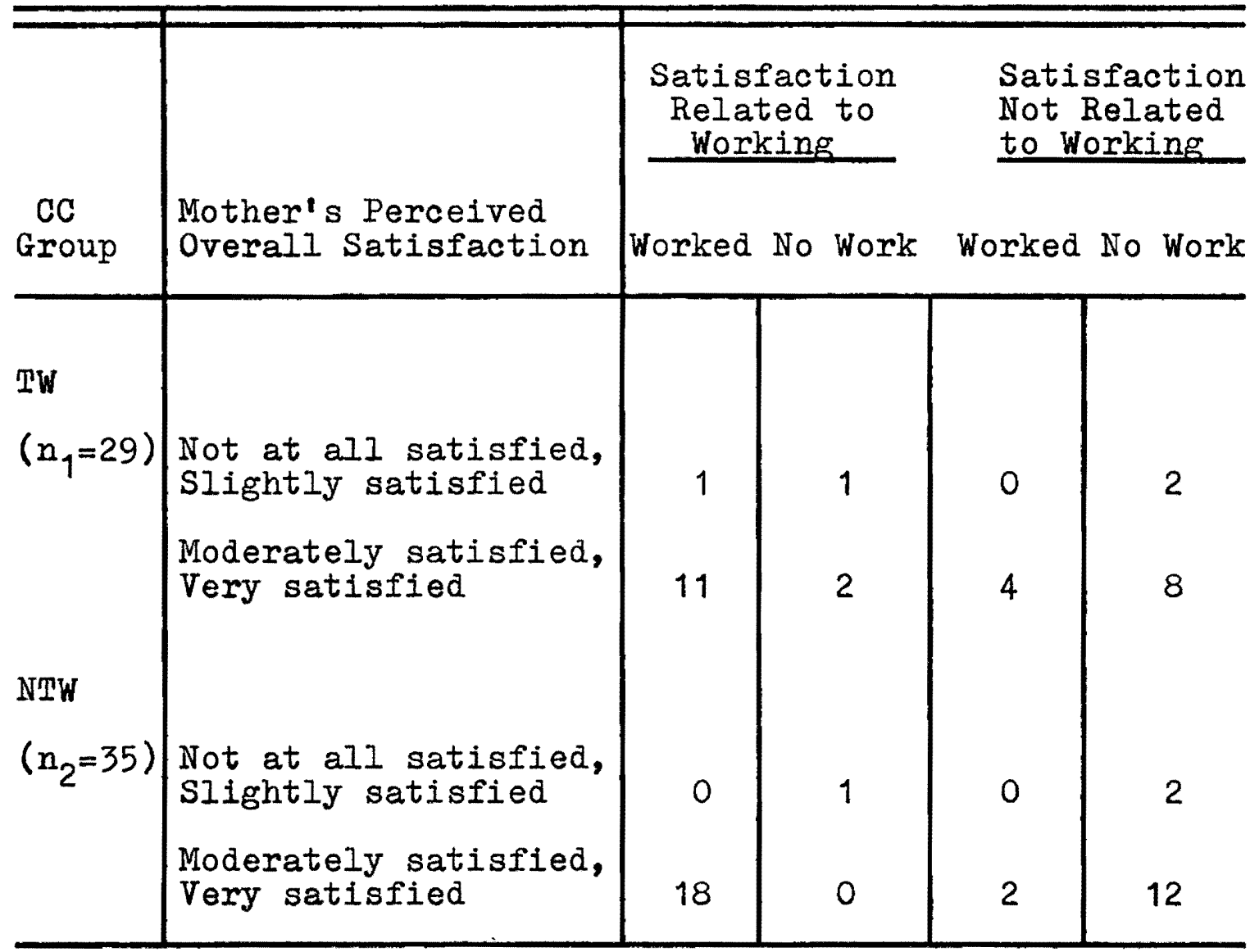

Note: Congruence between mother's perceived feelings about working and her work behavior was defined by S's responding that 1) mother wanted to work and did or 2T mother did not want to work and did not. (Perceptions of mother's feelings about working were not limited to working while there were children at home, i.e., mother might be perceived as wanting to work and did, but this might have occurred after $S$ had grown up, or completed high school.) 
TABIE XVIII

MOTHER'S PERCEIVED OVERAII SATISFACTION WHEN HER FEEIINGS ABOUT WORK AND HER WORK BEHAVIOR WERE PERCEIVED INCONGRUENT $(\mathrm{N}=26)$

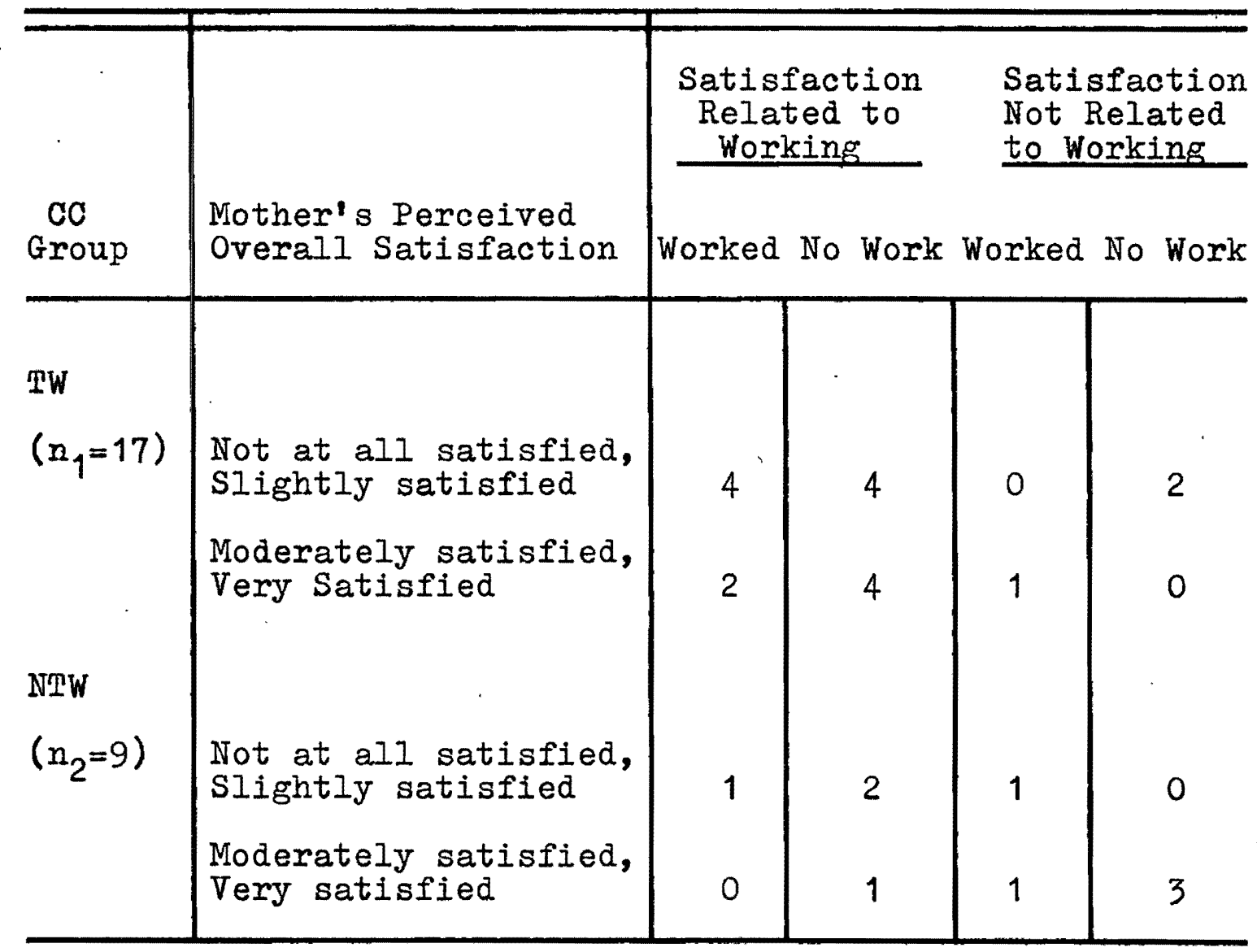

Note: Incongruence between mother's perceived feelings about working and her work behavior was defined by $\underline{S}^{\prime}$ s responding that 1) mother did not want to work and di $\bar{d}$ or 2) mother wanted to work and did not. (Perceptions of mother's feelings about working were not limited to working while there were children at home.) 
TABIE XIX

MOTHER'S EDUCATIONAI LEVEL AND OCCUPATIONAL

STATUS WHIIE SS WERE GROWING UP ( $N=92)$

Iess Than College Graduate College Graduate,

Postgraduate

CC Group Worked Did not Work Worked Did not Work

\begin{tabular}{l|r|r|r|r}
\hline TW $\left(n_{1}=48\right)$ & 14 & 24 & 5 & 5 \\
NTW $\left(n_{2}=44\right)$ & 9 & 22 & 6 & $7^{a}$ \\
\hline
\end{tabular}

${ }^{a}$ One perceived to have degree of dissatisfaction related to not working.

Overall, the mothers of the Ss were perceived to be more satisfied than dissatisfied with their lives whether or not they worked.

In summary, it did not appear that the maternal role model helped explicate the relations among the major variables. Consequently, further analysis was not considered. My findings are similar to some of the findings of an earlier study by Ziebarth (1970). She suggested that the maternal role model was not adequately defined or assessed by using one or two criteria, e.g., mother's work status and her perceived feelings about working/not working. A question which appears to remain for future research is how the maternal role model can be adequately defined and assessed. 
Current Importance of the Rela-

tions with Significant others

Overall, no group differences were apparent on a number of indices used to assess this variable, including items for ranking, rating and selecting statements which came closest to describing the interpersonal quality of the current relations.

Ranking Others. The Ss were asked to rank persons (from an extended list of possible significant others) according to the importance of the person's opinions to the $\underline{S}$. The results of the ranking support the widely held opinion that peers are more important than parents for white, college women. The significant others chosen for this study were ranked more often than any others in the extended list. As would be expected, husband/consort was the person most frequently selected (57/60) of the four significant others and was the person most often ranked first. Close friend received the next most frequent number of rankings (46/84) with the ranks equally distributed between 1 - 3. Mother was the next most frequently ranked person (48/94), most often ranked 2 and 3 . Father was ranked least frequently (36/94) with the ranks equally distributed between $1-3$ (See Table XX).

Interpersonal Quality of the Current Relations. The Ss were asked to select from a list of nine statements those which came closest to describing the current relations with 
TABLE XX

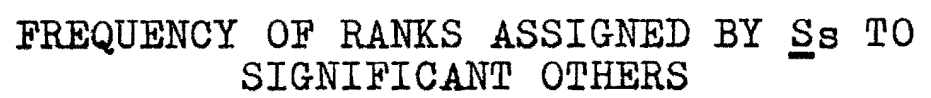

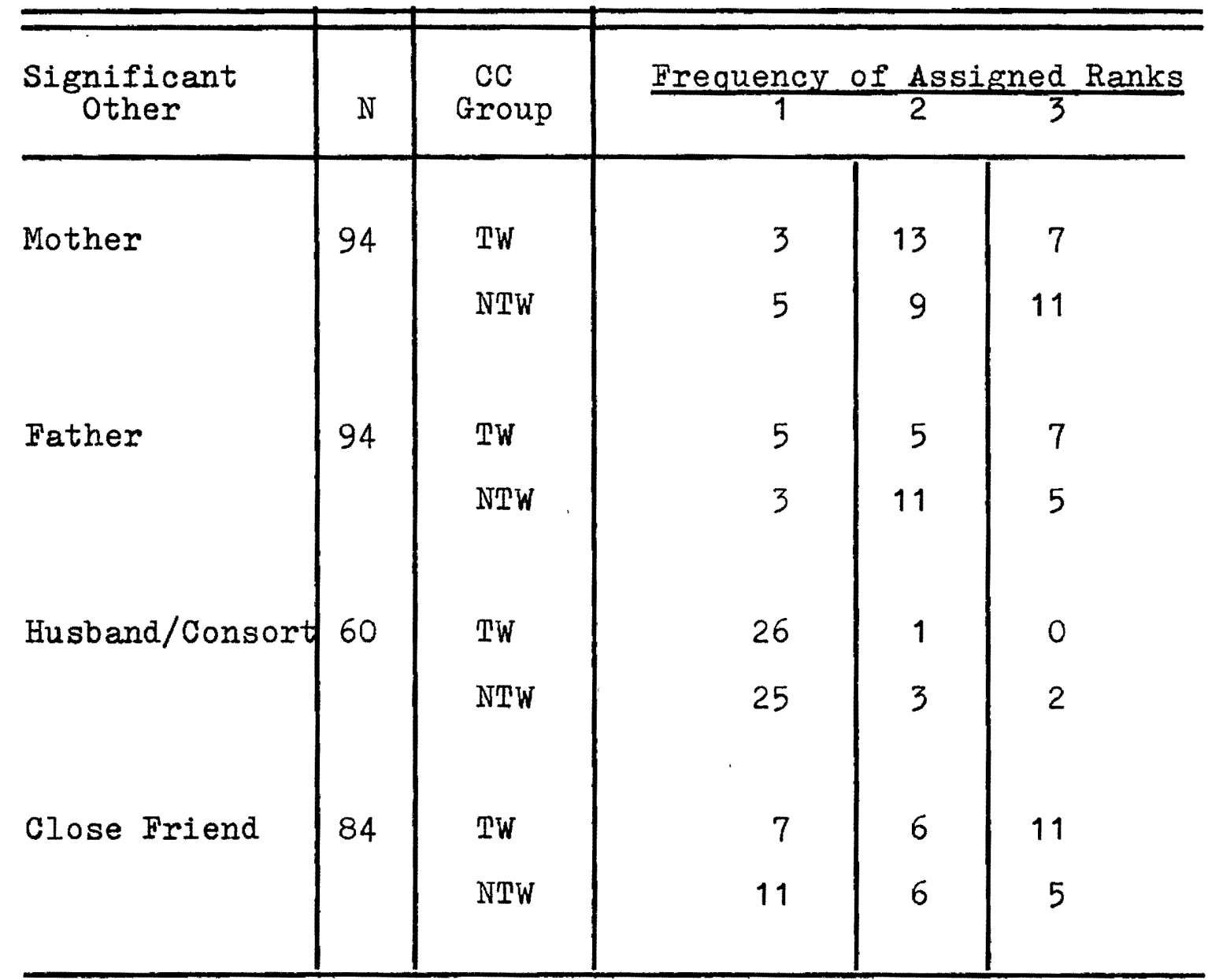

each significant other. The statements described different aspects of mutuality or openness to feelings between two persons. The pattern of responses obtained for this index was similar to the pattern obtained for the ranking index. The current relations with mother and father were generally characterized as being more closed and restricted than the relations with husband/consort and close friend. Relations 
with father appeared to be the most restricted (See Table XXI). Across the two CC groups, the direction of the difference between relations with peers and parents is congruent with the results of Hypothesis 1. Those results indicated that there was less relation between the measured Self attitudes and the perceived attitudes of mother or father than between four other comparisons of measured Self attitudes and the perceived views of mother, father, husband/consort and close friend (See pp. 58, 60).

Ratings of Current Relations. There were two items to rate. First, the $\underline{S}$ s were asked to rate the current relation with each specified significant other on a 4-point scale (bad - very good). The greatest proportion of ratings (at least $75 \%$ of the responses) were "good" or "very good" for each significant other (See Table XXII). Very good was the most frequent response. The same pattern of responses appeared in the second rating item. The $\underline{S} s$ were asked to rate their feelings of satisfaction with the current relations with each significant other on a 4-point scale (not at all satisfied - very satisfied). At least 75 percent of the responses for each significant other were "satisfied" or "very satisfied" (See Table XXIII). Very satisfied was the most frequent response. The results of the second rating item are not surprising since, overall, the Ss rated the current relations with each specified significant other as good or very good. 
TABIE XXI

SOCRES FOR DESCRIPTIVE QUALITY OF SS' CURRENT RELATIONS WITH SIGNIFICANT OTTHERS

\begin{tabular}{|c|c|c|c|c|}
\hline \multirow{2}{*}{$\begin{array}{c}\text { Significant } \\
\text { Other }\end{array}$} & \multirow[b]{2}{*}{$\mathrm{N}$} & \multirow[b]{2}{*}{$\begin{array}{l}\text { CC } \\
\text { Group }\end{array}$} & \multicolumn{2}{|c|}{ Sum of Scores } \\
\hline & & & $0-2^{a}$ & $3-5^{b}$ \\
\hline \multirow[t]{2}{*}{ Mother } & 95 & $\mathbf{T W}$ & 26 & 23 \\
\hline & & NTW & 23 & 23 \\
\hline \multirow[t]{2}{*}{ Father } & 95 & TW & 31 & 18 \\
\hline & & NTW & 32 & 14 \\
\hline \multirow[t]{2}{*}{ Husband/Consort } & 61 & $\mathrm{TW}$ & 4 & 27 \\
\hline & & NTW & 6 & 24 \\
\hline \multirow[t]{2}{*}{ Close Friend } & 84 & TW & 6 & 39 \\
\hline & & NTW & 5 & 34 \\
\hline
\end{tabular}

$a_{A}$ score of "O" was obtained if the $S$ did not include any statements reflecting some aspect of mutuality or openness to feelings in her current relation with the significant other. Scores of "1" and "2" were obtained if 1 or 2 such statements were included.

"Scores of "3" - "5" were obtained if the $\underline{S}$ included 3-5 statements reflecting aspects of mutuality and openness to feelings in her current relation with the significant other. 
TABIE XXII

Ss' RATING OF CURRENT RELATIONS WITH SIGNIFICANT OTHERS

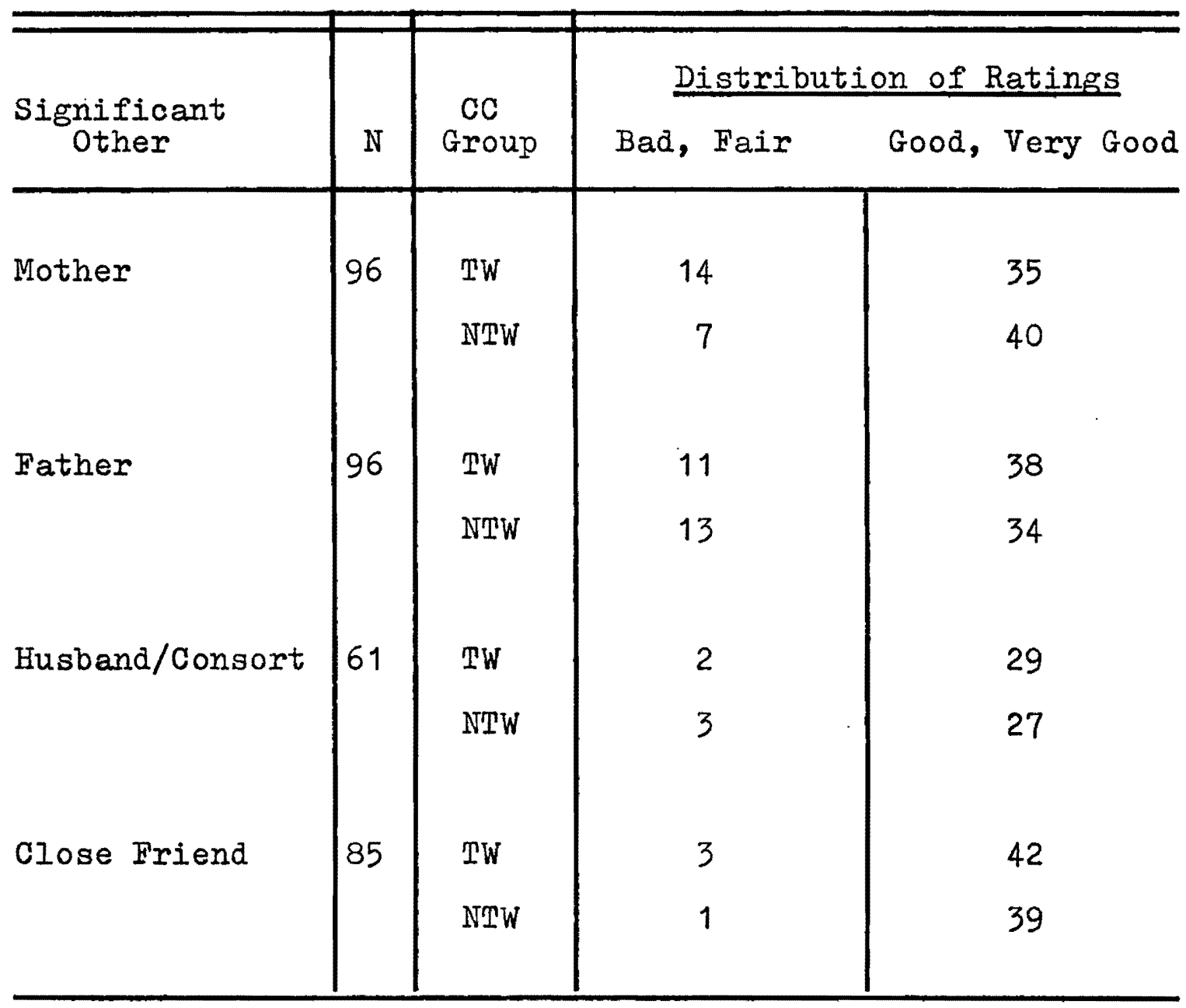


TABIE XXIII

SS' RATING OF SATISFACTION WITH CURRENT RELATIONS WITH SIGNIFICANT OTHERS

\begin{tabular}{|c|c|c|c|c|}
\hline $\begin{array}{c}\text { Significant } \\
\text { Other }\end{array}$ & $\mathrm{N}$ & $\begin{array}{c}\text { CC } \\
\text { Group }\end{array}$ & $\begin{array}{l}\text { Distribut } \\
\text { Not at all } \\
\text { Satisfied, } \\
\text { Minimally } \\
\text { Satisfied }\end{array}$ & $\begin{array}{l}\text { of Ratings } \\
\\
\text { Satisfied, } \\
\text { Very } \\
\text { Satisfied }\end{array}$ \\
\hline Mother & 96 & $\begin{array}{l}\text { PW } \\
\text { NTW }\end{array}$ & $\begin{array}{r}14 \\
5\end{array}$ & $\begin{array}{l}35 \\
42\end{array}$ \\
\hline Father & 95 & $\begin{array}{l}\text { TW } \\
\text { NTW }\end{array}$ & $\begin{array}{l}12 \\
11\end{array}$ & $\begin{array}{l}36 \\
36\end{array}$ \\
\hline Husband/Consort & 61 & $\begin{array}{l}\text { PW } \\
\text { NTW }\end{array}$ & $\begin{array}{l}2 \\
3\end{array}$ & $\begin{array}{l}29 \\
27\end{array}$ \\
\hline Close Friend & 85 & $\begin{array}{l}\text { TW } \\
\text { NTW }\end{array}$ & $\begin{array}{l}2 \\
0\end{array}$ & $\begin{array}{l}43 \\
40\end{array}$ \\
\hline
\end{tabular}


Additional Index of Current Importance of Relationship for Ss Currently Iiving with Husband/Consort. An additional item was included for the $\underline{S} s$ who were married or living in a marriage-like relationship to bring out some possible areas of discord in the current $\underline{S}$ - mate relationship. The Ss were asked whether or not they were satisfied with how they and their mates dealt with: 1) the $\underline{S}^{\prime} s$ school commitment, 2) S's work plans, 3) house chores, 4) time spent with children (if any) and 5) their interpersonal relation with each other. Almost all of the $\underline{S}$ s to whom this item applied $(N=61)$ indicated that they were satisfied with all of the above aspects in their current relations with their mates. House chores was the most frequently reported source of dissatisfaction, but only a few $\underline{S}$ expressed dissatisfaction even with this aspect.

In summary, the initial analyses of the attitudinal measures indicated that, overall, there was little congruence between the measured Self attitudes toward woman's roles and the perceived views of mother or father. The lack of perceived congruence between the attitudes of the $\underline{S} s$ and their parents might be expected to introduce strain in the current $\underline{S}$ - parent relationship or, perhaps inhibit the maintenance of good interpersonal relations between the $\underline{S}$ and her parents. The patterns of responses obtained in assessing the current importance of the relations with each significant other suggest that the relations between the 
$\underline{S} s$ and peers may be different from the relations between $\underline{S} s$ and parents with respect to different expectations. For example, overall, $\underline{S}$ sere more satisfied than dissatisfied with their current relations (rated "good" or "very good") with the significant others. This was true for $\underline{S}$ - parent relations, where there were definite value differences and a tendency to characterize the interpersonal quality of the relations with parents as closed or very restricted, and for $\underline{S}$ - peer relations, where there was perceived congruence for certain values (i.e., attitudes toward woman's roles) and a strong tendency to describe the interpersonal quality of the current relations as mutual sharing of experiences and feelings.

Expressed Identification with Parents

No group differences were apparent in the $\underline{S} s^{\prime}$ responses on six indices used to explore instrumental and affective components in the current $\underline{S}$ - parents relations to gain additional insight into possible effects of parental role modeling (See Table XXIV). The items which referred to the instrumental components were: 1) Which parent are you most like, in terms of personality, temperament, outlook on life? 2) Which parent comes closest to your idea of an attractive person? 3) Which parent's values, in general, do you agree with? 4) Which parent's career goals for you do you agree with? The items which referred to the affective bond were: 
TABLE XXIV

SS' EXPRESSED IDENTIFICATION WITH PARENTS

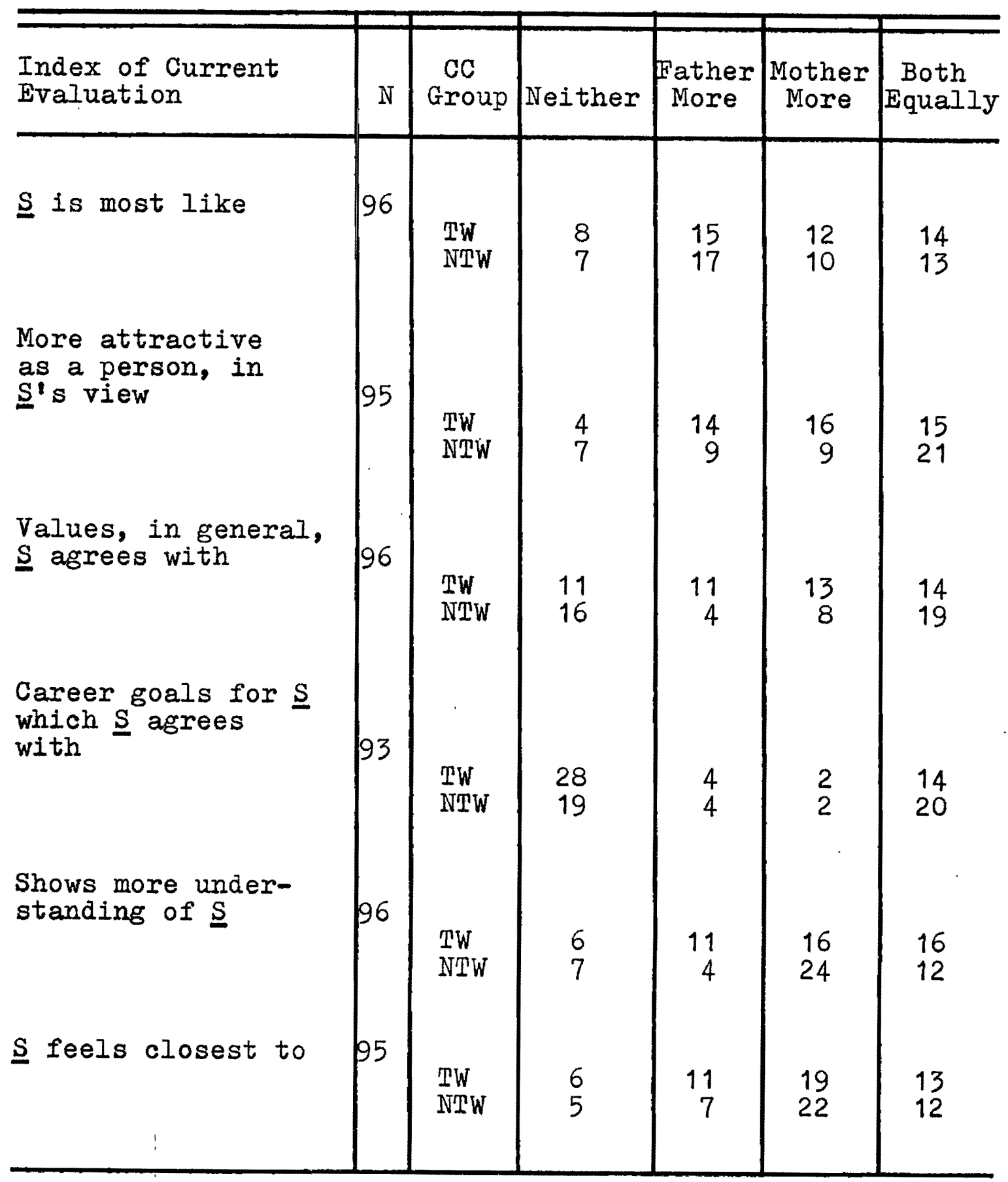


5) Which parent do you feel closest to? and 6) Which parent shows more understanding of you?

Instrumental Components. The Ss responded most frequently $(36 \%)$ that they were "most like" father. The next most frequent response (28\%) was "both equally" (mother and father). The $\underline{S} s$ responded most frequently (38\%) that both mother and father were "attractive" people. The next most frequent response to this question was "mother more" (26\%) and then "father more" (24\%). To the question about "values, in general," the most frequent response (34\%) was "both equally." The next most frequent response (28\%) was "neither" (mother or father). To the question about "goals" for the S, 51 percent of the sample responded "neither." The next most frequent response (37\%) was "both equally."

Affective Bond. The most frequent response to both questions was "mother more." To the question about "understanding," 42 percent of the Ss replied "mother more" and to the question about "feel closest to," 43 percent replied "mother more." The next most frequent response for both questions was "both equally" (29\% for "understanding" and $26 \%$ for "closest to").

Interpretation of Findings. It is difficult to interpret the overall pattern of findings. The affective bond does appear to be stronger with mother than with father. This finding parallels the findings of the current importance of mother compared to father as indicated in: 1) 
ranking others whose opinions are most valued and 2) describing the interpersonal quality of the current relations (See pp. 79, 80). Neither parent emerges clearly as the one the Ss identify with as "most like." Both parents appear to have equal amounts of desirable attributes (according to what is "attractive" to the $\underline{S}$ ). When the questions about "values" and "career goals" were asked, the strongest response tendencies were "neither" (i.e., 28\% for "values," $51 \%$ for "career goals") or "both equally" (i.e., $34 \%$ for "values," 37\% for "career goals"). It seems reasonable that "values-in-general" and "career goals" are likely places for generations to differ because of changing cultural norms.

One finding which appeared to be interesting enough to pursue further was that $\underline{S}$ in the TW group appeared to disagree more with parents on career goals than the $\underline{S}$ in the NTW group (See Table XXIV). In an effort to understand why this might occur, three indices related to parental role modeling were looked at: 1) father's perceived overall satisfaction with his life, 2) mother's perceived overall satisfaction with her life, and 3) Ss' perceptions of their parents' relationships. Comparing the SS' perceptions of mother's and father's overall satisfaction, NTW Ss perceived mother and father equally as either satisfied (81\%) or dissatisfied (19\%). Mothers of TW S s were perceived to be minimally satisfied (not at all, slightly satisfied) almost 
twice as often as father ( $31 \%$ vs, $16 \%)$ and there was a tendency to perceive father as more satisfied (moderately, very satisfied) than mother ( $84 \%$ vs. $69 \%$ ) (See Table XXV). Comparing the $\underline{S} s^{\prime}$ perceptions of their parents' relationships, NTW Ss tended to reflect what might be interpreted as a more normative or harmonious parental relationship. Eightyfive percent of the NTW $S s$ perceived "father dominant" or mutual respect of the two parents for each other. Only 60 percent of the TW $\underline{S} s$ perceived these two conditions in their parents' relationships. More than twice as many TW $\underline{S}$ s than NTW S s perceived "mother dominant" (21\% vs. 9\%). Nearly three times as many TW $\underline{S}$ s than NTW $\underline{S} s$ perceived "neither dominant-both in struggle for dominance" (19\% vs. $6.5 \%$ ).

TABIE XXV

SS' PERCEPTIONS OF OVERALI SATISFACTION OF MOTHER AND FATHER $(\mathrm{N}=96)$

Distribution of Ratings

Not at $\mathrm{All}$

Satisfied Satisfied
Moderately Satisfied
Very Satisfied

CC Group Mother Father Mother Father Mother Father Mother Father

\begin{tabular}{ll|l|l|l|l|l|l|l}
\hline TW & & & & & & & & \\
$\left(\mathrm{n}_{1}=49\right)$ & 7 & 3 & 8 & 5 & 17 & 25 & 17 & 16 \\
$\begin{array}{ll}\mathrm{NTW} \\
\left(\mathrm{n}_{2}=47\right)\end{array}$ & 5 & 4 & 4 & 16 & 15 & 22 & 23 \\
\hline
\end{tabular}


The latter two conditions might be interpreted as contranormative ("mother dominant") and equal but antagonistic, which might imply more potential for conflict in those parent relationships than for the more normative or harmonious conditions. There was a stronger tendency for the TW Ss to perceive the less harmonious conditions in their parents' relationships than NTW Ss (40\% vs. 15\%) (See Table XXVI).

In an attempt to understand the pattern other indices examined were: 1) Ss' $^{\prime}$ ratings of their current relations with mother, 2) Ss' feelings of satisfaction with that relationship, and 3) Ss' perceptions of mother's overall satisfaction, whether or not her perceived satisfaction had

\section{PABIE XXVI}

SS' PERCEPTIONS OF RELATIONSHIP BETWEEN PARENTS $(\mathrm{N}=94)$

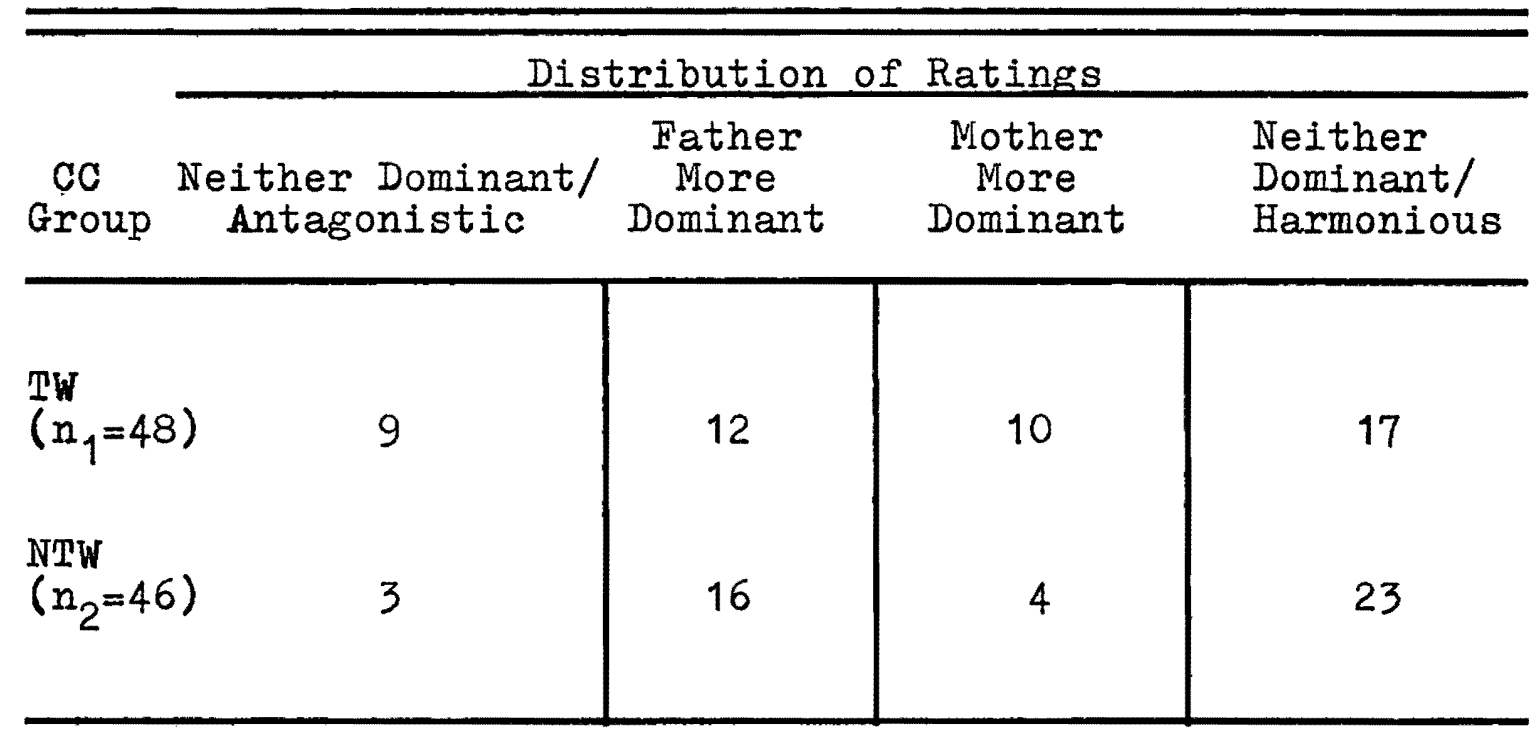


to do with working/not working outside the home, and mother's feelings about working outside the home. Nearly twice as many $\mathrm{TW} \underline{\mathrm{S}} \mathrm{s}$ than NTW $\underline{S} s$ rated the current relations with mother as bad or fair (29\% vs. 15\%) (See Table XXII). Almost three times as many TW Ss than NTW Ss reported more dissatisfaction (not at all satisfied, slightly satisfied) with the current relation with mother (29\% vs. 11\%) (See Table XXIII). The third index reviewed related to mother's perceived overall satisfaction and her feelings about working/not working outside the home (See Tables XVII, XVIII). There were two reasons for looking at these items together. First, it was done to gain some idea of the degree of congruence/incongruence between mother's perceived feelings about working/not working and what she did (worked/did not work). Second, it was done to see how the condition of mother working/not working related to her perceived overall satisfaction. For the sample as a whole $(N=90)$, more than two-thirds of the $\underline{S}$ (64/90) perceived congruence between mother's feelings about working and her behavior. In this group, 36 mothers worked and 28 mothers did not work. Thirty-four mothers (30 of whom worked) were perceived as having their overall satisfaction related to their working, and 30 mothers (24 of whom did not work) were perceived as not having their overall satisfaction related to working outside the home. No group differences were apparent (See Table XVII). In the group of $\underline{S} s$ who 
perceived incongruence between mother's feelings about working and her behavior (26/90), more TW Ss than NTW Ss perceived mother's overall satisfaction to be affected by the incongruence. Looking at the subgroup $(N=18)$, defined by perceived incongruence between mother's work feelings and behavior and where mother's overall satisfaction was perceived to be related to that incongruence, 11 mothers were perceived to be not at all or slightly satisfied. Of these 11, eight were mothers of TW $\underline{S}$ (See Table XVIII).

In summary, the perceived incongruence between mother's work feelings and behavior, when also perceived to adversely affect mother's overall satisfaction, may be useful in future research for exploring effects of maternal role modeling on adult career choices of college women. 1 I am also suggesting that in the face of certain tensions within the family, which may be accompanied by a breakdown in communications between the parents and the $\underline{S}$, the parental models may be a source of confusion. One possible consequence of this confusion may be reinforcement for setting "safe" career goals by some middle and uppermiddle class women who have career aspirations. "Safe" careers for women were and still are teaching, nursing and social work (used in this study to indicate TW career

${ }^{1}$ Since the condition interpreted here as an adverse condition applied only to a small proportion of the total sample $(11 / 90)$ in my study, formal analysis was not done. 
choices). They are "safe" in relation to the norms of the culture, past and present.

\section{CAREER ORIENTATION}

Two indices were originally thought to be useful in conjunction with the criteria of TW, NTW degree programs for defining the two career choice (CC) groups but were not used. These were: 1) the S's plans for work after getting her degree (i.e., what the activity would be and the likely place of employment) and 2) the effect of having children on $\underline{S} s^{\prime}$ intentions to work.

The index of $\underline{S} s^{\prime}$ work plans was only of value for indicating that nearly all of the $S s(N=96)$ intended to work immediately after getting their degrees. The index of S $s^{\prime}$ intentions to work in relation to having children did not show any difference between the two CC groups, as defined by TW, NTW degree programs. Since it was not considered useful for subdividing the two CC groups it was not used in any analysis. Overall, 67.5 percent of the sample who had or intended to have children ( 13 did not) responded that they intended to work more or less continuously, regardless of the ages of the children at home. One-fourth of the sample (for whom the topic of children was relevant) responded that they intended to work more or less continuously but not until the children were preschool or grade school age (See Table XXVII). Overall, 
TABIE XXVII

SS' INTENTIONS TO WORK BY EXPECTATIONS OF HAVING CHILDREN ( $N=93$ )

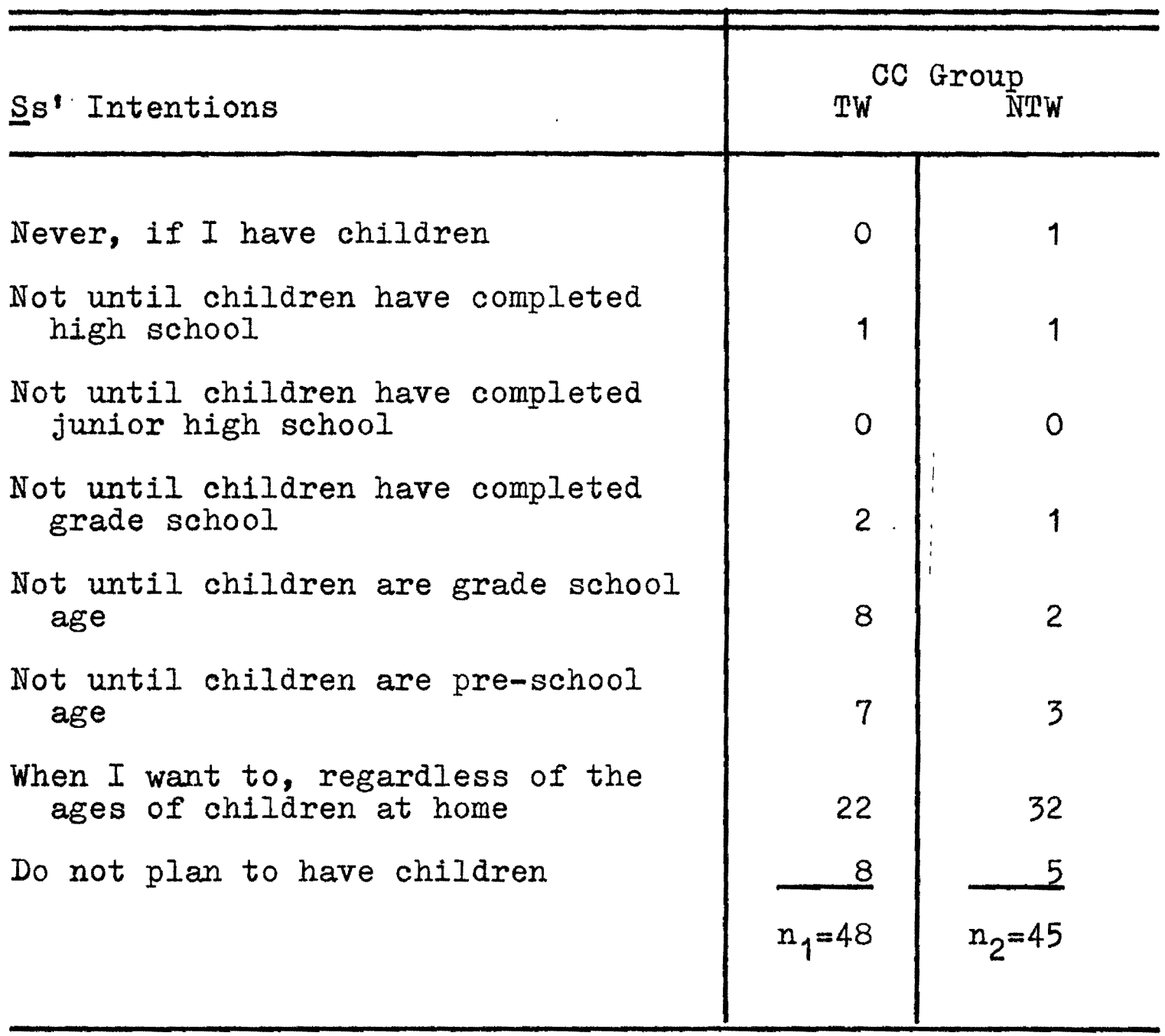

the responses may be interpreted as reflecting the changing attitudes in the culture about the necessity or responsibility of mother to be at home full-time beyond the early, formative years of her children. 
CHAPTER IV

\section{DISCUSSION}

Only one of the three hypotheses in my study was supported by the findings. Hypothesis 1, which was accepted, predicted that women's attitudes toward woman's roles would be more congruent with the perceived attitudes of husband/ consort and close friend than with the perceived attitudes of mother and father. Hypothesis 2, which was rejected, predicted that women who choose NTW occupations would prefer more androgynous roles and that women who choose TW occupations would prefer more dichotomous roles. Hypothesis 3, which was rejected, predicted that women's occupational choices would be consistent with the perceived attitudes of husband/consort and close friend toward woman's roles (i.e., women pursuing NTW occupations would perceive those significant others preferring androgynous roles and women pursuing TW occupations would perceive those significant others preferring dichotomous roles). The hypotheses were formulated with the particular sample used in the present study in mind, i.e., white, American, graduate student women.

The major variables and intervening variables in my study were listed in Chapter One. Previous research had 
not established clear expectations or predictions for the intervening variables but had suggested their potential utility. Consequently, specific formal hypotheses were not formulated but supplementary questions were proposed to suggest how the intervening variables might explicate the relationships among the major variables. Overall, the findings in my study did not indicate that the intervening variables shed any light on those relationships. Significant differences between the two career choice (CC) groups on these variables were not apparent.

The results obtained in the present study appear to have some validity insofar as the findings support some of the findings of an earlier study by Edwards (1969), even though I used a different instrument and procedure. A brief review of that study together with the related findings in my study follows.

In a study of senior women in nursing and teaching programs, Edwards (1969) did not find a direct relationship between Ss' role-decisions ("family," "compromise," and "career") and their perceptions of the role values of seven significant others. In my study a similar finding was obtained. A direct relationship was not found between the career choices (TW, NTW) of the women graduate students and their perceptions of the attitudes of their significant others toward woman's roles (Hypothesis 3). Similar findings were found in Edwards' study and my study on whose role 
values or attitudes were more closely related to the attitudes of white college women. Edwards found that the perceived values of best girlfriend and boyfriend were more often congruent with the role values of the $\underline{S} s$ than were the perceived values of parents, school and society. In my study, as hypothesized, the graduate students' attitudes toward woman's roles were found to be more congruent with the perceived attitudes of husband/consort and close friend than with the perceived attitudes of mother and father (Hypothesis 1). My findings differ from those of Edwards' on role values or attitudes. In Edwards' study, the role values of undergraduates differentiated the roledecisions of the $\underline{S} s$ and were consistent with those roledecisions. In my study, graduate students in the two CC groups were not found to differ significantly in their attitudes toward woman's roles (Hypothesis 2).

It is important to consider why my results differed from those of some previous research. One consistent finding is that the attitudes of $\underline{S}$ s differentiate decision groups, such as role/career choices, orientations, expectations or in potential conflict situations. I will discuss possible explanations for my findings within the context of the following topics: 1) methodological considerations, 2) reconsideration of the literature, and 3) passage of time. Suggestions for future research will also be presented. 


\section{METHODOLOGICAL CONSIDERATIONS}

Four aspects of the methodology used in my study are significant in terms of their possible influences on my results. The aspects which I will consider are: 1) the adequacy of the hypotheses, 2) the selection and measurement of the major variables, 3) the instrument which was used, and 4) the selection of the sample.

\section{Adequacy of the Hypotheses}

Hypotheses 2 and 3 were not supported in my study, although they seem well based on a large number of published works. Hypothesis 2 expected that women's attitudes toward woman's roles would differentiate $\underline{S}$ s pursuing TW occupations from those pursuing NTW occupations. A consistent finding in previous research has been that white college women who are oriented to TW or NTW careers, or traditional/nontraditional role choices, or who have lower/higher educational aspirations differ significantly from each other in their own role concepts (Bailyn, 1970; Edwards, 1969; Fogarty et al., 1971; Karman, 1972; Iipman-Blumen, 1972a, 1972b; McKenzie, 1971; Ziebarth, 1970). However, except for the study by Makenzie (1971), the samples in prior research did not include women in graduate school but included college student women and women who had some college or who graduated from college. 
Hypothesis 3 expected that $\underline{S} s$ who were pursuing TW occupations would perceive husband/consort and close friend preferring dichotomous roles, and that $\underline{S} s$ who were pursuing NTW occupations would perceive husband/consort and close friend preferring androgynous roles. This hypothesis was also based on the findings in previous research (Bailyn, 1970; Edwards, 1969; Fogarty et al., 1971; Hawley, 1971, 1972; Horner, 1972a, 1972b; Leland, 1966; Schwenn, 1970; Tangri, 1969). In general, the prior findings indicated that the perceived attitudes toward woman's roles of significant male peers, particularly, seem to be directly related to the role/career choices of college women. The studies indicated that women appear to make behavioral choices (e.g., role, career) which are consistent with their perceptions of support for TW or NTW choices from significant male peers. The usual interpretation was that the perceived views of significant males had a determining influence on women's behavior.

Selection and Measurement of the Major Variables

The major variables measured in my study were chosen because prior work showed their importance to the questions of interest in this thesis.(Bailyn, 1970; Edwards, 1969; Fogarty et al., 1971; Hawley, 1971, 1972; Horner, 1968, 1972a, 1972b; Karman, 1972; Leland, 1966; McKenzie, 1971; Schwenn, 1970; Tangri, 1969; Wolkon, 1972; Ziebarth, 1970). 
However, my sample did differ from previous studies and one of the interests in my study was to see how the findings of the earlier works would generalize to other settings, e.g., women in graduate school.

The measurement of the major variables also followed previous research. The data collected included responses on items measuring both affect and behavior. Data collection on Ss' background, opinions and attitudes utilized measures which previously have been shown to have some value.

In Part One of the questionnaire, data collection was elaborated or extended in line with the findings of previous research. There was some question when my study was designed about how to adequately measure the intervening variables (maternal role modeling, expressed identification with parents, current importance of the relations with each specified significant other). It was, in part, in an effort to find out how those variables might be measured that they were included.

Part Two of the questionnaire consisted of an Attitudes Toward Woman's Roles (AWR) inventory. Only three of twenty-four items were originally devised for this study. Twenty-one items were taken directly or adapted, for updating purposes, from previous studies which had indicated their validity for this type of study. The AWR scores provided measures for the two dependent variables in the present study: attitudes toward woman's roles and percep- 
tions of the attitudes of certain significant others. (See Appendix $C$ for the five subscales and items which were included in the AWR inventory and additional notes which might be useful in future research with this type of instrument.)

The Instrument: Questionnaire

It is often said that self-report instruments allow Ss to hide their true feelings. For example, in my study, the AWR scores for Self attitudes tended to cluster towards the androgynous end of the scale. This might be viewed as reflecting the expected, stereotypic responses for this type of sample at this particular time. One way to evaluate this possibility might be to note how often the options "I don't know" (perceived views of others) and "No opinion" (Self attitudes) were used by the $\underline{\text { s. }}$. The options, or neutral responses, might be interpreted as non-commitment, indifferent or honest impasse responses. I am assuming that if $\underline{S} s$ wanted to hide their feelings, it would be easy to do so by taking these options. It is relevant to note how often the options were used, and by which Ss.

There was a noticeable difference between the two CC groups in the use of these options. In the TW group $\left(n_{1}=49\right)$ three Ss responded "I don't know" to at least eight (onethird) of the AWR inventory items for perceptions of father's attitudes. In the NTW group $\left(n_{2}=47\right)$ ten $\underline{S}$ included eight or 
more of the neutral responses on one or more AWR subscales (i.e., 16 subscale scores were affected). The distribution of the high proportion of neutral responses in the NTW group was: two for Self attitudes, four for perceived attitudes of mother, seven for perceived attitudes of father, one for perceived attitudes of husband/consort, and two for perceived attitudes of close friend. Six of the $10 \underline{S}$ s were $\mathbb{N D}$ students. The remaining $\underline{S}$ (4) were balanced among the other NTW subgroups. It could be argued that the AWR scores which contained a high proportion of neutral responses should not have been included in any analysis. However, one cannot dismiss the possibility that the "neutral" responses were sincere. In any case, this condition applied to only 19 (approximately 4 percent) of 433 total AWR scores for the sample $(N=96)$. Since this percentage was considered to be too small to affect the overall results, these scores were included in the analyses. In summary, although the possibility remains that $\underline{S}$ expressed socially acceptable responses, the data do not show that $\underline{\underline{S}} \mathbf{s}$ tried to avoid expressing an attitude. ${ }^{1}$ Moreover, the experimental procedure encouraged honest expression

${ }^{1}$ In an earlier study, Ziebarth (1970) commented that there might have been a "problem" with her measure of college student women's role concepts since there was a general tendency for $S s$ to respond in a more nontraditional way. She implied, however, that this might be expected for college samples without implying that this reflected a less honest expression of attitudes. 
of attitudes by assuring anonymity and by appeals for honest cooperation and promises to share the results of the study.

\section{Selection of the Sample}

The sample consisted of American, white, women currently enrolled in $\mathrm{Ph} . \mathrm{D}$. and professional degree programs at Portland State University and the University of Oregon Medical and Nursing Schools who were between the ages of 21 and 45 years and were from intact homes. This particular sample was selected because some interests of my study were to see how data from an older sample of college women who would soon be eligible for jobs and were showing serious interest in an academic or professional career would relate to some findings in earlier studies. There are three possibilities which immediately come to mind for consideration: 1) the sample was not correctly drawn, 2) the age of the sample affected the data, and 3) the educational level of the sample affected the data.

Was the sample correctly drawn in terms of TW, NTW career choices? One basis for designating a career choice as typically feminine or typically masculine is the proportion of men to women in the field. Using this as a criterion for group assignment in my study, the sample used does appear to be reasonable. It may well be, however, that any differences between the two groups were obscured by combining samples of subgroups under the general classifications, TW 
and NTW. In other words, the two groups might have been too heterogeneous on occupational choice. I thought it was important to represent different subgroups to offset any bias towards ascribing what may be characteristic of one subgroup (e.g., teachers) to also be characteristic of the main group (e.g., women in TW careers). For example, prior studies have relied primarily upon samples of undergraduate nurses and teachers to represent TW careers and math-science majors to represent NTW careers and significant differences in role attitudes and plans/behaviors were found among these three subgroups. However, by combining teachers and nurses (as one group) to compare with mathscience majors (a second group) the differences that exist within the first group (teachers and nurses) tend to disappear. In my study there were no significant differences between the two groups (TW, NTW) in measured Self attitudes toward woman's roles and in the perceptions of the views of specified significant others.

The Age of the Sample. It was expected that my sample would be older, on the average, than samples used in previous studies and that this might affect the results obtained. It was not possible, however, to specify the direction of the expected difference. The overall mean age for my sample was 29.05 years. The mean age for the TW group was 29.9 years and for the NTW group was 28.2 years. Some earlier studies used samples which might have been com- 
parable to mine on age (Bailyn, 1970; Fogarty et al., 1971; Hawley, 1972). In the studies by Bailyn (1970) and Fogarty et al. (1971), the mean age of $\underline{S} s$ was not reported but might be inferred from the fact that the women sampled had graduated from British universities in 1960 and were surveyed in 1968. In the study by Hawley (1972), 62 percent of her sample were college undergraduates (teachers, math-science majors) with a mean age of 26 years. Thirty-eight percent of her sample were counselors-in-training with a mean age of 33 years. Hawley found the counselors' perceptions of significant males' attitudes toward the feminine ideal were much closer to the math-science group (NTW) than to the teacher group (TW) rather than occupying an intermediate position between the two groups (TW, NTW) as expected. The most obvious difference between the sample in my study and other samples which were comparable in age is the overall difference in educational level, since all of my sample were graduate students.

Another aspect of the age factor to consider is that although my sample was purposefully selected to be heterogeneous on age, perhaps the broad age range (21-44 years) obscured the differences between the two groups. Additional analyses of measured Self attitudes were done to see if there was an interaction effect of age and occupational group. The results showed a weak effect for the age of an $\underline{S}$ on her responses, suggesting that had the sample included 
only women older than 27 years, differences between the two groups would not have been found. Had the sample included only women younger than 27 years, differences between the two groups would have appeared. ${ }^{2}$ Most prior studies finding differences which failed to appear in this thesis used younger samples (Edwards, 1969; Karman, 1972; Iipman-Blumen, 1972a, 1972b; Ziebarth, 1970). Differences have also been found for a sample of older women who had graudated from college (Bailyn, 1970; Fogarty et al., 1971). One earlier study which used a sample heterogeneous on age found less difference between the older subgroup (counselors) and one younger subgroup (math-science majors) than between the two younger subgroups (teachers, math-science majors) (Hawley, 1972). Again it appeared that level of education had more of an overall effect than age.

Educational Level. It seems possible to argue that enroliment in a professional degree program, whether TW or NTW, is a concrete behavioral index of commitment to a nontraditional role. Consequently, for the sample used in my

2 The results of additional analyses to check on the possible interaction effect of marital status and occupational group were similar to the results obtained for the analyses on age. That is, there was a weak effect for the marital status of an $S$ on her responses as mentioned in Chapter Three. More recent studies (Ziebarth, 1970; Hawley, 1972) did not find a significant effect for marital status on $S^{\prime}$ s responses. In the studies by Bailyn (1970) and Fogarty et al. (1971) the findings implied that marital status might have affected S's responses. However, the results reported were only for a subsample of married women. Hence, it is not known whether marital status had an effect or what kind of effect it might have had. 
study, the differences between the two CC groups (TW, NTW) in attitudes toward woman's roles may have been minimal. Previous studies, for the most part, have used samples of college student women and women who had some college or did not continue beyond the baccalaureate level.

Significant Findings. In my study, out of 50 tests performed on the data, only five results were significant. However, in four of the five cases, the results were in the opposite direction than expected. It is of interest to note that the MD subgroup appears to be the major contributor to this effect and that a similar effect was not shown by the other women in (non-medical) doctoral programs. What might account for the effect observed? One possibility which immediately comes to mind is the size and mean age of the MD subgroup. The MD subgroup (18 $\mathrm{S} s$ ) was larger than any of the other subgroups in the NTW group (See Table II) and represented 38 percent of the $S s$ in the NTW group. In the four cases where the significant results were in the opposite direction than expected, at least 50 percent of the NTW Ss who contributed to this effect were medical students. The MD Ss also accounted for 60 percent of the NTW $\underline{S} s$ who liberally utilized the neutral response options ("No opinion," "I don't know") in the AWR inventory. The mean age of the MD subgroup (23.8 years) is noticeably younger than any other subgroup in the total sample (See Table II). The significant results found in additional analyses of measured 
Self attitudes for the possible effects of age and marital

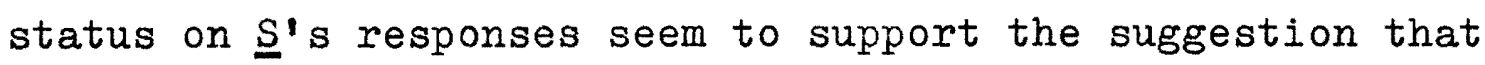
the effect observed might have been partly due to the younger age of the MD subgroup.

Another possibility to consider is that women in medical school may be under greater pressure to have conservative role attitudes than other women doctoral candidates. This was suggested by some behavioral observations which were made during the group administrations of the questionnaire. The observations were not documented because they were unexpected. However, they might be of interest for future research. I noted that the women medical students appeared to be more defensive than other $\underline{S} s$ about my inquiry into role concepts. Their defensiveness was inferred from their behavior towards me when I administered the test (e.g., ignoring me), among themselves (e.g., little group interaction), and "fleeing" from the room as soon as they completed the questionnaire. Moreover, I was told spontaneously by some of the women medical students that hostility towards women in medicine was often expressed by male faculty and peers. If hostility towards them is one aspect of their daily experience, ND $\underline{S} s$ may be more sensitized to the subject of role concepts than other women doctoral candidates. Because of their sex, their personal resolves may be continually challenged and their efforts discouraged. A recent analysis by Drukman (1973) of the 
socio-political structure at the University of Oregon Medical School gives evidence to support the inference that the women medical students sampled in my study may be in a more "sex-conscious" environment than other (non-medical) doctoral candidates.

\section{RECONSIDERATION OF THE IITERAIURE}

In an effort to place the results of my study in perspective in relation to previous findings, it might be valuable to look again at the previous research on sex roles and other topics related to sex roles. The discussion which follows includes two topics: 1) sex-role stereotyping and changes in attitudes toward woman's roles and 2) cultural bias and sex role research. The general question of interest is whether the unexpected findings of my study are an artifact of my method or whether they fit within other existing knowledge.

\section{Sex-role Stereotyping and Changes} in Attitudes toward Woman's Roles

\section{Sex-role Stereotyping. As suggested earlier in} Chapter One, stereotypic conceptions (of which sex-role stereotypes are examples) may be difficult to eliminate because of their tendency to develop functional autonomy. In other words, the context in which they evolved is forgotten and the concepts are maintained out of context. One question about the dynamics of sex-role stereotyping is: 
What is the functional value of sex roles? Millman (1971) criticized the sociological research on sex roles for neglecting to examine the functional value of sex roles in our society in general: "It is important to understand not only what our sex roles are, and how individuals learn them, but why these roles develop and why they are or aren't changing" $(p$. 774). The same criticism may be applied to the research on sex roles in psychology. It does not appear sufficient to merely publicize evidence for and accumulate documentation of sex-role stereotyping and sex-based discrimination. ${ }^{3}$ Nor does it appear sufficient to resolve the question of sex roles by pointing to the socialization process. What I am suggesting is that an undoubtedly more difficult and complex problem remains to be dealt with in order to understand: 1) why sex roles are valued for individuals and 2) what personal factors facilitate or inhibit change in the current sex-role definitions or stereotypes. Some questions are: Who benefits from maintaining the status quo? What does the current sex-role stereotyping protect? What is feared if the prevailing stereotypes are no longer endorsed?

A recently encountered view in the psychological literature on why sex roles develop is that sex-role

3 From a functional point of view, stereotyping may be viewed as a very efficient psychological mechanism for maintaining the status quo, in sex roles or any other dimension. 
division is necessary for socialization and psychic development of the individual and to harmonize differences (i.e., to maintain a group life when individual members of the group are not all identical) (Douvan, 1972). A similar view (Tresemer and Pleck, 1972) is that sex-role definitions or sex-role stereotypes (i.e., sets of widespread, stable and consensual images in the culture) provide individuals with an external referent structure to facilitate the development of a sense of identity (i.e., integrated sense of self with "inner continuity and sameness") (Erikson, 1965). In the latter view, sex-role definition not only facilitates the development of sex-role-appropriate behavior (which contributes to the development of personal identity) but also defines when one will receive affection and acceptance (i.e., for the "right" behavior) and when one will be punished (i.e., for overstepping the ascribed limitations of one's own sex roles). In other words, Tresemer and Pleck view the function of sex-role definition as establishing boundaries to provide external stability and maintaining those boundaries by explicit approach and avoidance or reward and punishment conditions. Both views (cited above) assume that the past dichotomization of sex roles no longer meets the current needs of either the individual or society. It seems to me, however, that as long as one argues that divisions or boundaries between the sexes are necessary, it is difficult to move toward androgynous roles. A ques- 
tion which arises is: How are those divisions or boundaries to be redrawn? As Epstein (1972) points out, sexrole definitions have most often been based on subjective rather than objective judgments. And, in the past, the limitations imposed on an individual's growth and options by the subjective role definitions have been compounded by the tendency to exploit the sex-role relationships as defined. She cites as an example the institutionalization of the "helper" status of women, whether at home or at work, regardless of the level of performance.

One approach to investigating why sex roles are or aren't changing has been suggested by Tresemer and Pleck (1972). In their view, two major dynamics are involved in the processes of "boundary-maintenance" of sex roles. One is the "avoidance of behavior that is inappropriate for one's own sex role" ( $p, 1)$. The second dynamic involves "the various responses to behavior in one's own and especially the other, sex which deviate from these traditional roles" ( $p, 1)$. They suggest that the degree of openness to or perceived threat from behavioral changes in the other sex depends upon the psychological investment men and women have in the relatively independent dimensions of male instrumental superiority and female expressive superiority. These two factors are viewed as relatively independent due to individual differences in personality and developmental experiences. 
The Relation between Sex-role Stereotyping and Changes in Attitudes Toward Woman's Roles. Many studies have found that sex-role stereotyping is often reflected in the selfconcepts of women. The general finding is often interpreted as indicating that changes in attitudes about woman's roles are not very noticeable. I suggest that the research findings should be examined to see whether self-concepts or role concepts are being measured and to be certain that only sexrole stereotypes are being measured. These suggestions are made for the reasons which follow.

It appears from the literature that the two terms self-concept and role concept are often used interchangeably. This results in some confusion in the literature since the two terms are not synonomous. I suggest that a person's self-concept and role concept may be equivalent, but that they need not necessarily be equivalent. A person's evaluation of self (self-concept) may not necessarily predict how she/he feels or would like to feel about herself/himself in relation to another (role concept). For example, a woman may view herself as "being" more "feminine" (i.e., expressive, nurturant, non-aggressive) than "masculine" (i.e., independent, autonomous, assertive). However, if she preferred to "be" more "masculine" it would not necessarily be contradictory for her beliefs or attitudes toward woman's roles to express another mode of "being." In other words, she might prefer a more egalitarian relation to others, one 
that may be characterized by androgynous role concepts. An earlier study, using a framework of self-concepts, showed that both men and women incorporated both sex-role stereotypes and sex-role ideals without contradiction (Elman, Press, and Rosenkrantz, 1970). The study investigated the differences between the effects of sex-role stereotypes and sex-role ideals on the self-concepts of individuals. ${ }^{4}$ Ss' $^{\prime}$ conceptions of actual self-concepts (real self) were expected to reflect sex-role stereotypes and ideal-selfconcepts were expected to reflect sex-role ideals. It was also expected that individuals' conceptions of "ideal male" and "ideal female" (sex-role ideals) would be more similar to each other than their characterizations of "typical male" and "typical female" (sex-role stereotypes). All the hypotheses were supported and consistently similar patterns for men and women were found. Both women and men Ss perceived ideal man and woman and ideal self as possessing many values which are presently valued for the other sex, in addition to same-sex valued traits.

Whether one chooses to make a distinction between self-concept and role concept or to distinguish between stereotypes and ideals using a framework of self-concepts, I am suggesting that some distinction may be useful to

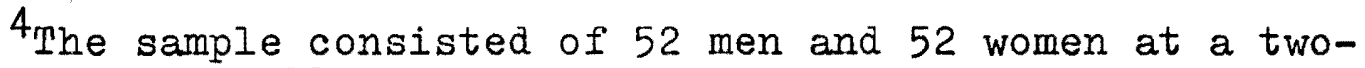
year community college. 
separate out the areas where the imprint of the socialization process may be strongest or more difficult to consciously change (e.g., self-concept) from other areas where there are options which can be consciously negotiated in response to changes in the culture (e.g., role concepts). ${ }^{5}$ In general, a shift towards the equality of sex roles does appear to be occurring in attitudes toward woman's and man's roles. The shift is most often reflected in ideal role concepts. A parallel shift also seems to be occurring in self-concepts with both women and men reflecting in their ideal self-concepts a preference for both sexes to share many of the personal characteristics previously sexlinked. ${ }^{6}$ Those characteristics have been conceptualized as "agency" and "communion" (Bakan, 1966), self- and otherorientations (Fand, 1955), instrumental and expressive factors (Parsons and Bales, 1955), and assertive and yielding (Bem, 1972). The changes in attitudes about sex roles

${ }^{5}$ Douvan (1972) observed that there is much evidence in human physiology and psychology to assert that, theoretically, "man's adaptability and capacity to institute [behavioral] change is virtually unlimited. Much more questionable it seems to me is our ability to control and direct change; . ." (p. 2).

${ }^{6} \mathrm{~A}$ scale has been recently developed which might more accurately reflect the self-concepts of both men and women today (Bem, in press). The sex-role inventory which was developed differs conceptually from previous inventories by treating masculinity and femininity as two independent dimensions rather than bipolar ends of a single continuum. This was done so that a negative correlation between masculinity and femininity was not artifactually forced. Persons who are, in fact, "androgynous" might no longer be "lost" due to an intrinsic procedural bias. 
are often obscured by the misperceptions or suspicions both men and women appear to have of each other. Hence, the findings often reflect conflict between a person's role aspirations and her perceptions of what others expect of her.

It also appears important that the measure of stereotyping used does, in fact, measure that and not something else. The findings of a recent study made this clear (Nowacki and Poe, 1973). In their study, 117 men and 138 women college undergraduates were asked to rate a mentally healthy male and female. The purpose of the study was to investigate the generalizability of the findings of a previous study (Broverman, Broverman, Clarkson, Rosenkrantz, and Vogel, 1970). In the Broverman et al. study, clinicians were found to have different conceptions of mental health for men and women. The conceptions for each were in accord with the current sex-role stereotypes of passive woman and aggressive man. Nowacki and Poe (1973) used the Broverman sex-role stereotypic scale and a semantic differential scale. Their results supported the hypothesis that the conception of mental health for a man is different than for a woman and they also found that these conceptions differ depending upon the sex of the rater. The authors suggested that the ratings of mental health seem to measure something else beside male/female stereotypes for two 
reasons. ${ }^{7}$ One is that the items on the semantic differential scale were not primarily sex-role stereotypic items as were the items on the Broverman scale and both scales appeared to be measuring the same thing (i.e., conceptions of mental health). Secondly, a large part of the variance of the ratings of the two scales was not common to both of them. The correlation between the two scales was moderate, accounting for 19 percent of the total variance of the ratings.

In summary, at this particular time it is conceivable that women's self-concepts will reflect more of the "nonconscious ideology" and "structured inequality" than their role concepts. An observation of Bailyn (1964) seems pertinent here. In her view, the socialization process has given women, particularly in the middle class, freedom of choice at the wrong time. The choice has not been given when it is necessary to ensure a woman's ability to utilize. later options (i.e., beginning in early childhood) but when it leads to confusion (i.e., introducing complications into the family role as an adult). In a recent assessment of the psychological impact of feminist ideology on educated women (i.e., those with some higher education or the

7 Areas to investigate in order to identify the variables operating in the different ratings of mental health for males and females were not reported but are included in an extended report which can be obtained from the authors (Nowacki and Poe, 1973). 
equivalent), two effects were noted which illustrate changes in the sources and the content of conflict and confusion for women today (Westervelt, 1973). One effect concerns guilt and shame, i.e., more educated women now than previously are likely to feel guilty or ashamed if they are unable to achieve a "well-rounded" identity, which involves generally higher self-imposed standards and levels of maturity. A second effect is that rather than conflicts centering on choosing between marriage and career (formerly mutually exclusive role options), conflicts and confusion are now apt to center on how to integrate dual roles and the degree of pressure the individual can cope with in order to achieve, if achievement seems essential to self-fulfillment.

Some Implications for Future Research on Sex Roles. A question of interest which remains unanswered is: How can the process of change in attitudes about sex roles be facilitated? The type of sample which is selected for study might affect the detection of any changes in attitudes toward woman's roles. I have also suggested that the same changes might not be reflected in self-concepts (evaluation of current self) and role concepts (sex-role attitudes). There are many variables (one being current sex-role stereotypes) to be considered for understanding the interaction between the self-concept and role concept of an individual. An example of the complexity involved in the relation between the self-concept and role concept of an individual is shown 
in a study by Baruch (1972). An overall tendency to devalue women's competence was not found among her sample of college undergraduate women. Moreover, although a woman did not devalue female competence, she did not necessarily endorse a dual role pattern for herself. Mother's attitudes about and experiences with working outside the home were important mediating factors for understanding the relation between $\underline{\text { Ss' }}$ tendency to devalue and their role-orientations. The perceived personal consequences of what mother did seemed to influence whether or not her daughter perceived a dual role to be desirable or undesirable for herself:

Thus, if a subject's mother had worked but had also experienced negative personal consequences because of her career, the subject evaluated women's competence highly but was unfavorable to the dual role patterm (p. 37).

The results of my study suggest that graduate student women pursuing TW and NTW careers may not differ significantly in their attitudes toward woman's roles (role concepts). (This suggestion pertains only to the role concepts of these women, not to their self-concepts which were not assessed.) It is also Iimited to American, white, graduate student women from the middle and upper-middle classes, attending Portland State University and the University of Oregon Medical and Nursing Schools.

\section{Cultural Bias and Sex Role Research}

Evidence of Cultural Bias in Sex Role Research. Critical observations on research on sex roles in sociology 
(Millman, 1971) and psychology (Bem, 1972; Rossi, 1964) include evidence of cultural bias which may influence the findings obtained and the interpretation of results. For example, Millman (1971) pointed out that in sociological research on sex roles the focus has been on those institutions and relationships which are most stable and least likely to change, e.g., the family. She pointed out that the finding that within families the traditional role distinctions are still maintained, regardless of whether or not the woman is working outside the home, is usually interpreted as indicating that little change in sex-role attitudes and behavior has occurred. In psychological studies, the diverse patterns of results found for college samples might suggest which aspects of role attitudes and behavior are most responsive, or most resistant, to change. To interpret the findings two factors should be considered. One is personal history, which seems to greatly influence the degree of congruence found between verbally expressed role concepts and actual behavior. The degree to which a woman can overcome the limitations of her socialization seems to depend, in part, upon the distinctive characteristics of her history. Although general patterns among individuals' histories may be discerned, there is not a simple, linear relation between what parents said and/or did and the attitudes of college women toward woman's roles and their role/career behaviors. The second factor to 
consider is where congruence between role attitudes and career choice is anticipated. For example, a woman may prefer an occupation which has always been considered an appropriate female pursuit (e.g., teaching). However, it may no longer be reasonable to assume or interpret that particular choice to also mean that the woman prefers dichotomous roles.

More specifically, as others have observed (Bem, 1972; Millman, 1971; Rossi, 1964), the cultural bias may be reflected in: 1) the way the research questions are formulated (e.g., looking for how well "adjusted" individuals are to their appropriate roles), 2) the concepts and terms used (e.g., "masculine," "feminine," "maternal deprivation" when mother is absent from the family, "father absence" when father is absent), and 3) the measures used to collect the data (e.g., inventories which inversely correlate masculinity and femininity). I suggest that either cultural bias or defensiveness may also be reflected in 4) the interpretation and presentation of results. Results may be interpreted in a way which exaggerates statistically significant outcomes without considering how meaningful (in terms of persons' lives) the significant findings may be. Perhaps this tendency is due to some fear that to acknowledge the greater proportion of moderate or nonsignificant outcomes might jeopardize a point of view. For example, Iipman-Blumen (Blumen, 1970; Iipman-BIumen, 
1972a, 1972b) was interested in the complex interaction between sex-role ideology, socialization practices and adult role choices of women. Sex-role ideology scores were obtained from $\underline{S} s^{\prime}$ responses to a 6 -item attitudinal scale. Mode of achievement was chosen to represent one aspect of socialization practices. Adult role choice was indicated by $\mathrm{Ss}^{\prime}$ level of educational aspiration, which was considered to be measured conservatively by asking what degree the Śs' expected to complete. A number of analyses were done for different subsamples of married women in the Boston area $(\mathrm{N}=1,868)$ (Blumen, 1970). Iipman-Blumen (1972b) apparently wanted to emphasize the high cost for women of discriminatory socialization practices. The point is brought out by noting the technical significance of a difference in proportions of married college graduate women with high expectations (complete a degree beyond the masters level) and contemporary role ideology (relationships between the sexes are ideally egalitarian) and those with high expectations and traditional role ideology. For the subsample $(\mathrm{N}=636), 27 \underline{\mathrm{S}} \mathrm{s}$ (4\%) were in the high expectations/contemporary group and seven $\underline{S} s(1 \%)$ were in the high expectations/traditional group. A question arises about how to translate technically significant difference where the "n"'s are so low into a meaningful difference in terms of persons' lives. It seems that a shift would not have to be very great to eliminate 
the difference. It might also be of interest to note that 39 Ss $(6 \%)$ had low expectations (do not expect to complete a higher degree) and contemporary role ideology. In short, I am suggesting that some findings of technical significance should be interpreted with caution.

Cultural bias or defensiveness may be reflected not only in how results are interpreted but also in the choice of results to interpret or which results may be overlooked. For example, in comparing the results obtained by LipmanBlumen (1972a, 1972b) for different subsamples it seemed interesting that the effect of completing college did not seem to affect role concepts, educational expectations or mode of achievement as one might expect. Reporting for $\underline{S} s$ who were wives of graduate students and had attended some college $(N=1,012,1972 a)$, role ideology scores were divided between the traditional (27\%) and contemporary (73\%) categories. Reporting for Ss who were married and college graduates and who had not continued beyond that degree $(N=685,1972 b)$, role ideology scores fell roughly into thirds for each category (traditional, mixed, contemporary). Both subsamples were comparable on age (median age was approximately 24 years) and length of time married (mean length was approximately 3 years). In terms of the interaction between $\mathrm{SS}^{\prime}$ role concepts and educational aspirations, controlling for college completion, the greatest shift in educational expectations occurs from the low (do 
not expect to complete a higher degree) to the medium (expect to complete a masters degree or equivalent) categories. This was found for $\underline{S}$ sith traditional or contemporary role ideologies. Similarly, when comparing Ss' mode of achievement (vicarious, balanced, direct orientations) and role ideology (traditional, contemporary), a shift occurred from the vicarious to the balanced orientation. There was almost no change at all in the number of Ss who expressed the direct orientation.

Finally, cultural bias or defensiveness may also be reflected in the presentation of results. This was brought to my attention by two different presentations of IipmanBlumen's results. At an invitational conference at Radcliffe College (Lipman-Blumen, 1972b) she focused on the significant difference between women's role ideology scores and high aspirations and the limiting of women's possibilities by socialization to the vicarious mode of achievement. For journal publication (Iipman-Blumen, 1972a) she gave a more balanced presentation, concluding that there appear to be two distinct life patterns where a woman can find fulfillment and meaning. Significant relationships among role ideology, educational aspiration and mode of achievement were reported together with the results of a measure of self-concept. There were no significant differences between the role ideology groups (traditional, contemporary) in self-esteem profiles, the women's confidence in their 
competence as wife and mother, and their feelings of competence in relation to being a student, employee, etc. Effects from Cultural Bias in Sex Role Research. One effect of cultural bias in research on sex roles, discussed above, refers to the influence of bias on the findings obtained and how they are interpreted. Another effect or consequence which comes to mind is the tendency to introduce new biases. For example, a problem in research on sex roles arises from the concern of many researchers, often women, with emphasizing the normality, legitimacy and desirability of role-innovative choices for women. Although the need or motive for doing so is certainly understandable, an implicit bias is often introduced against traditional career choices. At least two effects of this new bias can be seen. One is that stereotypic conceptions, such as "Cherry Ames, Nurse," are perpetuated. As happens with most stereotypic conceptions, the conception tends to deny or simplify the reality of a complex interaction between social and psychological factors. For example, according to one nurse, "Most people go into the profession because they have the attitude, 'I come last.' That's why we have so much trouble organizing" (Kushner, 1973, p. 72). Another effect is that TW choices come to represent aspects of choice which are to be rejected if a woman wants to demonstrate her commitment to a serious career or her intention of self-actualization. Teachers and nurses, for example, have usually had low status among 
the professions and are now subject to a new attack. One implicit assumption in much sex role research is that if the women who choose to be teachers and nurses are really interested in achievement and serious about a career, they would have chosen a different field. (The alternative presented for nurses is medical school.) The assumption made as to what constitutes real achievement and a serious career is not only unrealistic but it merely substitutes one rigid standard for another. The implications which follow for society, in general, are self-defeating in terms of professed values and needed changes. Another implicit assumption in much sex role research is that women in NTW occupations are more autonomous, independent and selfassertive than women in TW occupations. It may be very easy to equate NTW attitudes with NTW choice and planned action but this assurnes a simple, linear relation between attitudes and behavior and does not allow for individual differences. In short, I propose that Rossi's (1964) immodest proposal for equality between the sexes be extended to include equality within the sexes.

And it is not only in careers that one may see the effects of negative associations on choice of role. Another example is in the attitudes shown toward the roles of childbearing and childrearing, two key areas in sex-role definition. The need to separate out external, societal presses from specific biological functions for questions about role 
attitudes and behavior was clearly shown in a recent study of attitudes toward children (Lott, 1973) and in extrapolations from recent primate studies (Lancaster, 1973). Iott (1973) comments that within the women's liberation movement, some women are reflecting the existent cultural bias for the rejection of childrearing without having considered its source. Due to the negative associations between childrearing practices and having children, those women who would probably be better mothers feel that they must reject children. The "better" mothers in her study were, in her view, the "pro-liberation" women who were characterized as being independent, flexible and democratically oriented. ${ }^{8}$ For these women, however, motherhood is too much associated with woman's inferior status and is rejected. Compared with the "anti-liberation" women, the potentially "better" mothers were significantly less eager to have children and less interested in personally raising them, although they viewed childrearing as more creative than the "antiliberation" women did. 9 Lancaster (1973) points out that previous conclusions about role behavior among primates

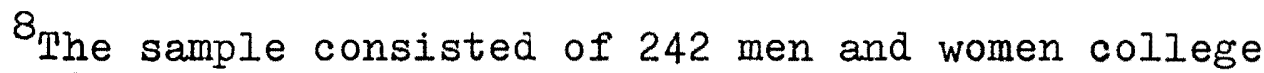
undergraduates.

${ }^{9}$ One finding of interest was that although sex differences in attitudes toward children were expected, what was not expected was that one-third of the male Ss would be in the highly positive category of attitudes toward children, That category was characterized by an expressed eagermess to have children and a personal interest in raising them. 
might have been drawn from insufficient data. Not only was the data insufficient with respect to quantity but also quality (i.e., researchers, usually male, approached the study of primates with human cultural sets). As a result, the roles other than mother for the female primate have been overlooked. The author comments: "Now, more than ever, we need to know if apparent differences in behavior between men and women are more or less biologically fixed or heavily influenced by experience" ( $p .30)$. In reviewing the evolution of human role behaviors she points out that the functional need for assigning specific roles to each sex is no longer relevant in a modern, technological culture. ${ }^{10}$ She also suggests what the role of biology is in relation to children:

Biology does place role restrictions on women. But it is not the biology of women themselves; it is the biologically based emotional needs of children that are demanding and undeniable $(p, 99)$.

She further points out that the maternal role can be carried out by man or woman. The only criterion is psychological: the willingness of a person, man or woman, to play a nurturing, protective role for the first four to six years of a child's life. This also means, in her view, that whoever

$1_{\text {Bem }}$ (1972) made a similar observation commenting that the two complementary domains of positive traits and behaviors (represented by "masculinity" and "femininity") became differentially associated with the two sexes because they reflect the different life roles that men and women had to play in a non-technological society. 
chooses to play this role must accept some restrictions on his or her activities.

\section{PASSAGE OF TIME}

The data for my study was collected during Spring, 1973; most other relevant studies were done before 1969. There were some indications in earlier research that some changes in attitudes about woman's roles were occurring. The time factor and indications of changing attitudes as early as 1955 might account for the lack of difference between the TW and NTW career choice groups in the present study. Also, as attitudes toward woman's roles have begun to shift away from the more traditional role expectations, it has become more difficult to predict which factors are most influential on sex-role attitudes and behavior. At one time certain antecedent factors (e.g., socio-economic background, birth order, type of parental model, identification with parents) as well as certain proximate factors (e.g., marital status, educational level) had some direct value for predicting role attitudes and career choices. Since 1955 the usefulness of antecedent and proximate factors for predicting role attitudes and behavior seems to depend partly on more elaborate conceptualization and measurement of the variables.

One possible way to interpret the results of my study is that the redefinition of sex roles appears to have 
affected how American, white women in TW careers, more than women in NTW careers, think about their own careers. The role redefinition appears to have given women, regardless of their particular career choices or role-orientations, an opportunity to be more assertive and demanding, less passive and compliant. It does not seem logical to argue that if women are, in fact, "liberated" they will embark, en masse, into fields previously reserved for "men only." It is also important to remember that many women chose their careers or jobs before receiving support for other alternatives. If these two considerations are valid, it follows that changes in attitudes about woman's roles is as possible and logical for women in TW careers as for women in NTW careers.

One possible implication of the interpretation, above, is where the change in attitudes toward woman's roles may be occurring. I suggest that woman's roles may be in the process of being remade from within career choices and that attitudes toward roles are shifting towards a generally more egalitarian or androgynous orientation for both men and women. The changes in role attitudes may be more noticeable among women in TW careers than NTW careers for two reasons. One is that the women in TW careers may feel freer to adopt new attitudes because of opportunities for feelings of solidarity among and support from the majority of their career group, i.e., other women. The second reason pertains 
to one implicit bias in sex role research. That is that women in TW careers are not expected to have views which differ from the stereotypic role attitudes which are assumed inherent in their choosing a TW career. Women in NTW careers, on the other hand, have to deal with the social pressure of a hostile majority (the men in that career). Consequently, some women in NTW careers such as medicine may not feel so confident about adopting new role attitudes. Their feelings of confusion or ambivalence, which I am suggesting, are reconcilable with the general finding that NTW verbally support new role attitudes. Women in NTW are expected to "be different" from women in TW careers and role attitudes reflect one aspect of that expectation. In my study, the results obtained with the women in medical school might be explained by viewing their AWR scores as a reflection of some feelings of uncertainty about "appropriate" role behaviors because of daily confrontation with conservative men (physicians and fellow students) in a conservative tradition (medicine).

Perhaps the results of my study might also be interpreted as suggesting that the impact of the women's movement may be becoming more evident among college students. A recent study (Iunneborg and Rosenwood, 1972) seems to offer some evidence in support of this interpretation. Their study was done to replicate the findings of a previous brief projective survey among undergraduate college women 
(Bardwick, 1971). The expectation in the replication study was that the traditional stereotypes of affiliative females and achievement-oriented males would not be as strong today, because of the current upheaval of sex-typed behaviors. Thus, males today might be more humanistic (affiliative) and women would show the influence of the women's movement which stresses striving, working and studying. Their sample. consisted of 279 men and 186 women college students. Four chi-square tests of differences between the sexes were done for the two needs (affiliation, achievement) under two experimental conditions (happy, sad/angry). Only one of the four tests reached significance $(p<.01$, affiliationhappy). Where the results of the tests were not significant, the sex differences found were in line with traditional expectations for greater affiliation motives in college women and greater achievement motives in college men. However, the authors commented that the strength of these tendencies were a far cry from the extreme findings in the previous study (Bardwick, 1971). The authors concluded that sex stereotypes in relation to affiliation and achievement needs are changing among both male and female college students.

IV. SUIMIMARY AND CONCLUSIONS

The present study was done to explore two general questions of interest. One question was: How do American, 
white college women view their roles? In an effort to answer this question, three research hypotheses were formulated in terms of some direct relationships among the major variables in my study, i.e.,: 1) attitudes toward woman's roles, 2) perceptions of the attitudes of significant others (mother, father, husband/consort, close friend), and 3) career choices. The second question was: Do women who are purusing NTW occupations (i.e., representing a more deviant choice) have greater social support for that choice? Social support was defined by antecedent, background and proximate factors. A related question was: Do aspects of a woman's personal history remain the principal determinants of her role attitudes and behavior, particularly career choice, as an adult? Previous research findings, mainly based on data collected prior to 1969, indicated that personal factors had precedence over current situational factors as determinants of women's role attitudes and behavior. Due to the basically exploratory purpose of the second question, the research questions of interest were termed supplementary questions, i.e., specific hypotheses were not formulated. The sample for analyses ( $N=96)$ consisted of American, white, graduate student women from intact homes who were between the ages of 21 and 45 years.

\section{Results}

With reference to the first question, cited above, 
the findings indicated that neither the women's own attitudes toward woman's roles, nor their perceptions of the attitudes of the significant others chosen for this study, served as a predictor of the career choices (TW, NTW) of the women. As many women who were pursuing TW careers as NTW careers expressed a preference for androgynous rather than dichotomous (sex segregated) roles. Similarly, the two CC groups were not found to differ in their perceptions of the attitudes of the significant others. Women pursuing TW careers did not necessarily perceive their significant others preferring dichotomous roles, and women pursuing NTW careers did not necessarily perceive their significant others preferring androgynous roles. For the sample as a whole, as predicted, the women's own attitudes were found to be more congruent with the perceived views of husband/ consort and those of close friend than with the perceived views of mother and those of father.

With reference to the second question, cited previously, the findings did not suggest that women pursuing NTW careers had more social support for their more deviant choice. There did not appear to be any differences between the two CC groups for the variables selected as indicators of social support, i.e., 1) maternal role model, 2) expressed identification with parents, 3) current importance of the relations with each significant other and 4) perceptions of the attitudes of significant others toward woman's roles. There 
also did not appear to be any differences between the two CC groups for selected characteristics of personal history, i.e., 1) the educational and occupational status of mother and father, 2) perceptions of the parents' relationship, and 3) perceptions of the overall satisfaction of mother and father with their lives. The findings are only suggestive because of the exploratory purpose of the research question. Previous related research had not established clear expectations of predictions for the variables used, but had suggested their potential usefulness for the questions of interest in my study.

Two factors seemed to account for some findings in my study which differed from some previous related research. One factor was the educational level of the sample used (i.e., unlike earlier studies, all $\underline{S} s$ in my study were currently enrolled in professional or Ph.D. programs). The second factor was the passage of time (i.e., most previous studies were done before 1969). It seemed that, in general, the findings might be interpreted as reflecting the recent social, economic and political changes in the culture which are likely to affect how college women view their roles, particularly if they are American, white women from the middle and upper-middle classes. The findings might also be interpreted as reflecting the impact of the women's movement which not only served as a motivating force for re-examining and redefining sex roles in the 
culture, but also provided external support for doing so, whether or not women consciously used that support.

\section{Future Research}

The following suggestions for future research are made in view of the results of my study and the findings of other studies.

In general, it seems important to pursue the question of the function, in the culture and the individual, of discriminatory sex-role prescriptions as well as the psychological consequences of such prescriptions. Iongitudinal studies will probably be of value for furthering our understanding of the personal dynamics which may be involved. However, longitudinal studies require considerable resources and time. Short-term studies could be valuable for focusing on current conditions in order to facilitate the attitudinal and behavioral changes which are professed to be important.

In particular, I would like to suggest two considerations for future research.

Elimination of Cultural Bias. It would certainly be of some value if researchers were able to avoid cultural bias in their own studies. A re-examination of concepts, terminology, instruments and how research questions are formulated might be useful in this regard. If some of the implicit operating assumptions were made more explicit, perhaps there would be less likelihood of substituting one 
rigid prescription for another.

In addition, what would be the consequences of thinking of criteria for defining levels of aspiration in terms other than amount of higher education? Perhaps some consideration of lateral networks of roles rather than vertical hierarchies would be useful for finding the variety of ways in which both men and women meaningfully invest time and energy.

External Support. A continuing concern should be with the conditions which maintain the psychological barriers against women in the field, whether in school or at work. These barriers may be quite overt (e.g., sex-based discriminatory practices) or covert (e.g., personal interactions). I am suggesting that attention be paid to the context in which women are being trained and in which they work. In the process of doing my study it occurred to me that women in the TW and NTW career choice groups might have expressed similar attitudes toward woman's roles, but that these same attitudes might have a different meaning for the women due to possible differences in attitudetesting experiences among the particular training situations. For example, in fields such as social work, nursing and education where women are in the majority, there may be feelings of solidarity between faculty and students. ${ }^{11}$ In

$11_{\text {There }}$ is some evidence to question the assumption that because there are more women than men in a given field (e.g., nursing) there are likely to be feelings of solidarity among the women (Kushner, 1973). 
fields such as medicine, for example, the feelings of solidarity for women may not extend to male faculty and students. In my study there seemed to be some indication of greater sensitivity to and defensiveness about the subject of role concepts among the women medical students than for the other women (non-medical doctoral candidates and professional degree students) sampled.

Besides the importance of understanding the different systems of external support which arise in contexts where women are engaged, there is another reason why external support should be an important concern. It does appear possible for "structured inequality" or the limitations of a woman's personal history to be overcome to some degree in the personal domain if they are not maintained in the external domain. Although the "nonconscious ideology" in the culture is becoming more explicit, it appears that many people within the professions, where initiation of change is anticipated, are able to avoid confronting their own prejudices and thereby withhold an important source of external support for career-aspiring women.

A question of interest is: Is there a battle within the sexes which also maintains psychological barriers against women in the fleld? To date, the research on sex roles and topics related to sex roles has focused on the battle between the sexes. This focus is undoubtedly meaningful for understanding certain relations between women's 
role attitudes and their career choices. However, investigation of same-sex relations may provide additional insight into external sources of support and sabotage for women. A group of researchers have recently identified "the Queen Bee syndrome" found in successful career women who strive to keep other women down (Staines, Tavris, and Jayaratne, 1973). The authors comment that the barrier effect of these women may be expected to diminish as more women hold high positions. However, the question has not been investigated, apparently because it has been overlooked rather than because it may not be relevant.

Another question of interest concerns the role of guilt in the relation between women's role attitudes and behaviors. Others have suggested that internal psychological barriers to achievement may remain for women not only because they have been socialized to accept traditional role behavior, but also because they have been socialized to feel guilty if they want to do for or think of themselves (Bergquist, 1973; Kushner, 1973). In other words, they have learned to feel that their appropriate place is last. The guilt feelings which women have to overcome are distinct from and yet may be difficult to separate out from feelings which tend to arouse the "motive to avoid success"--anticipated rejection.

In summary, Helson (1972) has commented that the problem women face is personal and institutional. One 
major problem for future research, in my view, is to separate the personal components from the institutional ones. I have suggested two points which might be of value for dealing with this problem. One is to minimize cultural bias in future studies. The other is to attend more closely to the context in which women and men are trained and work, and to consider same-sex relations together with other-sex relations. 
IIST OF REFERENCES

American Psychological Association, Task Force. Report of the task force on the status of women in psychology. American Psychologist, 1973, 28, 611-616.

Ashcraft, R. J. Comparison of employment status of men and women physical educators in four year public college and universities. (Doctoral dissertation, University of Iowa) Ann Arbor, Mich.: University Microfilms, 1972, No. 72-17, 534 .

Astin, H. S. The woman doctorate in America. Hartford, Conn.: Russell Sage Foundation, 1969.

Astin, H. S. and Bayer, A. E. Sex discrimination in academe. Educational Record. Spring 1972, 101-118.

Bachtold, I. M. and Werner, E. E. Personality profiles of gifted women: Psychologists. American Psychologist, $1970,25,234-243$.

$x$ Bailyn, I. Notes on the role of choice in the psychology of professional women. Daedalus, 1964, 23, 700-710. (Also in R. J. Iifton (Ed.), The woman in America. Boston: Houghton Mifflin, 1965).

Bailyn, I. Career and family orientations of husbands and wives in relation to marital happiness. Human Relations, 1970, 23, 97-114. (Also in J. M. Bardwick (Ed.), Readings on the psychology of women. New York: Harper and Row, 1972).

Bakan, D. The duality of human existence. Chicago: Rand McNaliy, 1966.

X Bardwick, J. M. Psychology of women. New York: Harper and Row, 1971.

$\times$ Baruch, G. Recent research in psychology relevant to the situation of women. Paper presented at the United States Office of Education Institute, Pittsburgh, June 1971. 
Baruch, G. K. Maternal influences upon college women's attitudes toward women and work. Developmental Psychology, 1972, $6,32-37$.

$\times$ Bem, S. I. Psychology looks at sex roles: Where have all the androgynous people gone? Paper presented at the University of California, Ios Angeles Symposium on Women, Ios Angeles, May 1972.

Y Bem, S. I. The measurement of psychological androgyny. Journal of Consulting and Clinical Psychologi, in press.

$\times$ Bem, S. I. and Bem, D. J. Case study of nonconscious ideology: Training the woman to know her place. In D.J. Bem (Ed.), Beliefs, attitudes and human affairs. Belmont, Calif.: Brooks/Cole, 1970.

×Bergquist, I. Recycling lives. Ms., 1973, 2 (2), 59-61, 104-105.

Block, J., von der Iippe, A., and Block, J. H. Sex-role and socialization patterns: Some personality concomitants and environmental antecedents. Journal of Counseling and Clinical Psychology, in press.

xBlock, J.H. Conceptions of sex role. American Psychologist, 1973, 28, 512-526.

Blumen, J. I. Selected dimensions of self-concept and educational aspiration of married women college graduates. Unpublished doctoral dissertation, Harvard Graduate School of Arts and Sciences, 1970.

Broverman, I. K., Broverman, D. M., Clarkson, F. E., Rosenkrantz, P. S., and Vogel, S. R. Sex-role stereotypes and clinical judgments of mental health. Journal of Consulting and Clinical Psychology, 1970, 34, 1-7.

Broverman, I. K., Vogel, S. R., Broverman, D. M., Clarkson, F. E., and Rosenkrantz, P. S. Sex-role stereotypes: A current appraisal. Journal of Social Issues, 1972 28 (2), 59-79.

Cartwright, I. Women in medical school. Unpublished doctoral dissertation, University of California, Berkeley, 1970.

Cartwright, I. Conscious factors entering into the decisions of women to study medicine. Journal of Social Issues, 1972 , 28 (2), 201-216. 
Clarkson, F. E., Vogel, S. R., Broverman, I. K., Broverman, D. M., and Rosenkrantz, P. S. Family size and sexrole stereotypes. Science, 1970, 167, 390-392.

$X$ Douvan, E. Changing sex roles: Some implications and constraints. Paper presented at the conference at the Radcliffe Institute (Women: Resource for a changing world). Cambridge, April 1972.

Drukman, M. Niedical school diagnosis. Oregon Times, 1973, $3(9), 17-20$.

XEdwards, C. N. Cultural values and role decisions: A study of educated women. Journal of Counseling Psychology, $1969,16,36-40$.

Elman, J., Press, A., and Rosenkrantz, P. Sex roles and self-concepts: Real and ideal. Proceedings of the $78 \mathrm{th}$ Annual Convention of the American Psychological Association, 1970, 5, 455-456. (Summary)

Xepstein, C. F. Sex role stereotyping, occupations and social exchange. Paper presented at the conference at the Radcliffe Institute (Women: Resource for a changing world). Cambridge, April 1972.

Erikson, E. H. Concluding remarks. In J. A. Mattfeld and C. G. Van Aken (Eds.), Women and the scientific professions. Cambridge: M.I.T. Press, 1965.

Fand, A. B. Sex-role and sex concept: A study of the feminine sex role as perceived by 85 college women for themselves, their ideal woman, the average woman and men's ideal woman. Unpublished doctoral dissertation, Cornell University, 1955.

Fecher, A. A. R. Career patterns of women in college and university administration. (Doctoral dissertation, Indiana University) Ann Arbor, Mich.: University Microfilms, 1972, No. 73-10, 765 .

Feldman, S. D. Escape from the doll's house: Women in graduate and professional school education. (Doctoral dissertation, University of Washington) Ann Arbor, Mich.: University Microfilms, 1972, No. 72-28, 596. .

X Ferber, M. A., and Loeb, J.W. Performance, rewards, and perceptions of sex discrimination among male and female faculty. American Journal of Sociology, 1973, 78, 995-1002. (Also in J. Huber (Ed.), Changing women in a changing society. Chicago: University of Chicago Press, 1973). 
X Fogarty, M. P., Rapoport, R., and Rapoport, R. N. Sex, career and family. London: Allen and Unwin, 1971.

Frieden, B. The feminine mystique. New York: Dell, 1963.

$X$ Ginzburg, E. Iife styles of educated women. New York:

Columbia University Press, 1966.

XGump, J. P. Sex-role attitudes and psychological wellbeing. Journal of Social Issues, 1972, 28 (2), 79-92.

$x$ Hawley, P. The relationship of women's perceptions of men's views of the feminine ideal to career choice. (USHEW, OE Final Report) Bethesda, Md.: ERIC Document Reproduction Service, 1970, No. CG 006111.

xHawley, P. What women think men think: Does it affect her career choice? Journal of Counseling Psychology, $1971,18,193-199$.

$x$ Hawley, P. Perceptions of male models of femininity related to career choice. Journal of Counseling Psychology, $1972,19,308-313$.

Helson, R. Women mathematicians and the creative personality. Journal of Consulting and Clinical Psychology, 1971 , 36, 210-220. (Also in J. M. Bardwiok (Ed.), Readings on the psychology of women. New York: Harper and Row, 1972).

$X$ Helson, $R$. The changing image of the career woman. Jourmal of Social Issues, 1972, 28 (2), 33-46.

Hoffman, I. W. Early childhood experiences and women's achievement motives. Journal of Social Issues, 1972, 28 (2), 129-155.

x Hollingshead, A. and Redlich, F. Social Class and Mental Illness. New York: Wiley, 1958. (Also in J.P. Robinson, R. Athanasiou, and K. B. Head (Eds.), Measures of occupational attitudes and occupational characteristics. Ann Arbor, Mich.: Institute for Social Research, 1969).

$x$ Horner, M. S. Sex differences in achievement motivation and performance in competitive and non-competitive situations. (Doctoral dissertation, University of Michigan) Ann Arbor, Mich.: University Microfilms, 1968, No. $69-12,135$. 
$x$ Horner, M. S. The motive to avoid success and changing aspirations of college women. In J. M. Bardwick (Ed.), Readings in the psychology of women. New York: Harper and Row, 1972. (a)

$x$ Horner, M. S. Achievement-related conflicts in women. Journal of Social Issues, 1972, 28 (2), 157-175.

Jensen, J. C. An examination of factors that differentiate male and female doctoral students in career opportunities. (Doctoral dissertation, University of Utah) Ann Arbor, Mich.: University Microfilms, 1972, No. $72-33,295$.

x Julius Guttman, M. A. Is the gray mare only a workhorse? Personnel and Guidance Journal, 1972, 51, 115-121.

$x$ Karman, F. J. Women: Personal and environmental factors in role identification and career choice. (Doctoral dissertation, University of California, Los Angeles) Ann Arbor, Mich.: University Microfilms, 1972, No. $72-25,789$.

Kushner, T. D. The nursing profession: Condition critical. MS, 1973, 2 (2), 72-77, 99-102.

${ }^{x}$ Lancaster, J. B. In praise of the achieving female monkey. Psychology Today, 1973, I (4), 30-36, 99.

Leland, C. A. Women-men-work: Women's carreer aspirations as affected by the male environment. (Doctoral dissertation, Stanford University) Ann Arbor, Mich.: University Microfilms, 1966, No. 67-4394.

x Lipman-Blumen, J. How ideology shapes women's lives. Scientific American, 1972, 22, 34-42. (a)

$x$ Iipman-Blumen, J. The development and impact of female role ideology. Paper presented at the conference at the Radcliffe Institute (Women: Resource for a changing world). Cambridge, April 1972. (b)

Lott, B. E. Who wants the children? American Psychologist, 1973, 28, 573-582.

$X$ Iunneborg, P. W. and Rosenwood, I. M. Need affiliation and achievement: Declining sex differences. Psychological Reports, 1972, 31, 795-798.

X Maccoby, E. E. (Ed.) The development of sex differences. Stanford: Stanford University Press, 1966. (a) 
$x$ Maccoby, E. E. Sex differences in intellectual functioning. In E. E. Maccoby (Ed.), The development of sex differences. Stanford: Stanford University Press, 1966. (b)

McKenzie, S. P. A comparative study of feminine role perceptions, selected personality characteristics, and traditional attitudes of professional women and housewives. (Doctoral dissertation, University of Houston) Ann Arbor, Mich.: University Microfilms, 1971, No. $72-4117$.

Millman, M. Observations on sex role research. Journal of Marriage and the Family, 1971, 33, 772-776.

Newoomb, T. M. The acquaintance process. New York: Holt, Rinehart and Winston, 1961.

Nowacki, C. M. and Poe, C. A. The concept of mental health as related to sex of person perceived. Journal of Consulting and Clinical Psychology, 1973, 40, 160.

Parsons, T. and Bales, R. F. Family, socialization and interaction process. Glencoe, IIl.: Free Press, 1955.

Porter, J. Sex-role concepts, their relationship to psychological well-being and to future plans in female college students. Unpublished doctoral dissertation, University of Rochester, 1967.

X Rappaport, A. F., Payne, D., and Steinmann, A. Marriage as a factor in the dyadic perception of female sex role. Psychological Reports, 1970, 27, 283-284.

Rosenkrantz, P. S., Vogel, S. R., Bee, H., Broverman, I. K., and Broverman, D. M. Sex-role stereotypes and selfconcepts in college students. Journal of Consulting and Clinical Psychology, 1968, 32, 287-295.

$X$ Rossi, A. S. Equality between the sexes. Daedalus, 1964, 23, 607-652. (Also in R. J. Iifton (Ed.), The woman in America. Boston: Houghton Mifflin, 1965).

KRossi, A. S. Barriers to the career choice of engineering, medicine, or science among American women. In J. A. Mattfield and C. G. van Aken (Eds.), Women and the scientific professions. Cambridge: M.I.T. Press, 1965.

Schwenn, M. Arousal of the motive to avoid success. Unpublished junior honors paper, Harvard University, 1970. 
Sells, I. W. Sex and discipline differences in doctoral attrition. (Doctoral dissertation in progress, University of California, Berkeley). In C. S. Weisman (Ed.), Current research on sex roles. (3rd ed.). Baltimore: Sociologists for Women in Society, 1973.

Solomon, I. D. Female doctoral chemists: Sexual discrepancies in career patterns. (Doctoral dissertation, Cornell University) Ann Arbor, Mich.: University Microfilms, 1972, No. 73-360.

X Staines, G. I., Tavris, C., and Jayaratne, T. E. The queen bee syndrome. 'In C. Tavris (Ed.j), The female experience. Del Mar, Calif.: C.R.M., Inc., 1973.

Steinmann, A. A study of the concept of feminine role of 51 middle class American families. Genetic Psychological Monographs, 1963, 67, 275-352.

X Steinmann, A. and Fox, D. J. Male-female perceptions of the female role in the United States. Journal of Psychology, 1966, 64, 265-276.

XSteinmann, A., Fox, D. J., and Farkas, R. Male and female perceptions of male sex roles. Proceedings of the $76 \mathrm{th}$ Annual Convention of the American Psychological Association, 1968, 3, 421-422. (Summary)

Steinmann, A., Levi, J., and Fox, D. J. Self-concept of college women compared with their concept of ideal woman and man's ideal woman. Journal of Counseling Psychology, 1964, 11, 370-374.

Strong, C. R. A study of attitudes toward the selection of women faculty in collegiate schools of business in the Southeastern U.S.A. (Doctoral dissertation, University of Alabama) Ann Arbor, Mich.: University Microfilms; 1972, No. 72-33, 136.

$X$ Tangri, $S$. Role-innovation in occupational choice. UnpubIished doctoral dissertation, University of Michigan, 1969 .

Tangri, S. S. Occupational role innovation among women. Journal of Social Issues, 1972, 28 (2), 177-200.

Tipple, M. E. Sexual discrimination: Attitudes toward the hireability of women for professional administrative positions in public education. (Doctoral dissertation, University of Michigan) Ann Arbor, Mich.: University Microfilms, 1972, No. 73-11, 277. 
YTresemer, D. Fear of success: Popular but unproven. In C. Tavris (Ed.), The female experience. Del Mar, Calif.: C.R.M., Inc., 1973.

$X$ Tresemer, D. and Pleck, J. Maintaining and changing sexrole boundaries in men (and women). Paper presented at the conference at the Radcliffe Institute (Women: Resource for a changing world). Cambridge, April 1972 .

Vogel, S. R., Broverman, I. K., Broverman, D. M., Clarkson, F. E., and Rosenkrantz, P. S. Maternal employment and perception of sex-roles among college students. Developmental Psychology, 1970, 3, 384-391.

$x$ Westervelt, E. M. A tide in the affairs of women: The psychological impact of feminism on educated women. Counseling Psychologist, 1973, 4, 3-26.

Wolkon, K. A. Pioneer vs traditional: Two distinct vocational patterns of college alumnae. Journal of Vocational Behavior, 1972, 2, 275-282.

XZiebarth, C. A. M. Feminine role conflict: The influence of models and expectations of others. (Doctoral dissertation, University of Colorado) Ann Arbor, Mich.: University Microfilms, 1970, No. 71-21, 637. 
APPENDIX A

IEPTER FOR RECRUITING SUBJECTS

FOR MAIN STUDY

\title{
ADDITIONAI INSTRUCTIONS FOR CONPIETING THE QUESTIONNAIRE AT HOIE (MAIN STUDY AND \\ RELIABILITY STUDY)
}

\author{
ADDIPIONAI INSTRUCTIONS FOR REIIABIIITY \\ STUDY (RETEST)
}


PORTIAND STATE UNIVERSITY

P.0. Box 751

Portland, Oregon 97207

Department of Psychology 317 Cramer Hall

April 16, 1973

WOMAN'S ROLES STUDY

Dear graduate student:

I am doing a study on current attitudes toward woman's roles for my master's thesis in psychology at Portland State University. I am asking for the cooperation of women who are currently enrolled in professional degree programs at Portland State University and the University of Oregon Medical and Nursing Schools. I would appreciate your cooperation since little is known about women graduate students. Studies, to date, have focused on undergraduates, college graduates, and women who have completed graduate work.

A questionnaire taking approximately 60 minutes to fill out has been prepared. Most questions can be answered with a check. It is necessary, however, for the form to be completed ON CAMPUS. I will set up different group meeting times, between MONDAY MAY 14 th and FRIDAY MAY 25th, so that everyone can participate.

A note on confidentiality--no one will ever see any information that could identify you.

I MUST DEPEND UPON YOUR COOPERATION to collect this data and I would very much appreciate any help you could give me. If you can help, please complete the following so that I can contact you about the group meeting times.

1. NANE

2. TELEPHONE (or address if no telephone

3. Please check AII of the following times you could meet: 


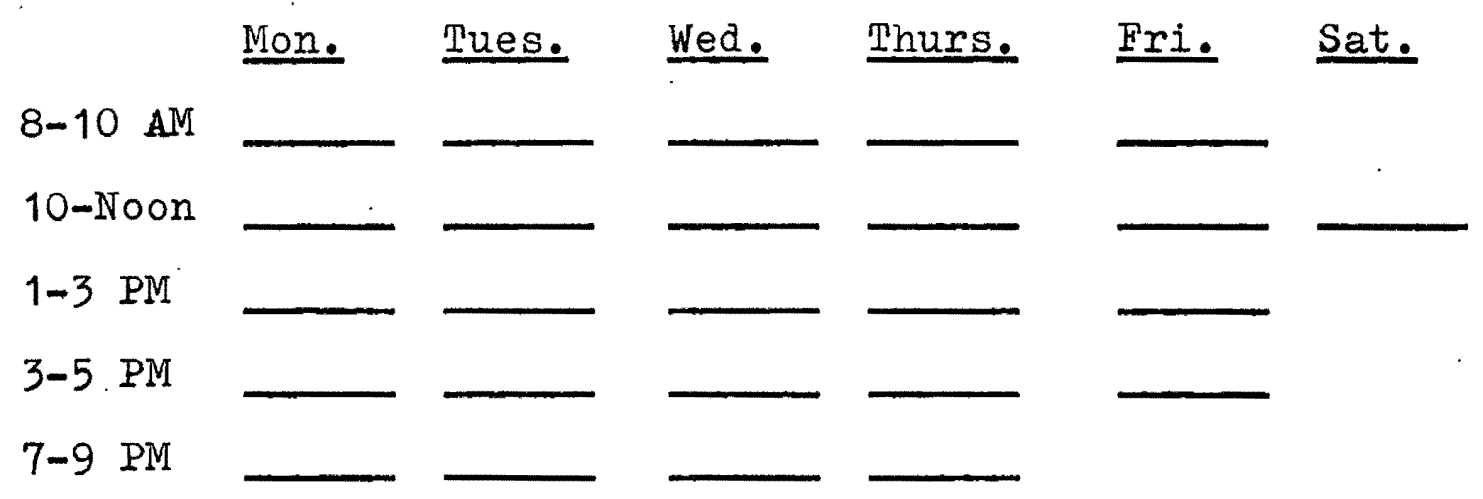

Thank you very much for your cooperation. Sincerely,

Barbara Backstrand

P.S. PIease put COMPIEIED FORMS in envelope marked, "BACKSTRAND," in YOUR MAILROOM. 
Form for Main Study

Woman's Roles Study

Portland State University

Portland, Oregon

ADDITIONAL INSTRUCPIONS FOR COMPIETING THE QUESTIONNAIRE AT HOME:

1. Please be sure to fill out the questionnaire by yourself. Do not consult with anyone else. There are no right or wrong answers.

2. It is not expected to take more than 60 minutes to complete the questionnaire.

3. Do not look ahead in the questionnaire. Please answer the questions in the order they are given.

4. Please mail the complete questionnaire in the enclosed envelope.

Thank you very much.

Barbara Backstrand

Department of Psychology

Portland State University 
Form for Reliability Study

Woman's Roles Study

Portland State University

Portland, Oregon

INSTRUCTIONS FOR CONPIETING THE QUESTIONNAIRE AT HOME:

1. Please be sure to fill out the questionnaire by yourself. Do not consult with anyone else. There are no right or wrong answers.

2. It is not expected to take more than 60 minutes to complete the questionnaire.

3. Do not look ahead in the questionnaire. Please answer the questions in the order they are given.

4. CODE ID NO.:

Please make a record of this number. In one month's time I will ask you to fill out a second questionnaire. In order to be able to use the results from both forms, I must be able to match the two questionnaires you have completed. The information contained in the questionnaires is completely CONFIDENTIAI. No one will EVER see any information that could identify you.

Thank you very much for your help.

Barbara Backstrand

Department of Psychology

Portland State University 
Form for Reliability Study--Retest

Woman's Roles Study

CODE ID NO.

Portland State University

Portland, Oregon

Dear participant:

You have already filled out and returned one questionnaire which asked for some background information and your own opinions and attitudes. IN ORDER TO USE THE RESULTS OF THAT QUESTIONNAIRE, I must ask that you fill out and return the attached questionnaire. Please put the completed questionnaire in my box in Room 317, Cramer Hall, NO LATER THAN

If you are interested in receiving the results of this study, please put your name and address on the enclosed index card. Please put the card in my box, as above. I hope to have the results by Fall, 1973.

REMINDERS FOR CONPIETING THE QUESTIONNAIRE:

1. THIS IS NOT A TEST. THERE ARE NO RIGHT OR WRONG ANSWERS.

2. Please be sure to fill out the questionnaire by yourself. Do not consult with anyone else.

3. DO NOT IOOK AHEAD IN THE QUESTIONNAIRE. Please answer the questions in the order they are given.

4. Please be frank with your answers. NO ONE WILI EVER SEE ANY INFORMATION THAT COULD IDENTIFY YOU. DO NOT PUT YOUR NAME ON THIS QUESTIONNAIRE.

Thank you very much for your help.

Barbara Backstrand

Department of Psychology

Portland State University 


\section{APPENDIX B}

QUESTIONNAIRE (WITH SCORING KEY) AND ADDITIONAL NOTES FOR SCORING AND CODING 
Woman's Roles Study

Portland State University

Portland, Oregon

DO NOT PUT YOUR NAIE ON THIS QUESTIONNAIRE.

THIS IS NOT A TEST. THERE ARE NO RIGHT OR WRONG ANSWERS. We ask only for some background information and your own opinions and attitudes.

Most of the questions can be answered with an ( $X$ ) next to the category that applies to you. Some of the questions, however, have more complicated instructions. Please read the instructions at the beginning of each section.

Please be frank with your answers. No one will ever see any information that could identify you.

Your cooperation is greatly appreciated. It will provide some valuable insights into the way women see their roles today.

Thank you very much.

Barbara Backstrand

Department of Psychology

Portland State University

BEFORE YOU BEGIN, I would like to know if you are in my sample. Did you live with the same set of parents most of the time you were growing up--until you completed high school? Yes No. If "No," STOP and do not complete the questionnaire. 


\section{$\underline{\text { PART I }}$}

First, I would like to know some things about your school and career plans.

1. How old were you on your last birthday? (--) years old.

2. What is your field of interest in graduate school? ("O" for TW: "1" NTW.)

3. What degree will you get when you complete the program? (See Note 3.)

4. What do you plan to do after you get your degree? For example, "teaching in a university." Please explain what your activity will be and check which ONE of the following will be the likely place of employment?

self-employed: private practice
self-employed: group practice
government agency
private agency
clinic or hospital
school or university
business or industry
something else: (For example: "no plans to work.")

(See Note 4.)

5. What is your CURRENT marital status?

(1) single (never married, divorced or widowed) and living alone

(2) single (never married, divorced or widowed) and living in marriage-like relationship

(3) remarried after divorce

(continued) 
5. (continued)

(3) remarried after widowed

(4) married and living with my husband

(5) separated and living alone

(6) separated and living in marriage-like relationship

(5) divorced and living alone

(6) divorced and living in marriage-like relationship

(5) widowed and living alone

(6) widowed and living in marriage-like relationship

(7) something else: (For example: "married and NOT living with my husband but in marriage-like relationship with someone else.") Please explain:

(9) NA

6. How long have you been living in the situation checked above? months or years. (See Note 6.)

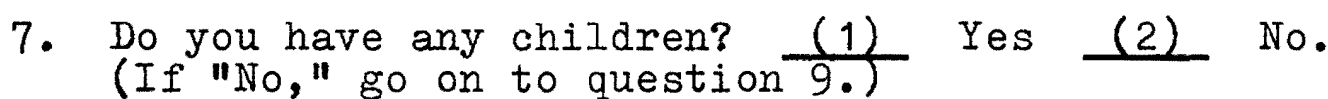

8. Please list the ages of the children now living with you, to their nearest birthdays. Begin with the youngest: (See Note 8)

9. Many women say that their long-term plans for working depend upon whether there are children at home. If you now have any children at home, or if you expect to have children at a future time, please check ONE of the following which comes closest to your feelings about work plans:

(1) I never intend to work if I have children.

(2) I intend to work more or less continuously but not until my children have completed high school.

(3) I intend to work more or less continuously but not until my children have completed junior high school.

(continued) 
9. (continued)

(4) I intend to work more or less continuously but not until my children have completed grade school.

(5) I intend to work more or less continuously but not until my children are grade school age.

(6) I intend to work more or less continuously but not until my children are pre-school age.

(7) I intend to work when I want to, regardless of the ages of children at home.

(8) I do not plan to have children.

(9): NA

Now, I would like to know some things about your mother, father, husband/consort and a close friend.

Please answer the following questions about MOTHER, thinking about the person you lived with most of the time you were growing up--until you completed high school.

10. What is your MOTHER'S age, to her nearest birthday? years old OR is deceased___. If deceased, for how long? months OR years. (See Note 10.)

11. If both parents are still alive, but have been divorced since the time you were living with them please check here (See Note 11).

12. Please check the highest number of years of school your MOTHER completed:

Elementary

High School

Some college

College graduate

Postgraduate degree

Other:

(See Note 12.)

(continued) 
13. What was your MOTHER'S PRINCIPAI OCCUPATION while you were growing up? Please describe, including job title, employer, and principal duties. (For example: "elementary school teacher working in public school, responsible for third grade curricuium.") (See Note 13.)

14. How many years did your MOTHER work outside the home while there were children at home? mother did not work. (See Note 14.) years OR

15. Is your mother CURRENTIY working outside the home? (1) Yes (2) No. (If "No," go on to question 17.)

16. What is your MOTHER'S PRINCIPAI OCCUPATION NOW? Please describe, including job title, employer, and principal duties ("2" or "3," see question 13; "g": NA).

17. When you were growing up, which activities did your MOTHER spend MOST of her time doing? Please rank the TOP THREE, according to those activities which your MOTHER spent most of her time doing.

Put a "1" by the item which indicates the activity your MOTHER spent the MOST time doing.

Put a "2" by the item which indicates the activity your MOTHER spent the next most amount of time doing.

Put a "3" by the item which indicates the activity your MOTHER spent the next most amount of time doing.

(3) part-time work

(3) full-time work

(1) child care

(1) housework

(2) voluntary associations, for local, national or international affairs

(2) self-expressive activities, such as painting, music, language, etc.

(2) religious or social groups

(continued) 
17. (continued)

(2) sports

(See Note 17.)

Please answer the following questions about FATHER, thinking about the person you lived with most of the time you were growing up--until you completed high school.

18. What is your FATHER'S age, to his nearest birthday? years old OR is deceased how long? months or years.

(See Note 18.)

19. Please check the highest number of years of school your FATHER completed:

Elementary

High school

Some college

College graduate

Postgraduate degree

Other:

(See Note 19.)

20. What was your FATHER'S PRINCIPAL OCCUPATION while you were growing up? Please describe, including job title, employer and principal duties.

OR DOING SOMETHING ELSE?

Other:

(See Note 20.)

Please answer the following questions about MATE, thinking about the person you are CURRENTIY living with, whether in a marriage or marriage-like relationship. (If you are NOT CURRENTIY living with a husband/consort, go on to question 24.)

(continued) 
21. What is your MATE'S age, to his/her nearest birthday? years old. (See Note 21.)

22. Please check the highest number of years of school your mate completed:

Elementary

High school

Some college

College graduate

Postgraduate degree

Other:

(See Note 22.)

23. What is your MATE'S CURRENT PRINCIPAI OCCUPATION? Please describe, including job title, employer and principal duties.

OR DOING SOMETHING ELSE?

student

other:

(See Note 23.)

Please answer the following questions about CLOSE FRIEND, thinking about a person you CURRENTIY confide in, regardiess of where the person lives or how often you talk to the person. The person must be someone OTHER than your parents or current mate. (If there is no one whom you CURRENTIY consider to be a close friend, go on to Question 28.)

Please answer ALI parts of the following question.

24. Is your CLOSE FRIEND,
a.
a man
(1) or woman
(2) ?
(9): NA
b. a family relation?
(3) Yes (4) No.
(9): NA
c. CURRENTLY living consort (6)
alone (9): $\overline{\mathrm{NA}}$
(5) or with husband/
(continued) 
24. (continued)

(Code "o" for parts $a, b$, c if no close friend.)

25. What is your CLOSE FRIEND'S age to his/her nearest birthday? $(--)$ years old.

(Code "Oo" if no close friend. Code "99": NA.)

26. Please check the highest number of years of school your CLOSE FRIEIND has completed: (See Note 12. Code "g" if no close friend or NA.)

Elementary

High school

Some college

College graduate

Postgraduate degree

Other:

27. What is your CLOSE FRIEND'S CURRENT PRINCIPAI OCCUPATION? Please describe, including job title, employer and principal duties.

OR DOING SOMETHING ELSE:

student

other:

(See Note 27.)

Now, think about YOUR MOTHER and answer the following questions. (If your mother is now deceased, answer about the time immediately prior to her death.)

28. How would you CURRENTLY rate your MOTHER'S overall satisfaction with her life?

(1) not at all satisfied

(2) slightly satisfied

(continued) 
28. (continued)

(3) moderately satisfied

(4) very satisfied

29. In your view, does your MOTHER'S overall satisfaction have anything to do with working outside the home? (1) Yes (2) No. (9): NA. Please check ONE of the following items which comes closest to describing your MOTHER'S feelings about work:

(1) she wanted to work and did

(2) she wanted to work and didn't

(3) she didn't want to work and did

(4) she didn't want to work and didn't

30. Most people are satisfied for different reasons. FIRST, read the following list and indicate with an (X) ALI items which seemed to be VERY IMPORTANT to your MOTHER. THEN, go back and for ALI items checked, indicate with an (X) how generally SATISFIED or DISSATISFIED she seemed to feel about how things worked out.

VERY INP. SATIS. DISSATIS. I DON'T KNOW

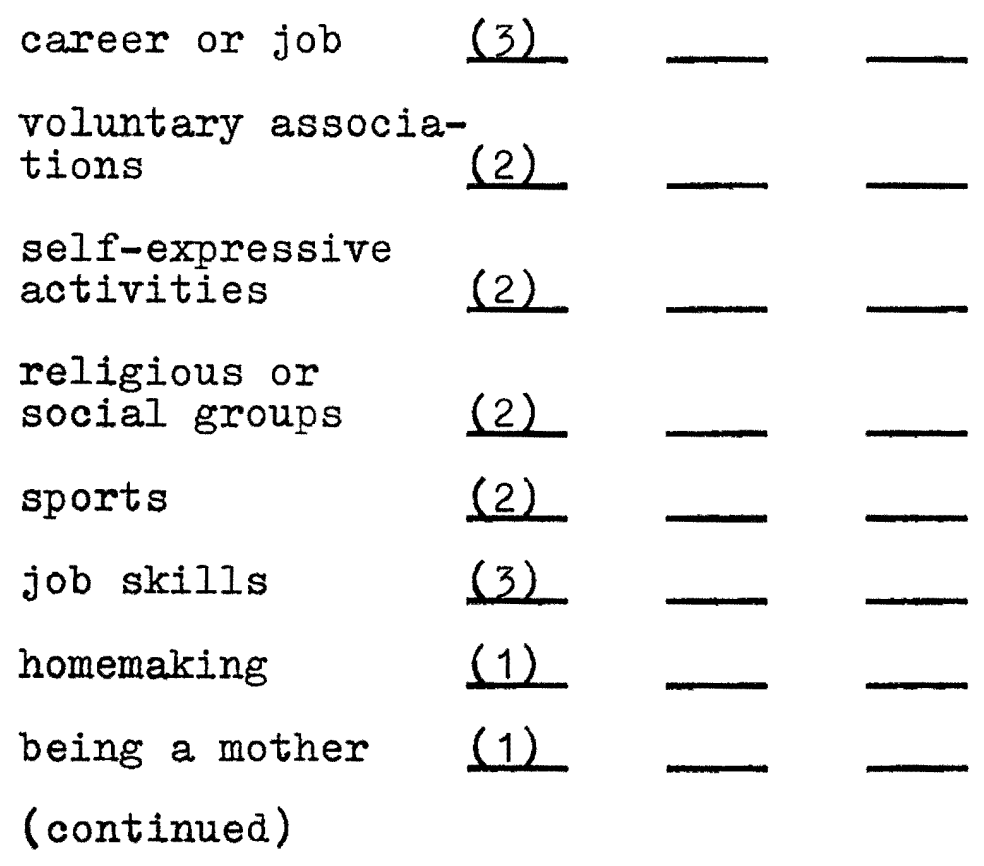


30. (continued) VERY IMP. SATIS. DISSATIS. I DON'T KNOW

relation to

spouse

(1)

relation to

others outside

immediate family (2)

(See Note 30.)

NOW, think about YOUR FATHER and answer the following questions. (If your father is now deceased, answer about the time immediately prior to his death.)

31. How would you CURRENTIY rate your FATHER'S overall satisfaction with his life?

(1) not at all satisfied

(2) slightly satisfied

(3) moderately satisfied

(4) very satisfied

32. FIRST, read the following list and indicate with an (X) AIL items which seemed to be VERY INPORTANT to your FATHER. THEN, go back and for ALI items checked, indicate with an (X) how generally SATISFIED or DISSATISFIED he seemed to feel about how things worked out.

VERY IMP. SATIS. DISSAPIS. I DON'T KNOW

career or job

voluntary associa-

tions

self-expressive

activities

religious or

social groups

sports

(continued) 
32. (continued) VERY INP. SATIS. DISSATIS. I DON'T KNOW job skills

being a father

relation to spouse

relation to

others outside immediate family

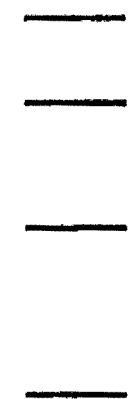

(See Note 32.)

33. In your parents' marriage, what is their relationship to each other like?. (If one or both parents are now deceased, answer about the time immediately prior to death. If your parents are now divorced, answer about the time immediately prior to divorce.)

(1) neither dominant--both in struggle for dominance

(2) father dominant

(3) mother dominant

(4) neither dominant--both freely expressed feelings and shared in decision making

(9): NA or unable to score

Please answer ALL parts of the following question. (If one or both parents are now deceased, answer about the time immediately prior to his/her death.)

34. AT PRESENT, neither father more mother more both equally

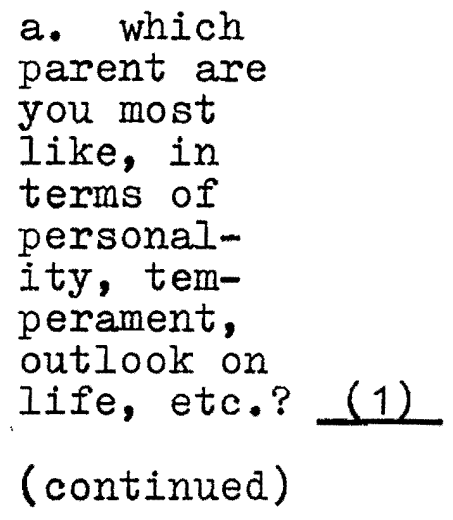


34. (continued) neither father more mother more both equally

b. which

parent comes

closest to

your idea

of an attrac-

tive person?

$(1)$

(2)

(3)

(4)

c. which

parent shows

more understanding of

you?

(1) (2)

(3)

(4)

d. which

parent do

you feel

closest

to?

$(1)$

(2)

(3)

(4)

e. which

parent's

values, in

general, do

you agree

with?

$(1)$

(2)

(3)

(4)

f. which

parent's

career

goals for

you do you

agree with?

(1) (2)

(3)

(4)

(Code "g": NA or unable to score for parts a-f.)

35. How would you rate your CURRENT relationship with the following people? Please answer ALI parts of the question.

(Code "9": NA or unable to score.)

a. MOTHER (If now deceased, answer about the time immediately prior to her death.)

(1) bad

(2) fair

(continued) 
35. (continued)

(3) good
(4) very good

b. FATHER (If now deceased, answer about the time immediately prior to his death.)

(1) bad

(2) fair

(3) good

(4) very good

c. MATE (If you are NOT CURRENTLY living with a husband/consort, go on to part "d".) (Code "O" if no mate.)

(1) bad

(2) fair

(3) good

(4) very good

d. CLOSE FRIEND (If there is no one whom you CURRENTLY consider to be a close friend go on to question 36.) (Code "O" if no close friend.)

(1) bad

(2) fair

(3) good

(4) very good

36. Among the following people, whose opinions about your own behavior are most important to you? Please rank the TOP THREE, according to whose opinion you MOST value about your own plans, activities, etc.

Put a "1" by the item which indicates the person whose opinion you MOST value.

(continued) 
36. (continued)

Put a "2" by the item which indicates the person whose opinion you next most value.

Put a "3" by the item which indicates the person whose opinion you next most value.

mother

father

sister

brother

other relative (such as grandparent, aunt, uncle, in-law, etc.)

Please explain

mate

my $\operatorname{child}(r e n)$

close friend

school faculty

employer

someone else (such as supervisor, minister, counselor, etc.)

Please explain

(See Note 36.)

37. How would you rate your CURRENT feelings of satisfaction with your current relationships with the following people? Please answer ALI parts of the question. (Code "g": NA.)

a. MOTHER (If now deceased, answer about the time immediately prior to her death.)

(1) not at all satisfied

(2) slightly satisfied

(continued) 
37. (continued)

(3) moderately satisfied

(4) very satisfied

b. FATHER (If now deceased, answer about the time immediately prior to his death.)

(1) not at all satisfied

(2) slightly satisfied

(3) moderately satisfied

(4) very satisfied

c. MAIE (If nOW NOT CURRENTLY living with a husband/ consort, go on to part "e".)

(1) not at all satisfied

(2) slightly satisfied

(3) moderately satisfied

(4) very satisfied

d. Most people in school are satisfied with their mates for various reasons. For ALI the following items, please indicate with an (X) how generally SATISFIED or DISSATISFIED you feel about how you and your mate have worked things out.

(Not scored.)

SATISFIED DISSATISFIED DOES NOT APPLY

your school

commitment

your work

plans

house chores

time spent

with children

relation to

each other

(continued) 
37. (continued)

e. CLOSE FRIEND (If there is no one whom you CURRENTIY consider to be a close friend, go on to question 38.)

(Code "O" if no close friend.)

(1) not at all satisfied

(2) slightly satisfied

(3) moderately satisfied

(4) very satisfied

38. Here are some statements which may or may not describe your CURRENT relationships with your father, mother, husband/consort and close friend. Please check ALI' of those items which come closest to describing your CURRENT relationships with the following people. Please answer ALI parts of the question.

a. MOTHER (If now deceased, answer about time immediately prior to her death.)

(0) There are few main subjects of mutual interest.

(1) There are many main subjects of mutual interest.

(0) I only feel free to discuss things outside of intimate personal matters.

(1) I feel free to discuss almost any intimate personal matter.

(1) I am able to express feelings rather fully.

(0) I feel I should hold back most of my feelings.

(1) We usually sense each other's feelings right away.

(0) I feel a certain amount of formality ought to be kept in this relationship.

(continued) 
38. (continued)

(1) I feel free to disagree. I know support would be given in case of need.

( Sum $=$ ).

b. FATHER (If now deceased, answer about time immediately prior to his death.)

(0) There are few main subjects of mutual interest. (1) There axe many main subjects of mutual.

(0) I only feel free to discuss things outside of intimate personal matters.

(1) I feel free to discuss almost any intimate personal matter.

(1) I am able to express feelings rather fully.

(0) I feel I should hold back most of my feelings.

(1) We usually sense each other's feelings right away. (0) I feel a certain amount of formality ought
to be kept in this relationship.

(1) I feel free to disagree. I know support would be given in case of need.

$(\operatorname{sum}=)$.

c. MATE (If you are NOT CURRENTLY living with a husband/ consort go on to part "d".)

(0) There are few main subjects of mutual interest.

(1) There are many main subjects of mutual interest.

(0) I only feel free to discuss things outside of intimate personal matters.

(continued) 
38. (continued)

(1) I feel free to discuss almost any intimate personal matter.

(1) I am able to express feelings rather fully.

(0) I feel I should hold back most of my feelings.

(1) We usually sense each other's feelings right away •

(0) I feel a certain amount of formality ought to be kept in this relationship.

(1) I feel free to disagree. I know support would be given in case of need.

$($ Sum $=)$.

d. CLOSE FRIEND (If there is no one whom you CURRENTLY consider to be a close friend, go on to Part II.)

(0) Where are few main subjects of mutual interest.

(1) There are many main subjects of mutual interest.

(0) I only feel free to discuss things outside of intimate personal matters.

(1) I feel free to discuss almost any intimate personal matter.

(1) I am able to express feelings rather fully.

(0) I feel I should hold back most of my feelings.

(1) We usually sense each other's feelings right away.

(0) I feel a certain amount of formality ought to be kept in this relationship.

(1) I feel free to disagree. I know support would be given in case of need.

$($ Sum $=)$. 


\section{PART II}

People have expressed many different attitudes toward woman's roles and satisfactions. I am interested in YOUR attitudes.

Please answer the questions on the next four pages in terms of your CURRENT views about woman's roles and satisfactions. Please indicate your agreement or disagreement with EACH of the following statements by putting an $(X)$ in the column which comes closest to describing your feelings. (Strongly disagree, mildly disagree, mildly agree, strongly agree or no opinion.) 
(SEE Additional Notes, Part II)

DISAGREE

AGREE

NO

STR'LY MIIDLY STR'IY MILDLY OPINION

1. Marriage and family

give a woman a

sense of identity

and purpose in

Iife which noth-

ing else can.

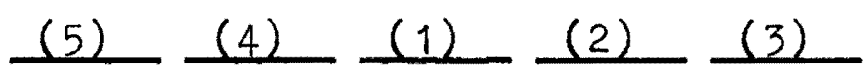

2. A woman should not make more concessions to her mate's wishes than he to hers.

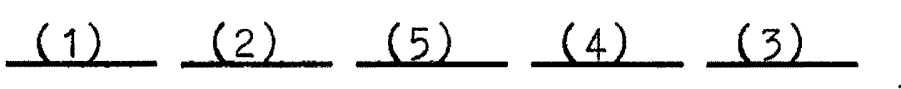

3. The main goal of a woman's life should be the successful rearing of welladjusted children.

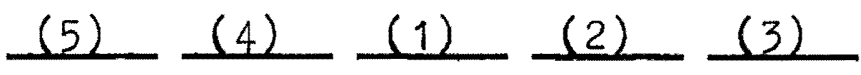

4. Marriage should only be the legitimization of a relationship, not a "career."

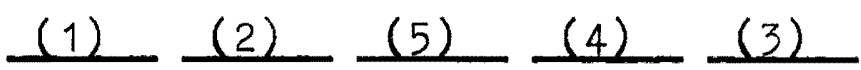

5. It is a woman's job to run the home and look after the children.

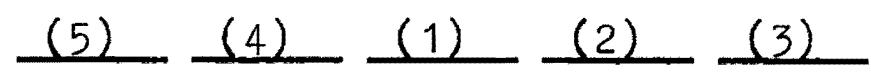

6. Many women, if given important jobs or responsible positions, are likely to fold up or panic under stress.

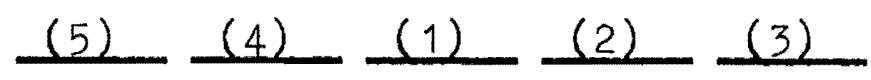

7. Most women can get just as much satisfaction out of a job as most men can.

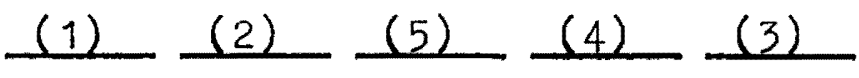

(continued) 
DISAGREE AGREE NO STR'IY MIIDIY STR' IY MIIDLY OPINION

8. A woman ought to try to cultivate the interests of her mate, rather than pursue independent interests and accomplishments on her own.

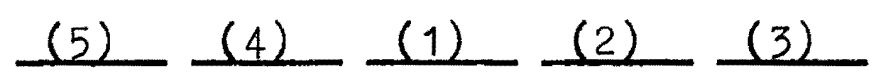

9. Raising children is definitely the most challenging and creative activity a woman can engage in.

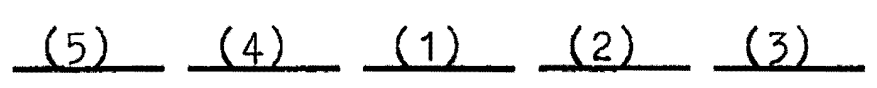

10. Most women need or at least appreciate the personal benefits of having a steady occupation or interest outside of home responsibilities.

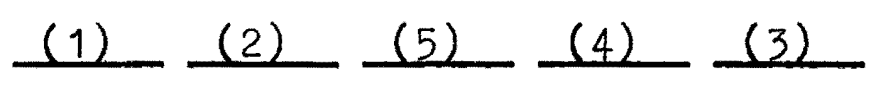

11. A woman should not expect her mate to do woman's work-cooking, laundry, cleaning, childcare.

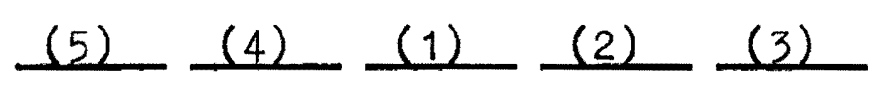

12. Most women are just as capable as men of holding responsible positions or handling important jobs.

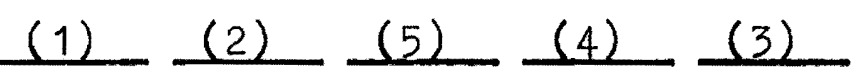

13. The most important thing a woman can do

(continued) 


\section{DISAGREE AGREE NO STR'IY MIIDLY STR'LY MILDLY OPINION}

13. (continued)

to ensure a good relationship with her mate is to be totally supportive of him.

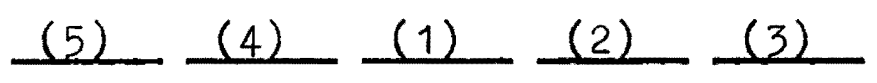

14. Children shouldn't always come first in a woman's life.

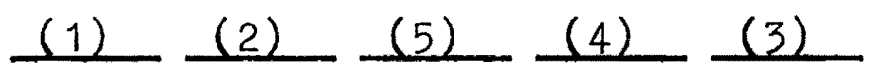

15. A woman who works loses most of the satisfactions from being a full-time wife and mother.

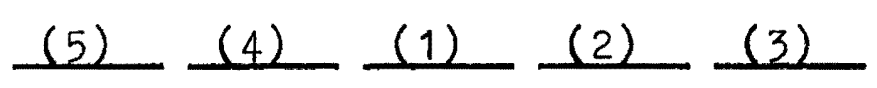

16. A man and woman should share household tasks and childcare according to individual interests and abilities rather than according to "woman's work" and "man's work."

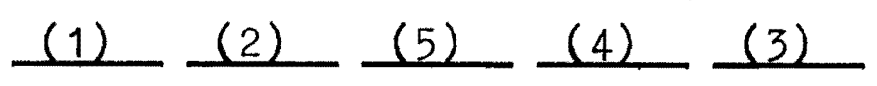

17. When a woman gets interested in a job she is as hardworking and likely to succeed as a man.

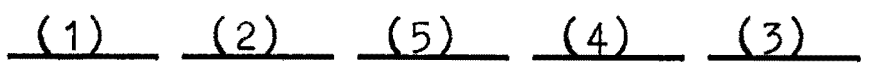

18. Most women do not need the same kind and amount of education as men do. (5) (4) (1) (2) (3)

19. Working often makes a woman more interesting as a person and thus more attractive. (1) (2) (5) (4) (3) (continued) 
DISAGREE

AGREE

NO

ST $\bar{R}^{\prime I Y}$ MIIDLY STR' LY MILDLY OPINION

20. Many professions

are more suited

to a man's abili-

ties than a

woman's.

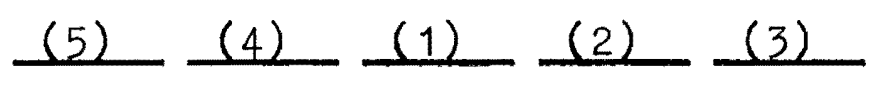

21. A woman who works can be as good a mother as the one who stays at home.

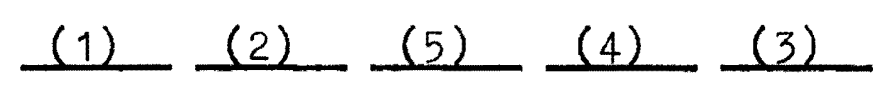

22. Most women do not become as interested as men do in their jobs because they are primarily interested in their families.

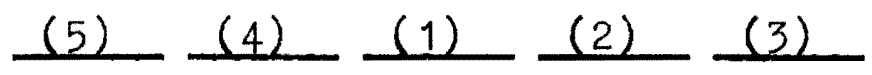

23. A woman's opinion should be as important as her mate's in most decisions.

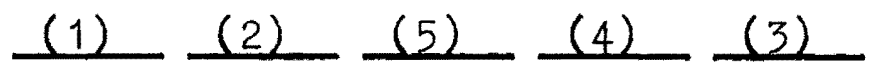

24. It is possible for a woman to handle both home and outside career and do justice to both.

(1) (2) (5) (4) (3)


Now, I would like you to go through the questions on the next four pages and answer them AS IF YOU WERE YOUR CURRENT MATE. That is, answer the questions AS YOU THINK YOUR CURRENT MATE WOUID IF GIVEN THE QUESTIONNAIRE TODAY. (If you are NOT CURRENTIY Iiving with a husband/consort, go on to the next section.)

REMENBER--TRY TO BECONE YOUR CURRENT MATE AND ANSWER THE QUESTIONS AS YOU THINK YOUR MATE WOUID. Respond the way your MATE seems to feel, regardless of what your mate says or does.

Please indicate how you think YOUR MATE would agree or disagree with $\mathrm{EACH}$ OF the following statements by putting an $(\mathrm{X})$ in the column which comes closest to describing how you think YOUR MATE feels. (Strongly disagree, mildly disagree, mildly agree, strongly agree or I don't know.) 


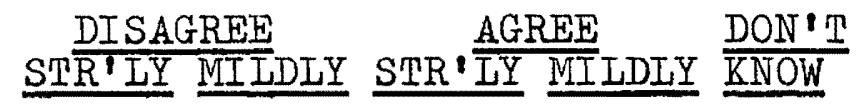

1. Marriage and family give a woman a sense of identity and purpose in life which nothing else can.

2. A woman should not make more concessions to her mate's wishes than he to hers.

3. The main goal of a woman's life should be the successful rearing of welladjusted children.

4. Marriage should only be the legitimization of a relationship, not a "career."

5. It is a woman's job to run the home and look after the children.

6. Many women, if given important jobs or responsible positions, are likely to fold up or panic under stress.

7. Most women can get just as much satisfaction out of a job as most men can.

8. A woman ought to try to cultivate the interests of her mate, rather than pursue independent interests and accomplishments on her own.

(continued) 
DISAGREE STR'IY NILDLY STR' LY MIIDIY

DON'T KNOW

9. Raising children is definitely the most challenging and creative activity a woman can engage in.

10. Most women need or at least appreciate the personal benefits of having a steady occupation or interest outside of home responsibilities.

11. A woman should not expect her mate to do woman's work--cooking, laundry, cleaning, chilacare.

12. Most women are just as capable as men of holding responsible positions or handling important jobs.

13. The most important thing a woman can do to ensure a good relationship with her mate is to be totally supportive of him.

14. Children shouldn't always come first in a woman's life.

15. A woman who works loses most of the satisfactions from

(continued) 


\section{DISAGREE AGREE DON T STR'LY MIIDLY STR'IY MILDLY KNOW}

15. (continued)

being a full-

time wife and

mother.

16. A man and woman should share household tasks and childcare according to individual interests and abilities rather than according to "woman's work" and "man's work."

17. When a woman gets interested in a job she is as hard-working and likely to succeed as a man.

18. Most women do not need the same kind and amount of education as men do.

19. Working often makes a woman more interesting as a person and thus more attractive.

20. Many professions are more suited to a man's abilities than a woman's.

21. A woman who works can be as good a mother as the one who stays home.

(continued) 
DISAGREE STR'LY MIIDLY STR' LY MILDLY

22. Most women do not become as interested as men do in their jobs because they are primarily interested in their families.

23. A woman's opinion should be as important as her mate's in most decisions.

24. It is possible for a woman to handle both home and outside career and do justice to both. 
Now, I would like you to go through the questions on the next four pages and answer them AS IF YOU WERE YOUR CLOSE FRIEND. That is, answer the questions AS YOU THINK YOUR CLOSE FRIEND WOULD IF GIVEN THE QUESTIONNAIRE TODAY. (If there is no one whom you CURRENTLY consider to be a close friend, go on to the next section.)

REMENBER--TRY TO BECONE YOUR CLOSE FRIEND AND ANSWER THE QUESTIONS AS YOU THINK YOUR CIOSE FRIEND WOULD. Respond the way your CLOSE FRIEND seems to feel, regardless of what your close friend says or does.

Please indicate how you think YOUR CLOSE FRIEND would agree or disagree with EACH of the following statements by putting an ( $X$ ) in the column which comes closest to describing how you think YOUR CIOSE FRIEND feels. (Strongly disagree, mildly disagree, mildly agree, strongly agree or I don't know.) 


\section{$\frac{\text { DISAGREE }}{\text { STR'LY }}$}

1. Marriage and family give a woman a sense of identity and purpose in life which nothing else can.

2. A woman should not make more concessions to her mate's wishes than he to hers.

3. The main goal of a woman's life should be the successful rearing of welladjusted children.

4. Marriage should only be the legitimization of a relationship, not a "career."

5. It is a woman's job to run the home and look after the children.

6. Many women, if given important jobs or responsible positions, are likely to fold up or panic under stress.

7. Most women can get just as much satisfaction out of a job as most men can.

8. A woman ought to try to cultivate the interests of her mate, rather than pursue independent interests and accomplishments on her own. (continued) 
DISAGREE

AGREE

STR'LY MIIDLY STR'IY MILDLY KNOW

9. Raising children is definitely the most challenging and creative activity a woman can engage in.

10. Most women need or at least appreciate the personal benefits of having a steady occupation or interest outside of home responsibilities.

11. A woman should not expect her mate to do woman's work-cooking, laundry, cleaning, childcare.

12. Most women are just as capable as men of holding responsible positions or handling important jobs.

13. The most important thing a woman can do to ensure a good relationship with her mate is to be totally supportive of him.

14. Children shouldn't always come first in a woman's life.

15. A woman who works loses most of the satisfactions from being a full-time wife and mother. (continued) 
DISAGREE ST $\bar{R}^{\prime} I Y$ MIIDLY SIR' LY MIIDLY

16. A man and woman should share household tasks and childcare according to individual interests and abilities rather than according to "woman's work" and "man's work."

17. When a woman gets interested in a job she is as hardworking and likely to succeed as a man.

18. Most women do not need the same kind and amount of education as men do.

19. Working often makes a woman more interesting as a person and thus more attractive.

20. Many professions are more suited to a man's abilities than a woman's.

21. A woman who works can be as good a mother as the one who stays at home.

22. Most women do not become as interested as men do in their jobs primarily because they are interested in their families. (continued) 
23. A woman's opinion should be as important as her mate's in most decisions.

24. It is possible for a woman to handle both home and outside career and do justice to both. 
Now, I would like you to go through the questions on the next four pages and answer them AS IF YOU WERE YOUR FATHER. That is, answer the questions AS YOU THINK YOUR FATHER WOULD IF GIVEN THE QUESTIONNAIRE TODAY. (If your father is now deceased, answer about the time immediately prior to his death.)

REMEMBER--TRY TO BECOME YOUR FATHER AND ANSWER THE QUESTIONS AS YOU THINK HE WOULD. Respond the way YOUR FATHER seems to feel, regardless of what he says or does.

Please indicate how you think YOUR FATHER would agree or disagree with EACH of the following statements by putting an $(X)$ in the column which comes closest to describing how you think YOUR FATHER feels. (Strongly disagree, mildly disagree, mildly agree, strongly agree or I don't know.) 


\section{DISAGREE AGREE DON'T STR'LY NILDLY STR'LY MILDLY KNOW}

1. Marriage and family give a woman a sense of identity and purpose in life which nothing else can.

2. A woman should not make more concessions to her mate's wishes than he to hers.

3. The main goal of a woman's life should be the successful rearing of welladjusted children.

4. Marriage should only be the legitimization of a relationship, not a "career."

5. It is a woman's job to run the home and look after the children.

6. Many women, if given important jobs or responsible positions, are likely to fold up or panic under stress.

7. Most women can get just as much satisfaction out of a job as most men can.

8. A woman ought to try to cultivate the interests of her mate, rather

(continued) 
DISAGREE STR'IY MIIDLY STR' $\underline{\text { LY MIIDLY }}$

DON'T

8. (continued)

than pursue independent interests and accomplishments of her own.

9. Raising children is definitely the most challenging and creative activity a woman can engage in.

10. Most women need or at least appreciate the personal benefits of having a steady occupation or interest outside of home responsibilities.

11. A woman should not expect her mate to do woman's work-cooking, laundry, cleaning, childcare.

12. Most women are just as capable as men of holding responsible positions or handling important jobs.

13. The most important thing a woman can do to ensure a good relationship with her mate is to be totally supportive of him.

14. Children shouldn't always come first in a woman's life. (continued) 


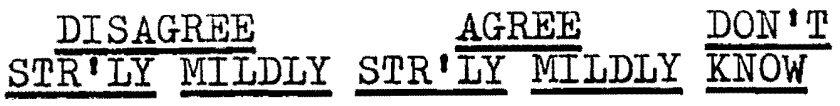

15. A woman who works Ioses most of the satisfactions from being a full-time wife and mother.

16. A man and woman should share household tasks and childcare according to individual interests and abilities rather than according to "woman's work" and "man's work."

17. When a woman gets interested in a job she is as hardworking and likely to succeed as a man.

18. Most women do not need the same kind and amount of education as men do.

19. Working often makes a woman more interesting as a person and thus more attractive.

20. Many professions are more suited to a man's abilities than a woman's.

21. A woman who works can be as good a mother as the one who stays at home. (continued)

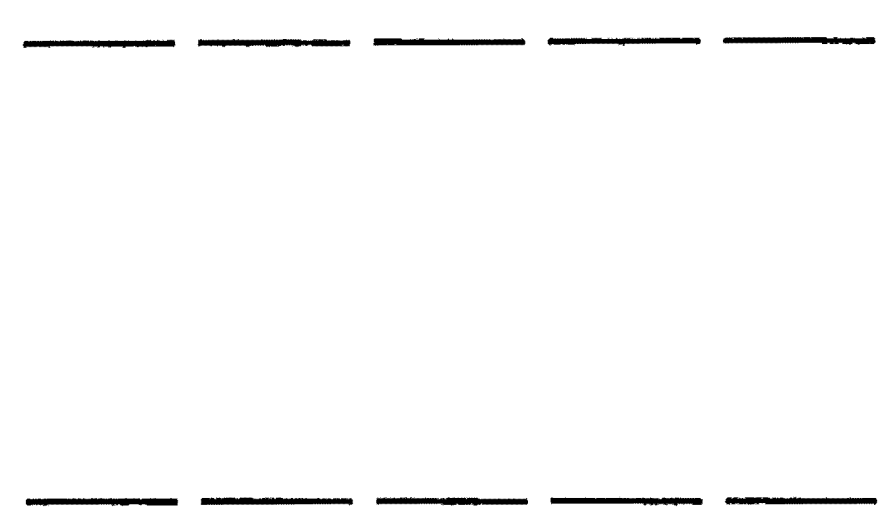


DISAGREE STR'LY MILDLY STR'

22. Most women do not become as interested as men do in their jobs because they are primarily interested in their families.

23. A woman's opinion should be as important as her mate's in most decisions.

24. It is possible for a woman to handle both home and outside career and do justice to both. 
Now, I would like you to go through the questions on the next four pages and answer them AS IF YOU WERE YOUR MOTHER. That is, answer the questions AS YOU THINK YOUR MOTHER WOULD IF GIVEN THE QUESTIONNAIRE TODAY. (If your mother is now deceased, answer about the time immediately prior to her death.)

REMEMBER--TRY TO BECOME YOUR MOTHER AND ANSWER THE QUESTIONS AS YOU THINK SHE WOULD. Respond the way YOUR MOTHER seems to feel, regardless of what she says or does.

Please indicate how you think YOUR MOTHER would agree or disagree with EACH of the following statements by putting an $(X)$ in the column which comes closest to describing how you think YOUR MOTHER feels. (Strongly disagree, mildly disagree, mildly agree, strongly agree or I don't know.) 


\section{DISAGREE AGREE DON'T STR'LY MIIDLY STR' LY MILDLY KNOW}

1. Marriage and family give a woman a sense of identity and purpose in life which nothing else can.

2. A woman should not make more concessions to her mate's wishes than he to hers.

3. The main goal of a woman's life should be the successful rearing of welladjusted children.

4. Marriage should only be the legitimization of a relationship, not a "career."

5. It is a woman's job to run the home and look after the children.

6. Many women, if given important jobs or responsible positions, are likely to fold up or panic under stress.

7. Most women can get just as much satisfaction out of a job as most men can.

8. A woman ought to try to cultivate the interests of her mate, rather than pursue independent interests and accomplishments on her own. (continued) 
$\frac{\text { DISAGREE }}{\text { STR'IY }}$

9. Raising children is definitely the most challenging and creative activity a woman can engage in.

10. Most women need or at least appreciate the personal benefits of having a steady occupation or interest outside of home responsibilities.

11. A woman should not expect her mate to do woman's work-cooking, laundry, cleaning, childcare.

12. Most women are just as capable as men of holding responsible positions or handling important jobs.

13. The most important thing a woman can do to ensure a good relationship with her mate is to be totally supportive of him.

14. Children shouldn't always come first in a woman's life.

15. A woman who works loses most of the satisfactions from being a full-time wife and mother. (continued) 
DISAGREE STR'IY MIIDLY STR' LY MIIDIY

16. A man and woman should share household tasks and childcare according to individual interests and abilities rather than according to "woman's work" and "man's work."

17. When a woman gets interested in a job she is as hardworking and likely to succeed as a man.

18. Most women do not need the same kind and amount of education as men do.

19. Working often makes a woman more interesting as a person and thus more attractive.

20. Many professions are more suited to a man's abilities than a woman's.

21. Most women do not become as interested as men do in their jobs because they are primarily interested in their families.

22. A woman who works can be as good a (continued) 


\section{DISAGREE AGREE DON'T STR'LY MIIDLY STR'IY MILDLY KNOW}

22. (continued)

mother as the one who stays at home.

23. A woman's opinion should be as important as her mate's in most decisions.

24. It is possible for a woman to handle both home and outside career and do justice to both.

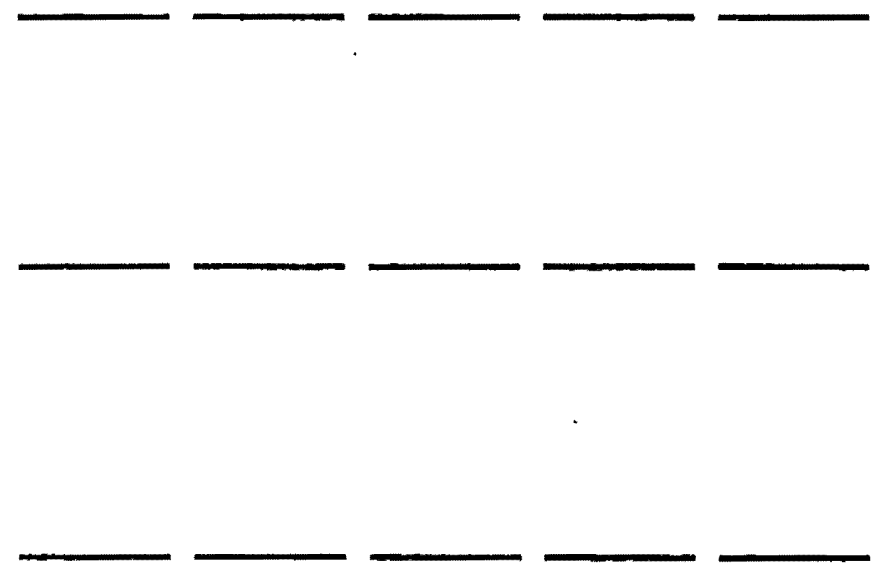

THANK YOU FOR COMPIETING THE QUESTIONNAIRE. 


\section{ADDITIONAL NOTES FOR SCORING AND CODING THE QUESTIONNAIRE}

\section{Part I}

3. The various degree programs were coded as follows:

Code $O$ for MS Ed. Adm.

Code 1 for Urban Studies, Ph.D. (Economics, Psychology, Sociology, Communications).

Code 2 for Environmental Sciences, Ph.D. ( $\begin{gathered}\text { Biology, } \\ \text { Botany). }\end{gathered}$

Code 3 for Biochemistry, Physiological Psychology, Ph.D. (University of Oregon Medical School).

Code 4 for $\mathrm{MBA}$.

Code 5 for MID.

Code 6 for MAT, IMST, MS Counseling, Iib. Certif.

Code 7 for MSW.

Code 8 for M. Nursing, BS Nursing.

Code 9 for M. Med. Tech.

4. This item was not included in any analysis. The purpose of including it in the data collection was to provide an additional index of career orientation, to differentiate TW and NTW career choices. The scoring scheme was the following: Work activity: Code "O" for TW, "1" for NTW activity. Likely place of employment:

Code 1 for self-employed (private or group practice).

Code 2 for government agency.

Code 3 for private agency.

Code 4 for clinic or hospital.

(continued) 
4. (continued)

Code 5 for school or university.

Code 6 for business or industry.

Code 7 for additional schooling or training.

Code 8 for no immediate plans for work or study.

Code 9 for NA or unable to score.

6. Code "oo" if married or living with consort for less than one year.

Score the number of years given if married or living with consort for more than one year.

(Score $\frac{1}{2}$ year to next highest number):

Code "99" if NA or single and living alone, with parents or with roommate.

8. Score the number of children and the number of children who are less than 6 years old.

Code "8," "8" if the subject has children (i.e., responded "yes" to Question 7) but none are currently living with the subject.

Code "9," "9" if the subject does not have any children (i.e., responded "no" to Question 7).

10. Score the age given for mother.

Code "Oo" if mother is deceased for less than one year.

Score the number of years given if mother is deceased for more than one year.

11. Code "1" for check mark indicating parents are divorced. Code "g" if NA.

12. An ordinal scale was used for scoring the responses. The value of the credential provided the basis for the scale.

Code "O" if mother did not complete elementary school. (continued) 
12. (continued)

Code "1" if mother completed elementary. school (through grade 8 ).

Code "2" if mother completed high school.

Code "3" if mother had some college, or attended technical/business/vocational school, or had practical nurse certificate.

Code "4" if mother was a college graduate.

Code "5" if mother had a postgraduate degree.

Code "g" if NA.

13. The responses were given scaled ranks, 1-3, on the following basis:

Code "1" if mother was a full-time housewife.

Code "2" if mother worked in a TW occupation, whether outside or within the home.

Code "3" if mother worked outside the home in a NTW occupation.

14. Score the number of years given if mother worked outside the home.

Code "OO" if mother did not work outside the home.

Code "88" if mother worked within the home.

Code "gg" if NA.

17. The item was included in the data collection to provide an additional index for defining the type of maternal role model in terms other than mother's work behavior: housewife, traditional work outside the home, nontraditional work outside the home. The scores obtained for this item were not, however, used in any analysis. It appears that the item was not adequately designed to elicit meaningful information. The responses were difficult to interpret. The scoring procedure was as follows:

The responses were subjected to two weightings. The score which was recorded was the sum of the two weightings, as follows:

(continued) 
17. (continued)

First, an ordinal scale of 1-3 was used to score the responses in terms of traditional--not-traditional activities. The weightings given the various activities are indicated on the reproduced questionnaire. Second, the scores obtained were weighted for ranks, as follows:

Weight "3" for rank" 1 .

Weight "2" for rank" 2 .

Weight "1" for rank 3 .

18. Code as for Question 10 (See Note 10).

19. Code as for Question 12 (See Note 12).

20. The Revised Scale for Rating Occupations (Hollingshead and Redlich, 1958), a 7-point ordinal scale, was used to code father's principal occupation. If father was unemployed, the response was coded "8." If there was NA or the response was too vague to score, those responses were coded "9."

21. Score the number of years given.

Code "OO" if there is no mate.

Code "99" if NA.

22. Code as for Question 12 (See Note 12). Code "O" if there is no mate.

23. Code "O" if there is no mate.

Code "1" - "7" as for Question 20 (See Note 20).

Code "8" if student.

Code "9" if NA or the response is too vague to score.

27. Code "O" if housewife.

Code "1" - "7" as for Question 20 (See Note 20).

Code "8" if student.

(continued) 
27. (continued)

Code "g" if NA, unable to code response, or if no close friend.

30. The item was included in the data collection to provide an additional index for defining the type of maternal role model (See Note 17). The responses obtained were not scored, however, because the instructions were apparently not clear enough. Miany Ss did not answer the second part of the question according to the instructions given. The proposed scoring scheme was as follows: Two scores were to be obtained and recorded:

The first part of the question was to be scored as follows. Score the responses for activities and personal relations which seemed VERY IMPORTANI to mother on an ordinal scale, 1-3, as indicated on the reproduced questionnaire. Record the sum of weights obtained. The possible range of scores for the first part of the question is 0-19. (The scale used involved a judgment as to whether the perceived priority reflected a more traditional (1) or less traditional (3) role orientation.)

For the second part of the question, the score was to be obtained by first subtracting the sum of "DISSATISFIED" responses from the sum of "SATISFIED" responses. (Items which were given "I don't know" responses were to be omitted from the scoring procedure.) Second, a correlation between the two summed responses (Satisfied, Dissatisfied) was to be calculated and recorded.

32. The item was included in the data collection to gain some idea of the paternal role model. The responses obtained were not scored, however, because the question was apparently misunderstood by most of the $\underline{S}$ (See Note 30).

32. The responses to this question were recorded in two ways, as follows:

First, a summary score was obtained, on the basis of the number of specified significant others (mother, father, husband/consort, close friend) who were included in those ranked. The possible range of scores was 0-4. Code "g" if NA or unable to score.

(continued) 
32. (continued)

Second, the recording was of the particular ranks (1-3) given to mother, father, husband/consort, close friend. Code "O" for each of the specified significant others who were not included in the rankings. Code "g" if NA or unable to score. 
$\underline{\text { Part II }}$

The standard procedure which was used to score the AWR inventory is as follows:

1. The individual responses were scored along a 5-point scale ("1" indicates the dichotomous pole of the scale, "5" indicates the androgynous pole of the scale). The numbers which appear in parentheses (in the reproduced questionnaire) for Self attitudes provide the key for scoring the responses. The same key was used to score all of the responses on all the inventories. (An identical form of the AWR inventory was used for Self attitudes and the perceptions of the views of mother, father, husband/consort and close friend.)

2. Sum the raw scores for each subscale. The possible range of scores for each subscale and the items which make up each subscale (as they appeared on the questionnaire given the $\underline{S} s$ ) are as follow:

Relation to Mate: Items 2, 8, 13, 23. Possible range of scores: 4-20.

Being a Parent: Items 3, 9, 14, 21. Possible range of scores: $4-20$.

Being a Homemaker: Items $5,11,16,14$. Possible range of scores: $4-20$.

Woman as Worker: Items $6,12,17,20,22$. Possible range of scores: $5-25$.

Satisfactions: Items 1, 4, 7, 10, 15, 18, 19. Possible range of scores: $7-35$.

3. Convert the sums of raw scores obtained for each subscale, as specified above, as follows. Divide the sum of raw scores for each subscale by the number of responses given for each subscale. The converted subscale scores represent positions on a metric scale (with a range of 1-5). The range of total possible AWR scores is conceptualized as positions along a dichotomous-androgynous continuum of attitudes toward woman's roles. Before conversion, the range of total possible AWR scores is 24-120. After conversion, the range of total possible AWR scores is $5-25$. (The scores were converted in order to compare subscale scores.)

(continued) 
3. (continued)

Record the converted individual subscale scores and the sum of the converted subscale scores (total AWR inventory score).

4. Code "0.0" for each of the five subscale scores for husband/consort and close friend if the AWR inventory is not completed for those persons. 


\section{APPENDIX 0}

ATTITUDES TOWARD WOMAN'S ROLES (AWR) INVENTORY AND ADDITIONAI NOTES FOR FUTURE RESEARCH 
ATTITUDES TOWARD WOMAN'S ROLES (AWR)

INVENTORY SUBSCAIES AND ITEMS

1. Relation to Mate. The attitude that a woman should be in a subordinate position to mate.

Items:

a. A woman should not make more concessions to her mate's wishes than he to hers (Ziebarth, 1970).

b. A woman ought to try to cultivate the interests of her mate, rather than pursue independent interests and accomplishments on her own (Ziebarth, 1970).

c. A woman's opinion should be as important as her mate's in most decisions (Ziebarth, 1970).

d. The most important thing a woman can do to ensure a good relationship with her mate is to be totally supportive of him (adaptation of Hawley, 1970).

2. Being a Parent. The attitude about the importance of childrearing in a woman's life.

Items:

a. The main goal of a woman's life should be the successful rearing of well-adjusted children (Porter, 1967; Ziebarth, 1970).

b. Raising children is definitely the most challenging and creative activity a woman can engage in (Porter, 1967; Ziebarth, 1970).

c. Children shouldn't always come first in a woman's life (Ziebarth, 1970).

d. A woman who works can be as good a mother as the one who stays at home (adaptation of Porter, 1967).

3. Being a Homemaker. The attitude that housework and childcare are entirely a woman's responsibility.

Items:

a. It is a woman's job to run the home and look after the children (adaptation of Ziebarth, 1970).

(continued) 
3. (continued)

b. A woman should not expect her mate to do woman's work--cooking, laundry, cleaning, childcare (adaptation of Ziebarth, 1970).

c. A man and woman should share household tasks and childcare according to individual interests and abilities rather than according to "woman's work" and "man's work" (adaptation of Ziebarth, 1970).

d. It is possible for a woman to handle both home and outside career and do justice to both (Hawley, 1970).

4. Woman as Worker. The attitude that women are not as able or committed as men.

Items:

a. Many women, if given important jobs or responsible positions, are likely to fold up or panic under stress (adaptation of Ziebarth, 1970).

b. Most women are just as capable as men of holding responsible positions or handling important jobs (adaptation of ziebarth, 1970).

c. When a woman gets interested in a job, she is as hardworking and likely to succeed as a man (Ziebarth, 1970).

d. Many professions are more suited to a man's abilities than a woman's (Original).

e. Most women do not become as interested as men do in their jobs because they are primarily interested in their families (Original).

5. Satisfactions. The attitude that women derive most satisfaction indirectly through others (mate and children) rather than directly, through their own accomplishments. Moreover, should they seek direct achievement, they will lose major satisfactions from total involvement as mate and mother. Also, the idea that working is incompatible with a woman's femininity.

a. Marriage and family give a woman a sense of identity and purpose in life which nothing else can (adaptation of Porter, 1967).

(continued) 
5. (continued)

b. Marriage should only be the legitimization of a relationship, not a "career" (Ziebarth, 1970).

c. Most women need or at least appreciate the personal benefits from having a steady occupation or interest outside of home responsibilities (Ziebarth, 1970).

d. Most women can get just as much satisfaction out of a job as most men can (Ziebarth, 1970).

e. Working often makes a woman more interesting as a person and thus more attractive (adaptation of Ziebarth, 1970).

f. A woman who works loses most of the satisfactions that come from being a full-time wife and mother (Original).

g. Most women do not need the same kind and amount of education as men do (Hawley, 1970). 
ADDITIONAI NOTES FOR FUTURE RESEARCH WITH ATTITUDE INVENTORY

Instructions

The instructions should emphasize the importance of responding to the items as stated, i.e., not to alter the items in any way (e.g., inserting, omitting, changing words or phrases). The $\underline{S}$ s should also be reminded that how they feel about the statements is of interest so that there is less tendency for them to respond in terms of how things are. In other words, S $s^{\prime}$ feelings, attitudes and beliefs are to provide the measure, not their observations of current practices which may influence certain tendencies or outcomes in the culture.

When asking for Ss' perceptions of the views of others, the instructions should emphasize that $S^{\prime}$ perceptions are of interest and that their perceptions are not to be automatically mistrusted or assumed to be "inaccurate." 